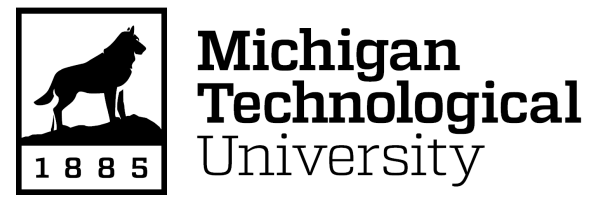

Michigan Technological University Digital Commons @ Michigan Tech

Dissertations, Master's Theses and Master's Reports

2015

\title{
A technical and cultural feasibility assessment of household microbial fuel cells for use in Hanan'g District, Tanzania
}

Erinn Kunik

Michigan Technological University, ekunik@mtu.edu

Copyright 2015 Erinn Kunik

\section{Recommended Citation}

Kunik, Erinn, "A technical and cultural feasibility assessment of household microbial fuel cells for use in Hanan'g District, Tanzania", Open Access Master's Thesis, Michigan Technological University, 2015.

https://doi.org/10.37099/mtu.dc.etdr/25

Follow this and additional works at: https://digitalcommons.mtu.edu/etdr

Part of the Environmental Engineering Commons 


\title{
A TECHNICAL AND CULTURAL FEASIBILITY ASSESSMENT OF HOUSEHOLD MICROBIAL FUEL CELLS FOR USE IN HANAN'G DISTRICT, TANZANIA
}

By

\author{
Erinn Kunik
}

\begin{abstract}
A THESIS
Submitted in partial fulfillment of the requirements for the degree of MASTER OF SCIENCE In Environmental Engineering
\end{abstract}

MICHIGAN TECHNOLOGICAL UNIVERSITY

2015

(C) 2015 Erinn Kunik 
This thesis has been approved in partial fulfillment of the requirements for the Degree of MASTER OF SCIENCE in Environmental Engineering.

Department of Civil and Environmental Engineering

Thesis Advisor: $\quad$ Dr. Jennifer Becker

Committee Member: Dr. Kari Henquinet

Committee Member: Dr. David Watkins

Department Chair: $\quad$ Dr. David W. Hand 


\section{Contents}

List of Figures ..............................................................................................

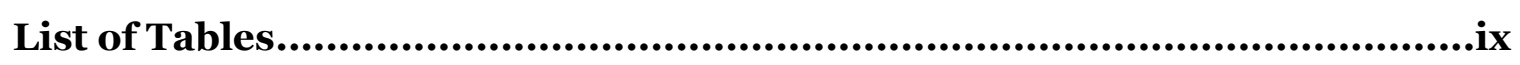

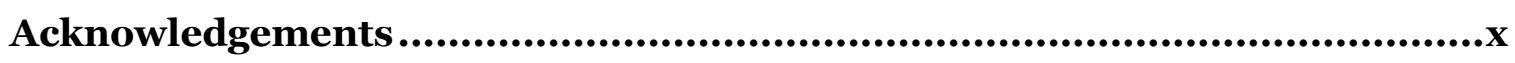

List of Abbreviations...................................................................................

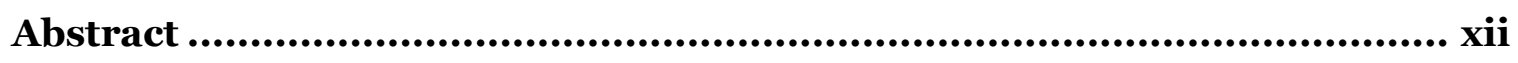

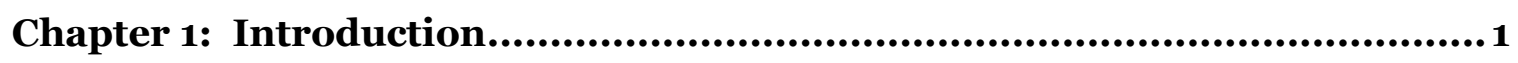

Microbial fuel cells: An emerging technology for electricity production .......................... 2

Chapter 2: Background ..................................................................................5

2.1: Project Site Background ...................................................................................... 5

2.2 Electricity in Rural Tanzania..............................................................................

2.2.1 Solar Electricity and Lighting in Tanzania.................................................10

2.2.2 Biogas for Electricity Use........................................................................... 11

2.2.3 Grid Expansion in Rural Tanzania ............................................................ 11

2.2.4 Microbial Fuel Cells in Tanzania ..................................................................13

2.3 Microbial Fuel Cell Fundamentals........................................................................14

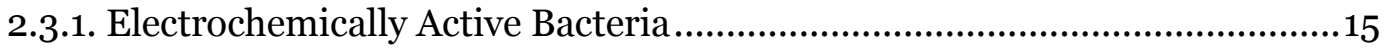

2.3.2 Electron Transfer Mechanisms....................................................................15

2.3.3 Electricity Generation with Microbial Fuel Cells............................................16

2.3.4 Electrochemical Performance........................................................................18

2.4 Microbial Fuel Cell Construction ……..................................................................... 23

2.4.1 MFC Configurations .............................................................................. 23

2.4.2 MFC Materials …………………………………………………………. 25

2.5 Utilization of MFCs in Practice ............................................................................. 27

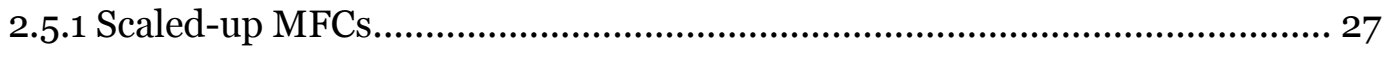

2.5.2 Use of Energy Harvesting Systems ………………..................................... 28

2.6 Manure as an MFC Fuel Source .......................................................................28

Chapter 3: Methods and Materials ..................................................................31

3.1 Interview Methods ................................................................................................

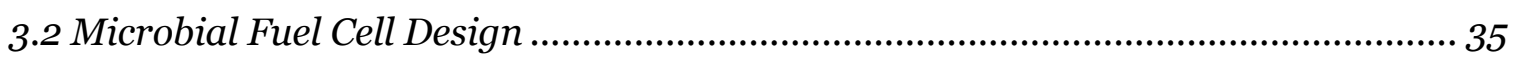

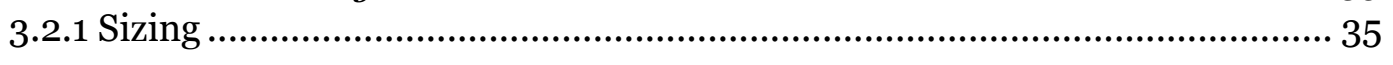

3.3 Microbial Fuel Cell Construction and Materials ...................................................... 35 
3.3.1 Original MFC Design ....................................................................... 35

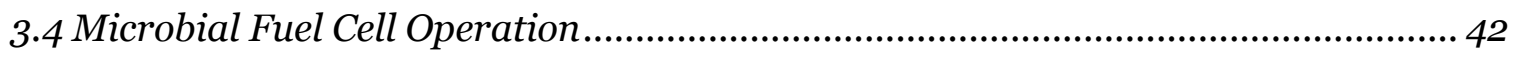

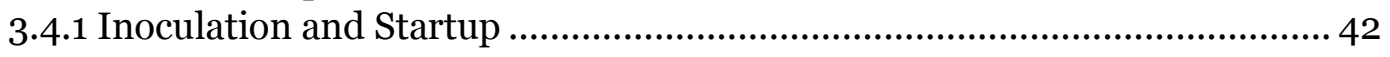

3.4.2 Substrate Preparation ............................................................................ 42

3.4.3 MFC Performance Monitoring …............................................................. 43

Chapter 4: Results................................................................... 48

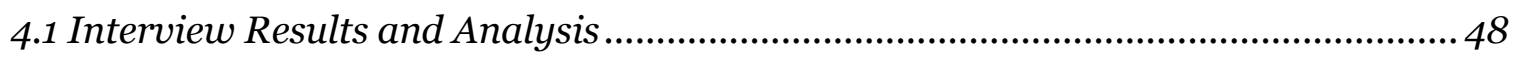

4.1.2 Manure Perceptions and Use ............................................................. 56

4.2 Microbial Fuel Cell Results and Analysis ..............................................................5

4.2.1 Electrochemical Performance during Startup .......................................... 59

4.2.2 Electrochemical Performance with Acetate Feed Cycle ............................ 63

4.2.3 Electrochemical Performance during Manure Feed Cycle 1.......................6 67

4.2.4 Electrochemical Performance During Manure Feed Cycle 2 ....................... 71

4.2.5 Summary of Electrochemical Performance …........................................... 74

4.2.6 MFC Inputs and Operation...................................................................75

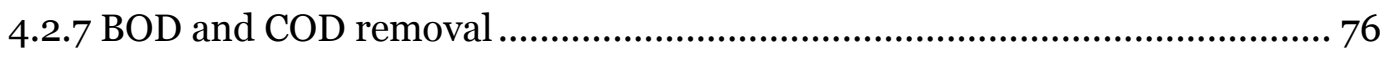

4.2.8 Coulombic Efficiencies .......................................................................77

4.2.9 Volatile Fatty Acids in Manure Slurry Batches...........................................77

4.2.10 Fecal Coliform Reduction .................................................................. 78

4.2.11 Methane Production ........................................................................... 78

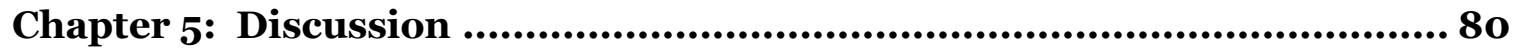

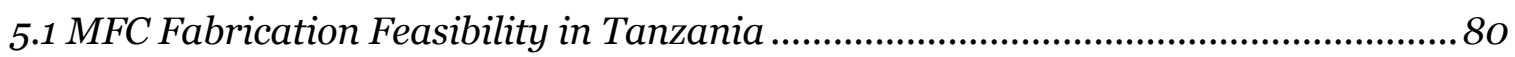

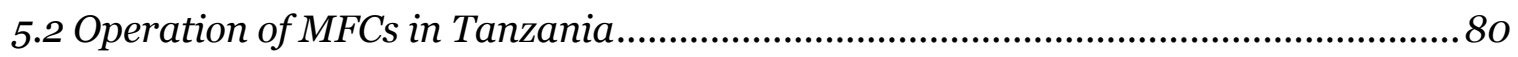

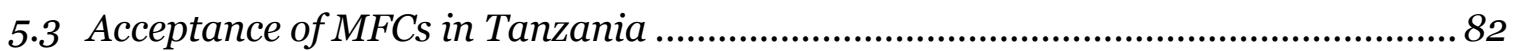

Chapter 6: Recommendations for Future Work ................................ 83

Chapter 7: Conclusions ................................................................ 85

Chapter 8: References ...................................................................87

Chapter 9: Appendices ...................................................................97

Appendix A: IRB Compliance Approval ................................................................... 97

Appendix B: Interview Oral Consent Form ............................................................... 99

Appendix C: Interview Written Consent Form........................................................ 100

Appendix D: Interview Outline .............................................................................103 
Appendix E: Interview Questions .........................................................................105

Appendix F: MFC Feed Solution Preparation .........................................................107

Appendix G: Compiled Data from the 2012 Tanzanian Census [4] ..............................111

Appendix H: Fair Use Statement ...........................................................................116 


\section{List of Figures}

Figure 2.1: Map of the continent of Africa. Tanzania is indicated with a star. (Source:

Google Maps)

Figure 2.2: A detailed map of Tanzania and the surrounding countries. The study site is indicated with an arrow. (Adapted from Google Earth)...................................

Figure 2.3: A map of the three sites where interviews were conducted. (Adapted from

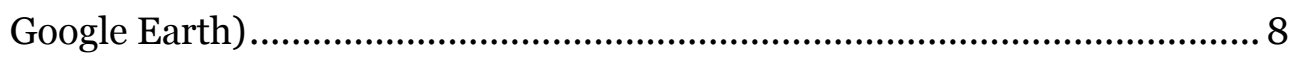

Figure 2.4: Light sources used in all Tanzanian households as of the 2012 Tanzanian Census [4]. 9

Figure 2.5: Many rural families in the Hanan'g District have purchased small solar lights (d.light model S2) to use in their homes and to help their children study at night (Photo by author). ............................................................................10

Figure 2.6: Diagram of a two-chambered MFC. Adapted from Logan [66]......................14

Figure 2.7: Reduction potentials of acetate and oxygen, which are commonly used in MFC research..............................................................................................17

Figure 2.8: Idealized relationship between power density and current density for a typical MFC. Adapted from Wang et al [60]................................................19

Figure 2.9: Categories of voltage losses on a voltage vs. current density polarization

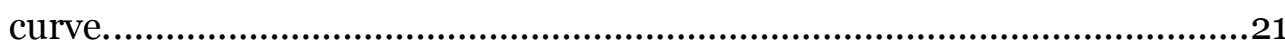

Figure 2.10: Diagram of where voltage losses occur within the MFC. 1. Anodic activation losses and mass transport losses. 2. Bacteria metabolism losses. 3. Ohmic losses at the anode. 4. Voltage drop from external resistor. 5. Ohmic losses at the PEM. 6. Ohmic losses at the cathode. 7. Activation and ohmic losses from oxygen reduction. Adapted from Rabaey and Verstraete [67]. .......... 22

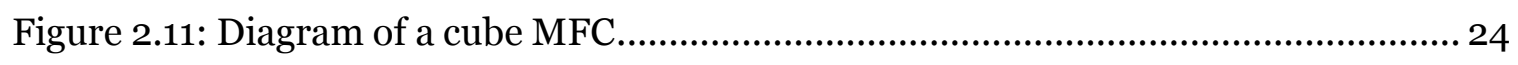

Figure 2.12: Photograph of a typical air cathode bottle reactor (Photo by author).......... 24

Figure 2.13: Tubular MFC configurations with (A) cathode wrapped around the exterior of the anode and (B) cathode in the center of the MFC (adapted from Liu et

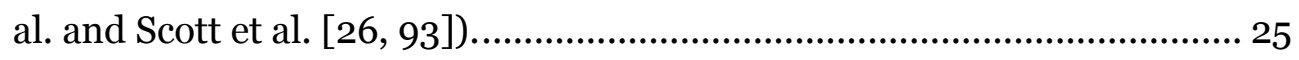

Figure 3.1: The reactor housing for the MFC consisted of PVC pipe with $1 \mathrm{~cm}$ diameter holes and two caps at each end. Dimension A was $36.8 \mathrm{~cm}$ (14.5 inches) and dimension B was $19.3 \mathrm{~cm}$ (7.6 inches) for the original design and dimension 
A was $24.9 \mathrm{~cm}$ ( 9.8 inches) and dimension B was $7.6 \mathrm{~cm}$ (3.0 inches) for the modified design as described in the text. 36

Figure 3.2: Diagram of the holes drilled into the reactor housing. ................................ 36

Figure 3.3: Photograph of graphite fiber brush and titanium wire (Photo by author)... 37

Figure 3.4: Photograph of the side of the carbon cloth after the carbon base layer and 4 diffusion layers were applied (Photo by author). 38

Figure 3.5: Photograph of the anode side of the cathode showing the layer of platinum

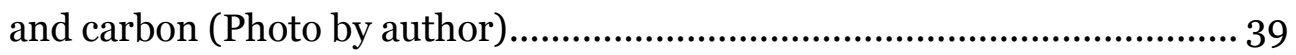

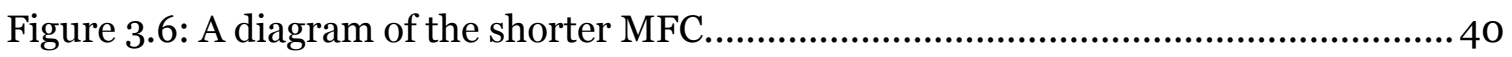

Figure 3.7: Photograph of the assembled MFC (Photo by author).................................41

Figure 3.8: Simple circuit diagram showing the MFC circuit setup..............................41

Figure 3.9: Typical electrochemical impedance spectroscopy Nyquist curve for MFCs. . 47

Figure 4.1: Women in rural Tanzania often cook inside the home and have little light for cooking (Photos by author)..................................................................5 51

Figure 4.2: Plot of light sources used for nighttime use by those without electricity (black) and for use during blackouts by those with electricity (striped)..... 52

Figure 4.3: Interview participants' perceptions of current electricity use for those with electricity (striped) and plans for electricity use for those without electricity (black). 53

Figure 4.4: Many families in rural Hanan'g district live with livestock in and around their homes (Photos by author).

Figure 4.5: A. Farmers in the Hanan'g area usually use cattle to help with their farming and use the manure as fertilizer in the fields. B. Most residents of the Hanan'g district, especially those in rural areas, rely on small farms and gardens for their food (Photos by author)............................................. 58

Figure 4.6: Voltage of the MFC during startup. Points a, b, and c show peak voltages for three batches. Point d shows the effects of rusting on the circuit elements. 60

Figure 4.7: Polarization curves from the LSV test on days 3 and 10 of MFC operation during startup. 62

Figure 4.8: Power curves from LSV test on days 3 and 10 of MFC operation during startup. 62 
Figure 4.9: MFC voltage during operation with a batch of feed acetate solution (acetate feed cycle 3) immediately after replacing the leaking cathode.

Figure 4.10: Polarization curves for days 3, 7, and 10 of operating the MFC during acetate feed cycle 3 .

Figure 4.11: Power curves for days 3, 7, and 10 of operating the MFC during acetate feed cycle 3 .

Figure 4.12: Polarization curves for forward and reverse LSV tests on the MFC during acetate feed cycle 3 on day 10 of operation. 66

Figure 4.13: A. Nyquist plot obtained from an EIS test on the MFC on day 8 of acetate feed cycle 3. B. Circle fit on the curved section of the Nyquist plot to estimate charge transfer resistance. 67

Figure 4.14: Working MFC voltage during manure feed cycle 1 68

Figure 4.15: Polarization curves from LSV tests on days 2, 6, and 12 of manure feed cycle 1. 69

Figure 4.16: Power curves from LSV tests on days 2, 6, and 12 of manure feed cycle 1... 70 Figure 4.17: A. Nyquist Plot from EIS test of manure feed cycle 1 on day 8. B. Circle fit of Nyquist plot to estimate charge transfer resistance. 71

Figure 4.18: Working voltage of MFC during manure feed cycle 2. 72

Figure 4.19: Polarization curves from LSV tests on days 3 and 7 of manure feed cycle 2.73 Figure 4.20: Power curves from LSV tests on days 3 and 7 of manure feed cycle 2. ....... 73 Figure 4.21: A. Nyquist plot from the EIS test on manure feed cycle 2. B. Circle fit of semicircle from Nyquist plot to determine charge transfer resistance. ...... 74 


\section{List of Tables}

Table 2.1: Summary of studies conducted on MFCs using manure as a fuel source....... 29

Table 2.2: Composition of fresh cattle manure ............................................................ 30

Table 3.1: A summary of selection variables for interview participants in each study site

Table 3.2: Examples of codes and code groups used in the qualitative analysis of the interviews

Table 4.1: Interview indicators pre-interview and post-interview, compared to census data

Table 4.2: Summary of electrochemical performance of the MFC during startup. .61

Table 4.3: Summary of electrochemical performance from LSV tests on the MFC on days 3,7 , and 10 of the third acetate feed cycle. 64

Table 4.4: Summary of electrochemical performance of the MFC from LSV tests on days 2,6 , and 12 of manure feed cycle 1 .

Table 4.5: Summary of electrochemical performance from manure feed cycle 2 LSV tests 72

Table 4.6: Summary of MFC electrochemical performance at the end of operation for each feed cycle 74

Table 4.7: COD values for each MFC batch and COD removal efficiencies. 76

Table 4.8: Summary of VFAs in manure slurry batches before and after MFC operation77

Table 9.1: Compiled data on roofing material used - 2012 Tanzanian census .................111

Table 9.2: Compiled data on flooring material used - 2012 Tanzanian census ...............111

Table 9.3: Compiled data on house wall material used - 2012 Tanzanian census .......... 112

Table 9.4: Compiled data on main energy source used for lighting - 2012 Tanzanian census 112

Table 9.5: Compiled data on main source of energy for cooking - 2012 Tanzanian census

Table 9.6: Compiled data on assets owned - 2012 Tanzanian census ............................ 113

Table 9.7: Compiled data on livestock keeping - 2012 Tanzanian census....................... 114

Table 9.8: Compiled data on agricultural households - 2012 Tanzanian census ............ 114

Table 9.9: Compiled data on household livestock keeping - 2012 Tanzanian census..... 114

Table 9.10: Compiled data on rural livestock keeping - 2012 Tanzanian census............ 114

Table 9.11: Compiled data on urban livestock keeping - 2012 Tanzanian census ........... 115 


\section{Acknowledgements}

I would like to thank my advisor, Dr. Jennifer Becker, for supporting me throughout the entirety of this project and giving me technical advice on my project. I would also like to thank my committee members Dr. Kari Henquinet and Dr. David Watkins for giving me great support throughout my Peace Corps service and Dr. Henquinet especially for helping me through the interview process and qualitative results analysis. Thank you for spending a great deal of time and energy with me on completing this thesis.

I would also like to thank my lab mates, especially Zhimin, Lindsey, and Christa who helped me with lab procedures after being out of the lab work routine for over two and a half years. I really appreciate all of the help you gave me and all of the questions you took time to answer. I also could not have finished this research without Rob Fritz's help in the machine shop and Dave Perram's help with all of my various lab equipment questions and issues.

To my PCMI friends at Tech, and to my Peace Corps friends in Tanzania, I could not have completed all of my work or gotten through the stress of culture shock/reverse culture shock without you all.

I also could not have finished my interviews without the help of my Peace Corps sitemate Alex, and Tanzanian friends Brigitha and Domy. Thank you for your help facilitating and translating for me. I also want to thank my other Katesh friends Bella, Mama Daktari, Mama Janeth, Zanura, Huba, and Mwalimu Zuberi. I would not have enjoyed my time in Katesh, nor been as successful as a Peace Corps volunteer without you all. 


\section{List of Abbreviations}

$\begin{array}{ll}\text { BOD } & \text { Biochemical oxygen demand } \\ \text { BOD5 } & \text { Biochemical oxygen demand after } 5 \text { days } \\ \text { CE } & \text { Coulombic Efficiency } \\ \text { COD } & \text { Chemical Oxygen Demand } \\ \text { DC } & \text { Direct current } \\ \text { Ecell } & \text { Electric potential of the MFC } \\ \text { EIS } & \text { Electrochemical impedance spectroscopy } \\ \text { FPT } & \text { Female pipe thread } \\ \text { GC } & \text { Gas chromatograph } \\ \text { HPLC } & \text { High pressure liquid chromatography } \\ \text { I } & \text { Current } \\ \text { IRB } & \text { Institutional Review Board } \\ \text { LSV } & \text { Linear sweep voltammetry } \\ \text { MFC(s) } & \text { Microbial fuel cell(s) } \\ \text { OCV } & \text { Open Circuit Voltage } \\ \text { P } & \text { Power } \\ \text { Pan } & \text { Power density normalized to the anode } \\ \text { Pca } & \text { Power density normalized to the cathode } \\ \text { PEM(s) } & \text { Proton exchange membrane(s) } \\ \text { PTFE } & \text { Polytetrafluoroethene } \\ \text { Pv } & \text { Power density normalized to the anode compartment volume } \\ \text { Rext } & \text { External resistance } \\ \text { Rint } & \text { Internal Resistance } \\ \text { TANESCO } & \text { Tanzania Electric Supply Company Limited } \\ \text { TCOD } & \text { Total chemical oxygen demand } \\ \text { TTCL } & \text { Tanzania Telecommunications Company Limited } \\ \text { VFA(s) } & \end{array}$




\begin{abstract}
Microbial fuel cells (MFCs) are an emerging electricity generation technology that has the potential for use in developing countries. This study assessed the feasibility of using MFCs in Tanzania through technical analysis of a MFC prototype alongside with interviews with Tanzanians for a cultural feasibility assessment of MFCs. For the technical analysis, this study evaluated the inputs needed for a household MFC to operate and produce electricity with cattle manure as a fuel and evaluated the electrochemical and chemical performance as well as the fecal coliform reduction of the manure during MFC operation. For this study, a MFC was built and operated with diluted manure. During operation with manure, the MFC achieved an open circuit voltage of $0.604 \mathrm{~V}$, a power density of $0.272 \mathrm{~W} / \mathrm{m}^{3}\left(16.1 \mathrm{~mW} / \mathrm{m}^{2}\right)$, and a coulombic efficiency of $14.7 \%$. Through MFC operation, there was a $93 \%$ reduction in fecal coliforms, although the manure slurry still did not meet the standards for organic manure fertilizer.

This study also used in-depth, semi-structured interviews with local Tanzanians in the Hanan'g District to evaluate the cultural feasibility of using MFCs in the home. It was found that there is discontent with the lack of reliable or available electricity in the area, as well as a great interest in MFCs, provided they are safe and clean. The Hanan'g District is also an area of livestock keepers, and the residents are open to the use of manure. The successful operation of the manure-fed MFC, along with the local Hanan'g residents' poor perceptions of Tanzania's electric supply company and their widespread use of manure, indicate that MFCs may be a feasible alternative to current electricity and lighting sources for some Hanan'g residents.
\end{abstract}




\section{Chapter 1: Introduction}

Electrification in developing countries has often been given a lower priority compared with clean water, nutrition, and universal education as necessities for development. Without widespread electrification, however, these other sectors have a hard time reaching the success needed for the country's development [1]. Thus, electrification is an essential aspect of development. This project focuses specifically on the issue of electrification in the East African country of Tanzania. Tanzania is currently classified as a low-income/low-development country, yet its economy is growing at a rate of $6 \%$ and the country is making strides towards development $[2,3]$. As of the 2012 Tanzanian census, only $21 \%$ of Tanzanians currently have some form of electricity in their homes, but this is significantly improved compared with the 2010 statistics (15\%) [4, 5]. Nevertheless, only $7 \%$ of households in rural Tanzania have electricity, as opposed to 48\% of urban households [4]. Therefore, the Tanzanian government must work on improving access to electricity throughout the country in order to improve Tanzanians' quality of life.

In particular, living without access to household electricity makes life difficult after the sun sets. Specifically, it is difficult for families without reliable sources of light to do much work after sunset. Students in homes without electricity also feel the effects of not having enough light at night. Their performance in school and on their national exams, which determine the future of each student's education, is often affected due to the difficulty in finding enough light to study in the evenings [6]. In rural areas especially, the majority of students fail their national exams and they then go to work in the fields instead of pursuing other job opportunities $[7,8]$.

Those households without electricity may have other sources of light that can be used after sunset, such as kerosene lamps, candles, firewood, cell phone flashlights, and small solar lights [4]. Unfortunately, these light sources all have significant shortcomings. Kerosene lamps are inefficient, and kerosene is expensive, especially for rural families who frequently need to travel to a town to purchase it. Likewise, candles cost around 20 cents each, and a family may burn through several candles a week, making them an expensive light source for families who have very little income. The average annual income for all Tanzanians is $\$ 930$, and rural Tanzanians in general make even less than 
this annually [9]. Firewood is often difficult to find, and the vast deforestation of rural Tanzania has contributed to soil degradation and poor agricultural production [10]. Finally, solar lights have a high upfront cost, do not work well in cloudy conditions, and very few rural Tanzanians are skilled in fixing broken solar lights. Many families without electricity use these light sources sparingly and share their few solar lights if they have them.

Approximately three-quarters of Tanzanians are farmers, and as a result they are generally aware of the effects of climate change that they have begun to experience [4]. The rainy seasons throughout Tanzania are becoming more unpredictable and the droughts are becoming more pronounced [10]. The increase in droughts has reduced the water available for hydropower production [3, 11]. Through working with the UN on their Sustainable Development Goals initiative, the Tanzanian government has adopted goals to use a higher percentage of renewable energy, including solar and wind power, for electricity [3, 12]. These goals are mainly focused on improving Tanzania's grid electricity, although most homes in rural Tanzania are located far from the grid or the home owners cannot afford to connect their homes to the grid [12, 13]. Houses constructed with mud, sticks, and thatch are generally not even considered for electrification by Tanzania's electrical supply company, which makes off-grid sources more desirable for rural areas [13]. Many rural Tanzanians choose to use renewable energy sources of electricity in their homes because of price increases, frequent blackouts, and other problems with the grid. Therefore, off-grid electricity and lighting options are more viable for most rural communities than grid-electrification [14]. Several aid projects, such as the World Bank Group and IMF's 'Lighting Africa' project and SolarAid's solar lighting project, have been promoting and facilitating the use of solar lighting in Tanzania $[15,16]$. This research focuses on exploring whether household use of microbial fuel cells (MFCs) could help alleviate the lack of sufficient lighting and electricity in many households of Tanzania's Hanan'g district.

\section{Microbial fuel cells: An emerging technology for electricity production}

MFCs are a technology in which electricity is generated from organic matter without the production of methane or hydrogen by bacteria in an anaerobic environment [17-19]. 
These bacteria oxidize the organic matter and transfer the resulting electrons to an anode, which is connected to a cathode via an external circuit (Figure 2.6). When an external load, e.g. a light bulb or a battery, is placed in the closed circuit, useful work can be done as electrons flow from the anode to the cathode. Electricity production in MFCs using a multitude of substrates or fuel sources such as acetate, glucose, cysteine, ethanol, marine sediments, urine, and various wastewaters, including brewery wastewater and livestock wastewater has been demonstrated at the lab scale and increasingly at the pilot scale [20-29].

MFCs have been tested less extensively in a developing country context. In 2009, a group of students from MIT and Harvard constructed an MFC with locally available materials and soil as a fuel source for the MIT Global Challenges contest; however, the power output and efficiency of this MFC have not yet been documented [30]. A member of this team, Aviva Aiden, continued to study MFCs for use in rural Africa, and was able to use soil-powered MFCs to power an LED light and a cell phone in rural Uganda [31]. In order to produce the voltage needed to power the light and charge the cell phone, an energy harvesting system and 100 MFCs operating in parallel were required [31]. Although the MFCs successfully powered useful devices and used low-cost, locally available materials, the feasibility of constructing and operating 100 MFCs or more in a household setting is low. Another study by Stafford et al. [32] compared various methods, including MFCs, for cleaning wastewater in South Africa, but this study focused on a more affluent area of South Africa. These studies are insufficient to determine if MFCs are actually feasible for use in rural Tanzania. In particular, almost nothing is known about the amount of substrate, water, and labor that would be required to maintain a MFC in this setting. Likewise, there is a lack of information on the longterm reliability of the MFCs. Finally, almost nothing is known about the attitudes of Tanzanians with regards to electricity use, the Tanzanian electricity supply company, and the use of manure in daily life and as a source of electricity.

For these reasons, this study focused on evaluating the viability of using MFCs in the Hanan'g district of Tanzania. Many areas in this district have no electricity and little infrastructure in place, but have a large number of livestock and a large amount of livestock manure. Specifically, this research examined the feasibility of utilizing a userfriendly household manure-fed MFC to address the problem of Tanzanian households' 
lack of access to electricity for lighting their homes and charging their mobile phones. The objectives of this study were to:

1. Design, build, and operate a tubular air cathode manure-fed MFC that can be operated in a household setting without access to laboratory chemicals and materials.

2. Quantify the inputs needed to operate the household MFC.

3. Characterize the electrochemical performance of the MFC and use the results to determine if the MFC meets the minimum voltage and power requirements to use with a DC/DC boost converter.

4. Quantify fecal coliform reduction in cattle manure used as a MFC fuel source.

5. Determine, through analysis of previously conducted field observations and interviews, if adoption of MFCs in Tanzanian households would be culturally feasible. 


\section{Chapter 2: Background}

In this chapter, background information on Tanzania and the Hanan'g district, where the cultural aspect to this research was conducted, as well as on microbial fuel cells, their construction, operation, and electricity generation is reviewed.

\section{1: Project Site Background}

Tanzania is a country in East Africa, home to over 130 ethnic groups, 95\% of them of Bantu origin, totaling over 49.6 million people [10]. It is bordered by the Indian Ocean to the east, where the three Tanzanian Islands of Zanzibar, Pemba and Mafia lie, by Kenya and Uganda to the north, by Rwanda and Burundi to the west, and by Zambia, Malawi and Mozambique to the south (Figures 2.1 and 2.2). Tanzania was previously the two countries of Tanganyika and Zanzibar, but they joined to form one country under President Nyerere in 1964, after both countries obtained independence from Britain [10]. In 2014, $80 \%$ of the Tanzanian working population was working in agriculture, and only 20\% was working in industry and services [10]. Agricultural products comprise only about a quarter of the country's GDP but $85 \%$ of its total exports [10]. Tanzania has been mainly an agrarian country since it won its independence. Tanzania's first president, Julius Nyerere, pushed for development through agriculture, and rural Tanzanians have since relied mainly on agriculture for their livelihoods [33, 34]. Agriculture has not brought development or wealth to rural Tanzanians, however. A United Nations report on Tanzania's development assistance plan states that approximately $34 \%$ of Tanzanians currently live under the poverty line and do not have access to their basic needs [35]. This poverty is widespread, affecting people from all parts of Tanzania. 


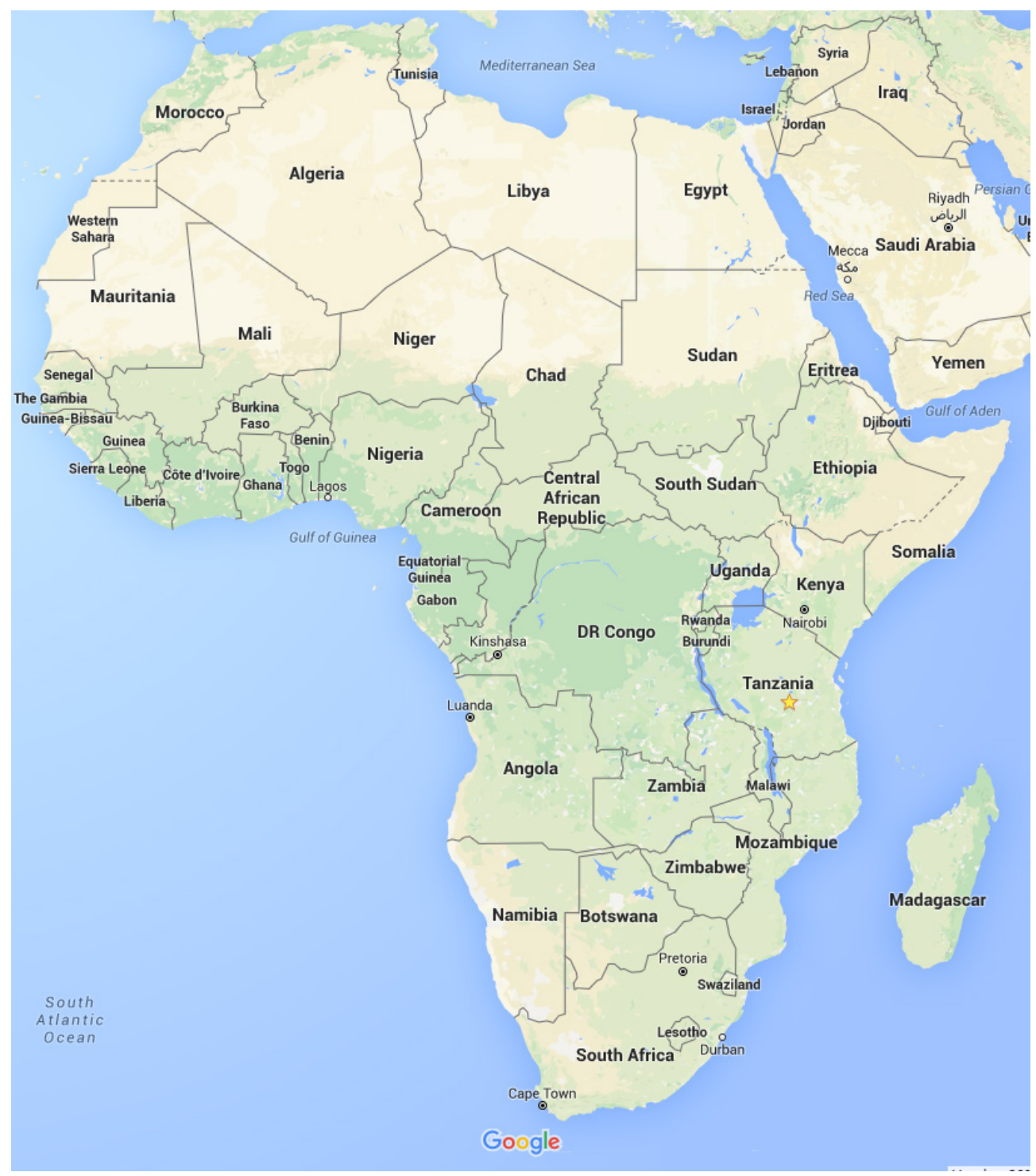

Figure 2.1: Map of the continent of Africa. Tanzania is indicated with a star. (Source: Google Maps) 


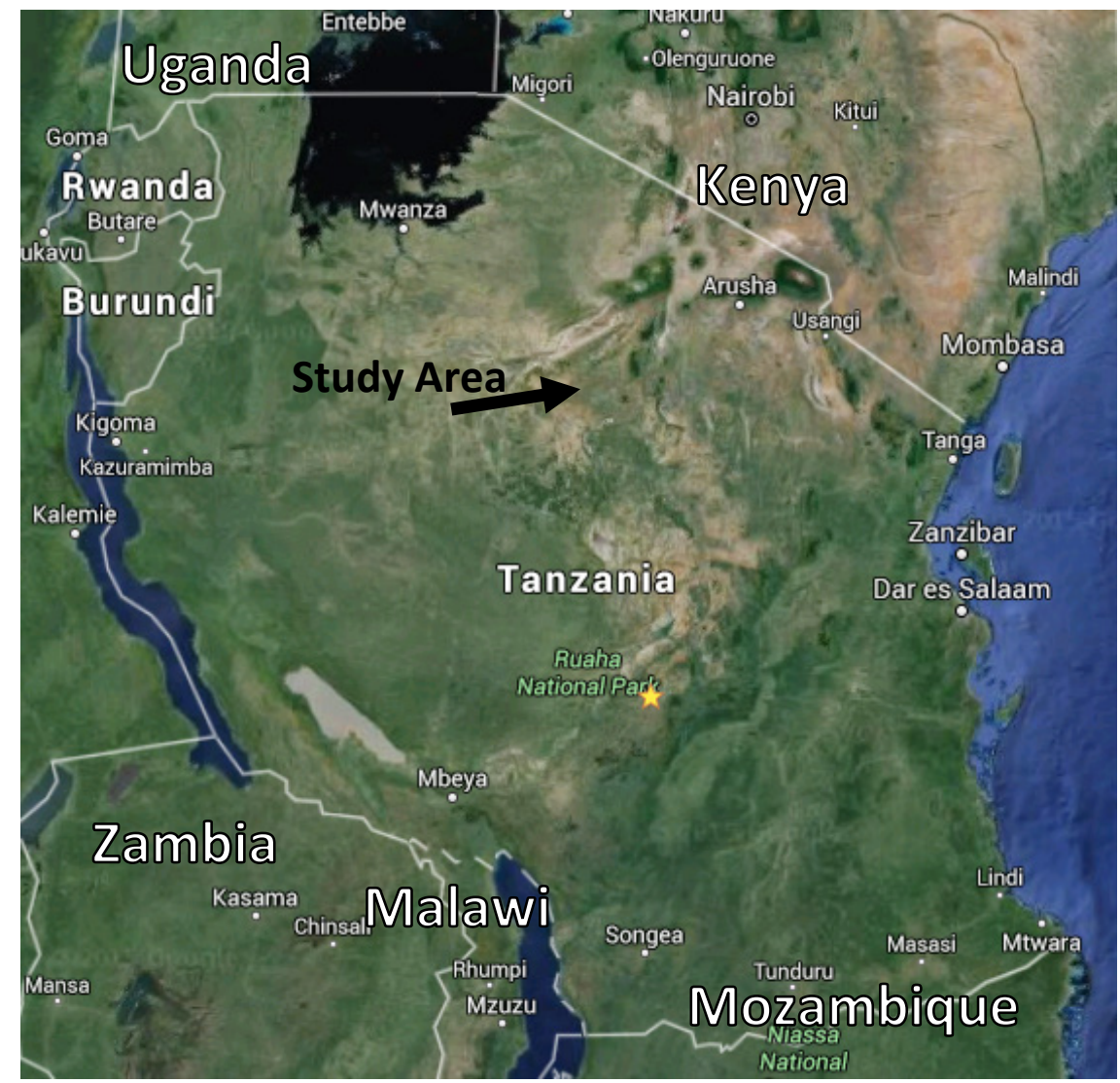

Figure 2.2: A detailed map of Tanzania and the surrounding countries. The study site is indicated with an arrow. (Adapted from Google Earth)

Hanan'g District, the area of study for this research, is in the Manyara Region (formerly Arusha Region), and is home to the $4^{\text {th }}$ highest mountain in Tanzania, Mount Hanan'g. Mount Hanan'g is 3417 meters high and helps to create a semi-arid micro-climate in the area, as compared to the mainly arid climate nearby. The area of study for this project comprised three separate communities, all very near to the base of Mount Hanan'g (Figure 2.3), and all at around an elevation of 1700 meters [36]. The area has a light rainy season from November to January, a short dry season in February and March, and then a heavy rainy season from March to May and a long dry season from June to October or November [37]. Many residents of the area reported that the rainy season has been changing lately, and they now often have only one rainy season from December or January until May, with less consistent rains than in previous years. Hanan'g district is home to mainly two ethnic groups: the Iraqw and the Barbaig, who are part of the Datooga people. The Iraqw are primarily farmers, who keep some livestock at home, and the Barbaig are primarily nomadic or semi-nomadic herders [37]. In the Hanan'g area, 
the main crops farmed are corn, beans, and sunflowers. Vegetables are often planted in home gardens, and fruit trees such as banana, avocado, papaya, and mango are commonly grown at home. Most families keep chickens, and many families also have cows, sheep, and goats. There are some differences between ethnic groups and their livelihoods throughout the Hanan'g district, as seen through the three study sites.

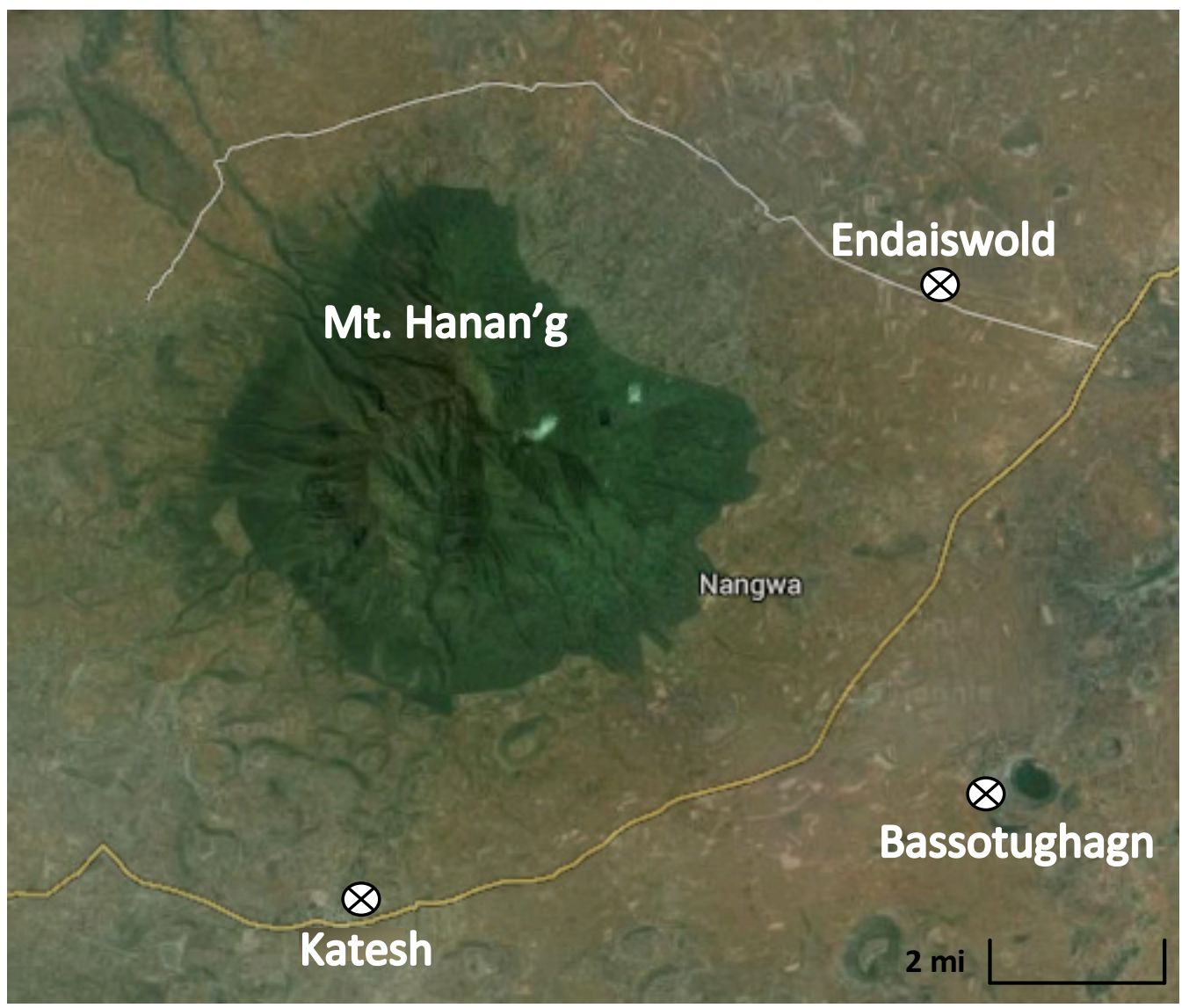

Figure 2.3: A map of the three sites where interviews were conducted. (Adapted from Google Earth)

The three specific sites where people were interviewed for this study were Bassotughagn village, Endaiswold village, and Katesh town (Figure 2.3). Bassotughagn has a population of 2238 adults, 1096 of which are women and 1142 men. There are 326 households in the village, most of which are farmers and livestock keepers of the Iraqw ethnic group [38]. Endaiswold village has a population of 4517 adults, and was established as a village in 1978 [39]. The village was originally settled by the Fyomi tribe, which are a part of the Barbaig tribe, but were forced out of the village in later years. Now, Endaiswold is mainly composed of Iraqw farmers and livestock keepers [39]. Katesh town is the district capital of Hanan'g District, and is composed of the Katesh and 
Ganana wards. The two wards together have a population of 16,317 adults: 8,484 women and 7,833 men [40]. Most of this population is Iraqw, but there are many Barbaig, and members of several other ethnic groups living there as well. People in Katesh have a variety of occupations including farmers, teachers, shop owners, government officials at the district head office, and doctors, nurses, and staff at the Tumaini Hospital in town. Most people also have a farm nearby outside of their regular work if they are not primarily farmers. Katesh was originally a small settlement of nomadic herders of the Barbaig tribe, ruled by Barbaig chief, Chief Gidobat, but after some time, the Iraqw farmers came in and settled the area. After Tanzania gained independence, chiefs were no longer allowed to rule, and by 1987, Katesh became the district capital [40].

\subsection{Electricity in Rural Tanzania}

Endaiswold and Bassotughagn villages have not been connected to the electricity grid that is powered by Tanzania's electrical supply company (TANESCO), but much of Katesh town has been connected to TANESCO's electricity grid. Only approximately 10\% of all Tanzanians are connected to the electric grid, however [4]. The majority of Tanzanians use expensive kerosene for their primary light source, with solar lights/rechargeable lamps as the second-most used light source (Figure 2.4) [4].

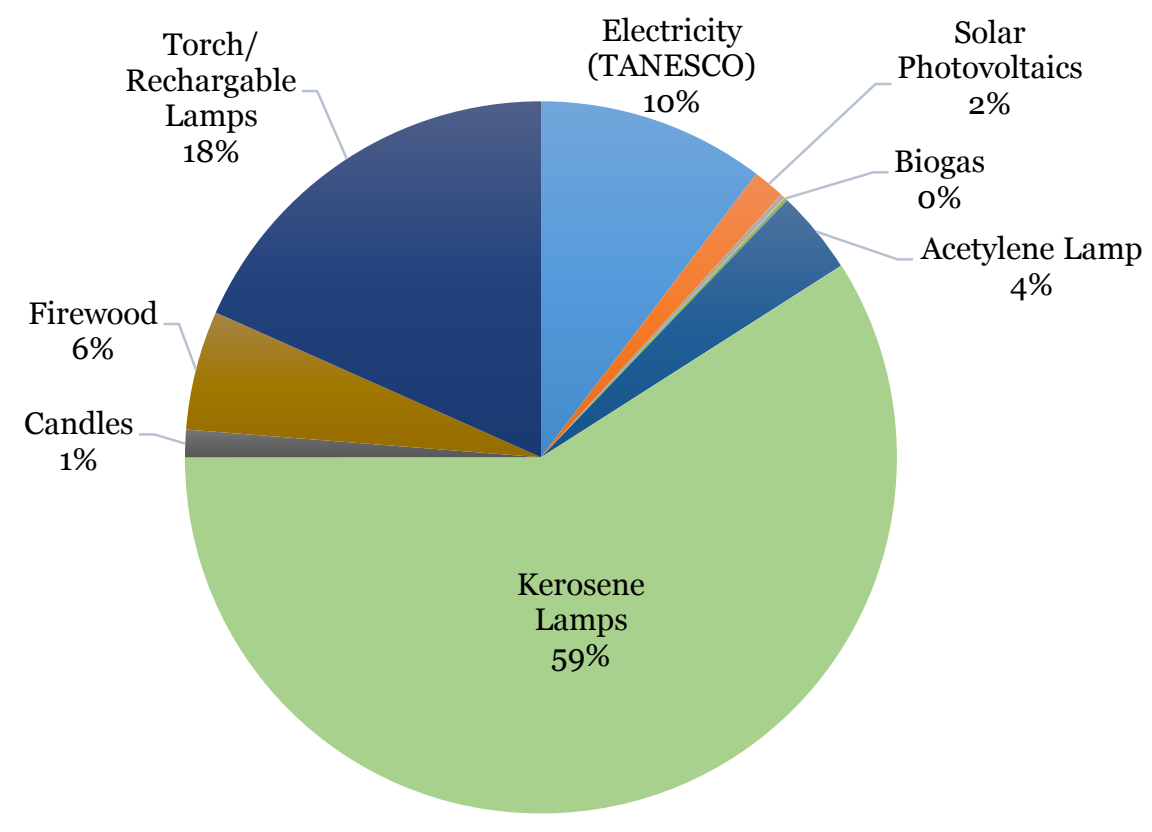

Figure 2.4: Light sources used in all Tanzanian households as of the 2012 Tanzanian Census [4]. 


\subsubsection{Solar Electricity and Lighting in Tanzania}

For households without electricity, small solar lights are becoming more popular in rural Tanzania, and are seen fairly widely around Endaiswold, Bassotughagn, and even Katesh. To promote the use of renewable energy technologies in Tanzania, the World Bank and Global Environment Facility with their program to reduce climate change have been providing funding, although most donor funding in the 1990 s went towards developing the expansion of grid electricity [41]. The World Bank's current program 'Lighting Africa' is more focused on off-grid lighting options for rural use in Africa [15]. In recent years, other aid organizations have promoted the use of household solar lights in Tanzania through discounts, distribution, and community information sessions. The organization SunnyMoney, a part of SolarAid, visits various community schools around Tanzania, educates students and teachers about solar lights, sells various versions of small household solar lights to participants and allows for community members to sell solar lights in the community as an entrepreneur [16]. In Tanzania, SunnyMoney mainly sells the d. light $\mathrm{S} 2$ model, which is a small light designed primarily for reading, but can be used throughout the house as well $[16,42]$. This light cost approximately $\$ 15$ and can be seen in Figure 2.5. Lighting Africa, SunnyMoney, and SolarAid use entrepreneurs in communities to sell the household solar lights to allow for the market to determine which products are the best to sell $[15,16]$. This use of the free market to determine the best solar light for households has been a successful alternative to NGO distribution of solar lights.

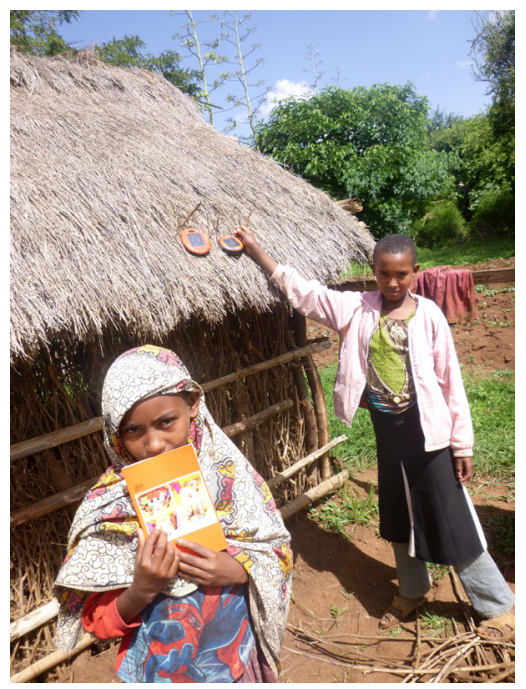

Figure 2.5: Many rural families in the Hanan'g District have purchased small solar lights (d.light model S2) to use in their homes and to help their children study at night (Photo by author). 


\subsubsection{Biogas for Electricity Use}

Biogas digesters, which produce methane gas from waste products, are generally used in developing countries for cooking, lighting, and electricity generation [43]. Livestock manure is the typical fuel for methane production, and can be used as a fertilizer on crops after being used in a biogas digester [44-46]. Using biogas for cooking and lighting fuels is fairly efficient, as the gas is used directly from the digester. However, biogas as a source of electricity is relatively inefficient and expensive, due to the need for either a fuel cell or an electric generator to produce the electricity [47, 48]. Therefore, most people using biogas, especially those in sub-Saharan Africa, use it as a cooking and lighting fuel [49]. Various NGOs throughout sub-Saharan Africa, and in Tanzania especially, have promoted the use of biogas systems for schools and health centers [49]. Over 1000 biogas systems have been constructed for this purpose, but they have largely failed due to the use of cheap and unreliable biogas digesters and limited trained maintenance personnel [49, 50]. With a more sustainable approach to introducing biogas digesters into communities, schools, and health clinics, they have the potential to be a successful lighting and cooking technology in rural developing communities [51, 52]. An increase in efficiency of electricity generation from biogas, along with a reduction in cost could also make biogas an effective technology for electricity production. However, as electricity production from biogas is still a difficult and expensive process, it is not an effective electricity generation technology for use in developing countries.

\subsubsection{Grid Expansion in Rural Tanzania}

Although many rural Tanzanians are interested in solar and biogas electricity sources, grid electricity is still the preferred electricity option. Yet there have been some issues with grid electricity performance and installation that make the grid a less desirable option. Although grid electricity has improved drastically over the past decade, power outages are still a regular occurrence throughout Tanzania. Due to the high percentage of electricity coming from hydro-power, blackouts occur frequently when river levels drop in the dry season [53]. Black outs also occur with there is a high demand for electricity. During popular events such as an election or the World Cup, frequent blackouts are experienced due to the high demand. For grid electricity as well as solar photovoltaics, there are also issues with the high expenses of making houses up to code for safe wiring, installation of the wiring, and the relatively high ongoing expenses due to electricity bills 
and the accumulation of appliances [41]. Electric grid expansion requires a high cost of installation and fees to the electricity company, and rural areas of Tanzania often lack well trained electricians that can safely wire a home [41]. Tanzania's electricity company has been working to expand the electric grid to an increasing number of towns and villages, but the cost of installation and getting connected to the grid has prohibited many rural Tanzanians from installing grid electricity [13]. Illicit connections due to the high costs of installation with TANESCO are present, but not common around the country. However, several illicit connections that have been made to the power lines have been dangerously connected and have led to deaths from the unsafe wiring [54].

\subsubsection{TANESCO}

TANESCO is currently the largest electrical supply and distribution company in Tanzania. They generate electricity, distribute it throughout the country via an electrical grid, and then sell the electricity to customers on their gridlines. The company was started in 1931. It comprised TANESCO (Tanganyika's electrical supply company) and DARESCO (Dar es Salaam city's electrical supply company) [35]. Both of these companies were bought by the Tanzanian government after gaining independence in 1961 (Tanzania was then Tanganyika). In 1968, after Tanganyika and Zanzibar had joined together to form Tanzania, the two companies were joined together to form the current company of TANESCO [11].

TANESCO is wholly owned by the Tanzanian government as a parastatal organization, but allows for private investors to invest in certain projects or in the company as a whole [35, 53, 55, 56]. Until 1992, TANESCO had a government-imposed monopoly in Tanzania. This was revoked in 1992 in order to encourage more electrical supply and distribution companies to help diversify the markets and bring competition into the market [11]. However, currently there is only one other major electrical supply and distribution company that works in Tanzania, Symbion Power LLC, and it works in a partnership with TANESCO, which has not helped to bring competition to the electricity market [57]. Nevertheless, their partnership with Symbion Power has helped TANESCO to increase total electricity generation as well as to diversify electricity sources [57]. TANESCO is currently trying to diversify their energy sources so $2 / 3$ of Tanzania's electricity comes from hydroelectric plants and 1/3 comes from natural gas plants, whereas previously, they relied more on hydroelectric power $[10,58]$. This diversification 
of electricity sources aims to reduce blackouts that have been occurring throughout the dry season in Tanzania. As Tanzania continues to develop, however, TANESCO will need to increase electricity generation significantly in order to reduce the frequency of largescale power outages throughout the country.

\subsubsection{Microbial Fuel Cells in Tanzania}

Microbial fuel cells (MFCs), like biogas digesters, can produce energy from waste. Unlike biogas digesters, they are designed to generate electricity without intermediate gas production. MFCs generate electricity anaerobically from organic matter using bacteria that convert the biochemical energy in the organic matter to useful electrical energy, as described below [17-19]. MFCs have been noted as a good potential technology for use in developing countries due to their ability to use wastes as a fuel source as well as their ability to treat wastewater with no electricity input $[26,31]$. A wide range of organic materials, including manure, food waste, corn cobs, and corn stover have successfully been used as substrates in MFCs and are all widely available in rural and urban Tanzania [27, 59-64].

\subsubsection{Low Cost MFCs}

Low cost MFCs were evaluated to determine if they could possibly be used in rural Tanzania. MFCs that use exclusively low cost materials have been found to have significantly lower power output and voltage than those using traditional materials, as discussed further in Section 2.3.2.2 [65]. Further, low cost materials are generally not locally available in Tanzania, and material prices tend to change over time. It is possible to increase the voltage of MFCs by stacking them or using an energy harvesting system, yet a minimum voltage must be achieved to run and energy harvesting system and a sufficient power output must also be achieved in order for the electricity to be useable. Therefore, this research focused on exploring the potential use of a simple or low-tech household MFC, but not one that was constructed exclusively using low-cost or locally available materials. The development of low cost materials to use in MFCs was outside the scope of this research, and it was assumed that the cost of MFCs would be subsidized by an NGO until they became affordable. 


\subsection{Microbial Fuel Cell Fundamentals}

Microbial fuel cells generate electricity through several processes that occur simultaneously. These processes can be explained with a simple two-chambered MFC, shown in Figure 2.6.

As shown in Figure 2.6, a two-chambered MFC consists of anode and cathode chambers separated by a proton exchange membrane (PEM) and an external circuit. Within the anode chamber, organic matter serves as the fuel source, and $\mathrm{CO}_{2}$, protons $\left(\mathrm{H}^{+}\right)$, and electrons ( $\mathrm{e}^{-}$) are produced by bacteria that oxidize the organic matter. Electrochemically active bacteria grow attached to the anode. These bacteria transfer electrons from the organic matter as it becomes oxidized to the anode and are conducted through the external circuit to the cathode. At the cathode, the electrons react with oxygen and protons to form water. Any load, capacitor, or a battery can be substituted for the external resistor in this figure.

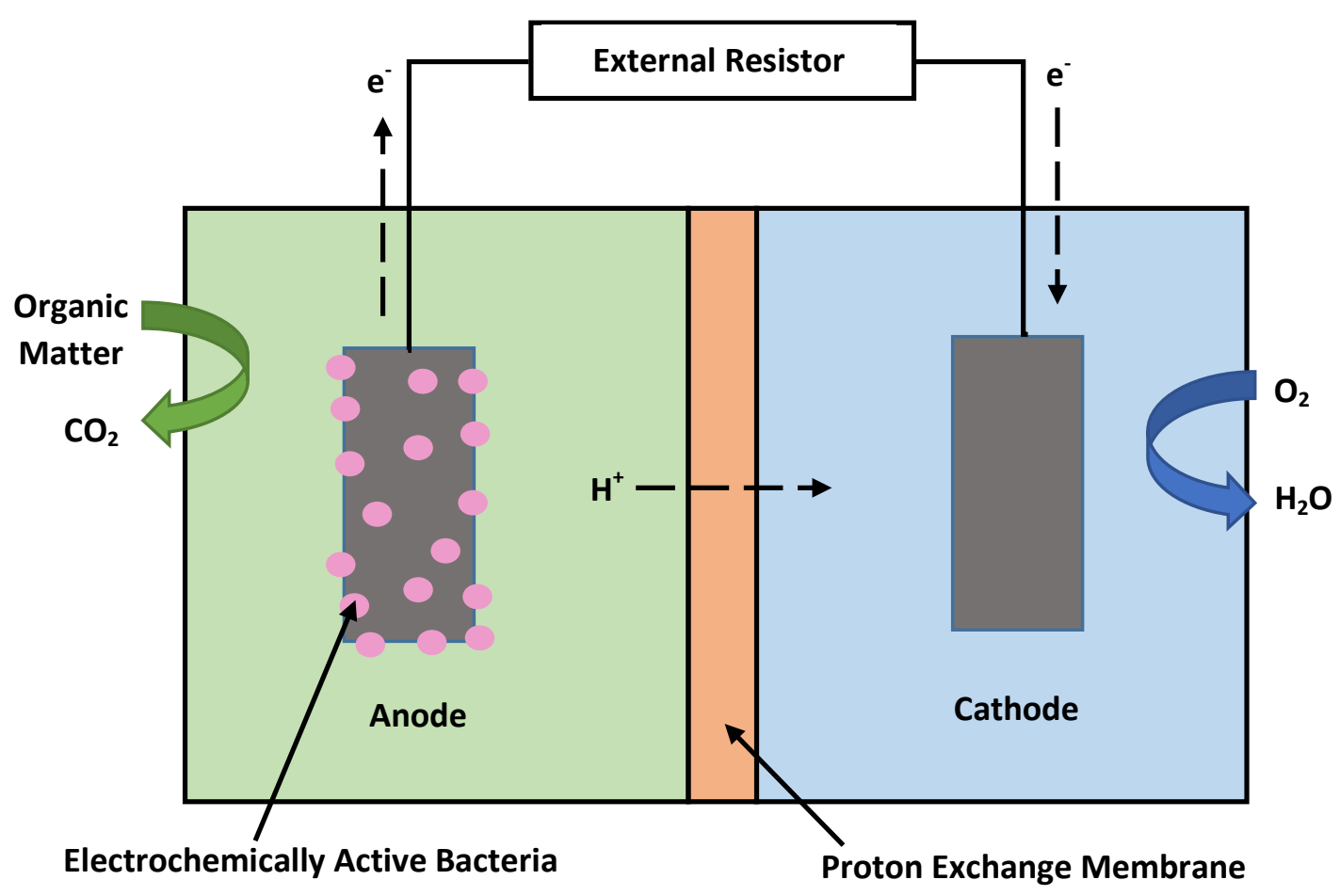

Figure 2.6: Diagram of a two-chambered MFC. Adapted from Logan [66].

Key information on electrochemically active bacteria, electron transfer mechanisms, electricity generation in MFCs, electrochemical performance parameters, MFC 
construction and materials, practical design and utilization of MFCs, and the use of manure as a fuel source are reviewed in the following sections.

\subsubsection{Electrochemically Active Bacteria}

Within MFCs, electrons are transferred from organic matter to the anode by electrochemically active bacteria, which are bacteria that can transfer electrons across the cell membrane [66]. Electrochemically active bacteria move the electrons to the anode via various electron transport mechanisms [66, 67]. Several strains of bacteria have been shown to be electrochemically active in MFCs, and additional electrochemically active bacteria presumably have not yet been characterized [66]. Iron(III)-reducing bacteria have been proven to be electrochemically active, and many of those bacteria, such as several in the Geobacter, Shewanella, and Pseudomonas genera, as well as Rhodoferax ferrireducens and Alcaligenes faecalis have been detected in association with the anode of MFCs [21, 25, 68-72]. In MFCs fed with wastewaters or other complex organic matter, these bacteria are enriched, along with many other species of bacteria, and produce electricity.

Electrochemically active bacteria include facultative and obligate anaerobes [73, 74]. Most MFCs can allow a very small amount of oxygen (up to $0.3 \mathrm{mg} / \mathrm{L}$ ) into the anode chamber without the bacteria failing, but oxygen in the anode chamber can cause other issues with MFC performance [73, 75]. Liu and Logan [76] found that glucose-fed MFCs could lose up to $28 \%$ of their power output due to aerobic respiration. When oxygen enters into the anode chamber, it also raises the redox potential in the anode chamber. The decreased difference in the potentials in the anode and cathode chambers reduces the free energy available that can be captured in the MFC. Therefore, keeping dissolved oxygen out of the anode chamber is essential to keep voltage and power output high.

\subsubsection{Electron Transfer Mechanisms}

Electrons derived from the oxidation of a substrate by bacteria must be transported to the anode in order to produce electricity. External mediators such as neutral red, potassium ferricyanide, methyl viologen, and thionine can be used to help the bacteria transfer electrons to the anode [77-80]. However, it is now known that mediators are not necessary for the transfer of electrons $[17,72,81]$. Without external mediators, bacteria 
produce their own mediators or use other methods to facilitate the movement of electrons [66].

Three mechanisms are the most important for electron transfer within an MFC. Bacteria transport electrons in MFCs via soluble electron shuttles, $c$-type cytochromes in the anodic biofilm, or by nanowires [73, 82]. Electron shuttles are bacteria-produced mediators that transfer electrons within the MFC without direct contact with the electron acceptor [83]. $C$-type cytochromes are proteins in the electron transport chains, and can transfer electrons from inside the cells to electron acceptors external to the cell, e.g. an anode [84-86]. Nanowires are biological electrically conductive wire-like attachments on bacteria that transfer electrons from the cell to the anode or to an anodic biofilm [82].

\subsubsection{Electricity Generation with Microbial Fuel Cells}

The oxidation of organic matter in a MFC occurs via a respiratory process in which electrons are transferred from the energy source or electron donor to an electron acceptor through an electron transport chain. This process produces energy in the form of ATP. In a MFC the oxidation half reaction is carried out in an anaerobic environment, and the anode serves as the electron acceptor.

The difference between the reduction potentials of the oxidation and reduction halfpotentials is the theoretical maximum electric potential achievable by the reaction. Many MFCs use acetate as an electron donor and oxygen is supplied as the electron acceptor in the cathode. Thus, the half reactions and reduction potentials, denoted as E/, are shown below for acetate and oxygen. All half reactions are written as reduction reactions.

$$
\begin{aligned}
& \frac{1}{8} \mathrm{CO}_{2}+\frac{1}{8} \mathrm{HCO}_{3}^{-}+\mathrm{H}^{+}+\mathrm{e}^{-} \rightarrow \frac{1}{8} \mathrm{CH}_{3} \mathrm{COO}^{-}+\frac{3}{8} \mathrm{H}_{2} \mathrm{O} \quad \mathrm{E}^{\mathrm{o} /}=-0.28 \mathrm{~V} \quad \text { Equation } 2.1 \\
& \frac{1}{4} \mathrm{O}_{2}+\mathrm{H}^{+}+\mathrm{e}^{-} \rightarrow \frac{1}{2} \mathrm{H}_{2} \mathrm{O} \quad \mathrm{E}^{\mathrm{o} /}=+0.82 \mathrm{~V} \quad \text { Equation } 2.2
\end{aligned}
$$

Under these conditions, the theoretical maximum electric potential that can be reached is $0.82 \mathrm{~V}-(-0.28 \mathrm{~V})=1.1 \mathrm{~V}$. In MFCs, the oxidation half-reaction (Equation 2.1) occurs at the anode, and the reduction half-reaction (Equation 2.2) occurs separately at the cathode, and the potential between the anode and cathode is available as the MFC working potential, as illustrated in Figure 2.7. However, MFCs cannot obtain the theoretical maximum potential of $1.1 \mathrm{~V}$ due to voltage losses and overpotentials within 
the MFC and the potential needed for growth of the electrochemically active bacteria. Working cell voltages depend on the organic matter being used as the electron donor, the inoculum used to enrich bacteria in the MFC, the electron acceptor used, as well as MFC architecture and materials used [87].

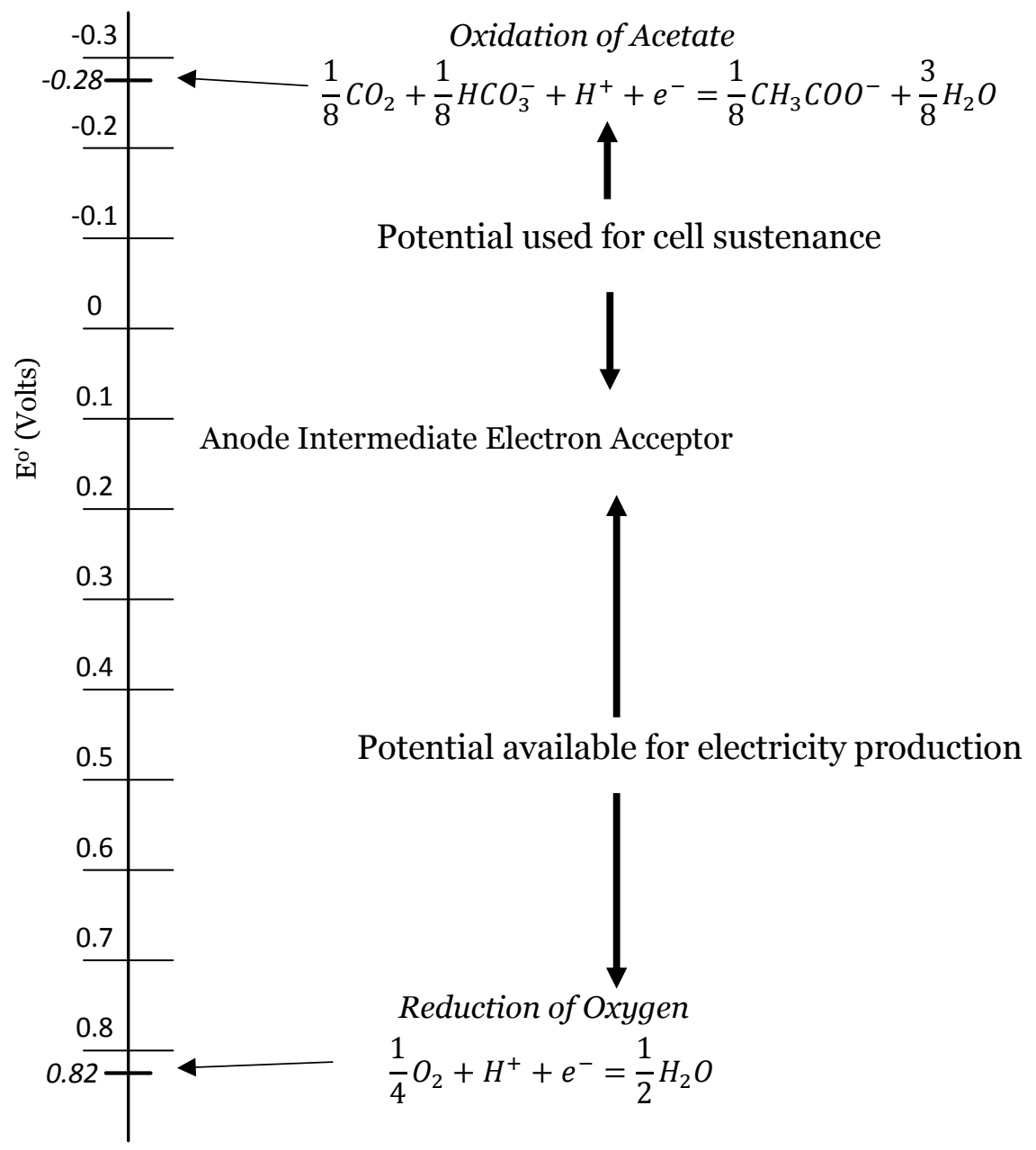

Figure 2.7: Reduction potentials of acetate and oxygen, which are commonly used in MFC research.

In addition to the anode and cathode, the external circuit includes an external resistor. The relationship between electric potential, resistance, and current in a MFC are described via Ohm's law.

$$
E_{\text {cell }}=I R_{\text {ext }}
$$

In this equation, $\mathrm{E}_{\text {cell }}$ (volts) is the electric potential of the MFC, I (amperes) is the current in the cell, and $\mathrm{R}_{\text {ext }}$ (ohms) is the external resistance applied to the cell. 


\subsubsection{Electrochemical Performance}

Several metrics are commonly reported to assess the performance of an MFC. MFC performance is evaluated by the open circuit voltage (OCV), amount of power generated, reported as power density (power per unit volume or electrode surface area), the efficiency of conversion of biochemical energy in the substrate to electrical energy (known as coulombic efficiency), and the ability to use and treat the organic matter within the MFC. Internal resistance is also a common measure of MFC performance.

The OCV is the maximum potential that the MFC can achieve and occurs when the resistance is infinitely high, according to Ohm's Law. It is found by disconnecting the external circuit and measuring the potential as the cell resistance goes to infinity. The open circuit potential is useful for comparing different MFCs, because both small and large MFCs can achieve similar OCVs.

The energy available from oxidation $(\Delta G)$ is proportional to the reduction potential according to Equation 2.4 .

$$
\Delta G=n \times F \times \Delta E
$$

Equation 2.4

where $\Delta \mathrm{G}$ (Joules) is the amount of energy gained in the oxidation reaction, $\mathrm{n}$ is the number of electrons transferred, $\mathrm{F}$ is Faraday's Constant ( 96,485 Coulombs/mole), and $\Delta \mathrm{E}$ is the potential difference between the electron donor (organic matter) and electron acceptor (anode).

Power is the rate of consumption of electrical energy over time. Power can be calculated according to:

$$
P=\frac{\Delta G}{t}
$$

Equation 2.5

where $\mathrm{P}$ (watts) is the power generated, and $\mathrm{t}$ is the time elapsed (seconds). Electrical power can also be conveniently calculated according to Equations 2.6 and 2.7.

$$
\begin{array}{ll}
P=I E_{\text {cell }} & \text { Equation } 2.6 \\
P=\frac{E_{\text {cell }}^{2}}{R_{\text {ext }}} & \text { Equation } 2.7
\end{array}
$$


Power production is a function of several factors, including MFC size and electrode area, and therefore it is generally not used to compare electrochemical performance in MFCs. A more common measure is power density, which normalizes the power to the anode area $\left(\mathrm{P}_{\mathrm{An}}\right)$, cathode area $\left(\mathrm{P}_{\mathrm{Ca}}\right)$, or reactor volume $\left(\mathrm{P}_{\mathrm{V}}\right)$ for air cathode $\mathrm{MFCs}$, as described by Equation 2.8 for normalization to anode area $\left[\mathrm{mW} / \mathrm{m}^{2}\right][20]$.

$$
P_{A n}=\frac{E_{\text {cell }}^{2}}{A_{A n} R_{\text {ext }}}
$$

where $A_{A n}$ is the surface area of the anode $\left[\mathrm{m}^{2}\right]$.

Power output in an MFC also depends on mixing and mass transfer in the anode chamber, bacterial kinetics, internal resistance, and performance of the proton exchange membrane [67]. Power output also depends on the current flowing through the external circuit (Equation 2.6). Figure 2.8 shows an idealized relationship between power density and current density.

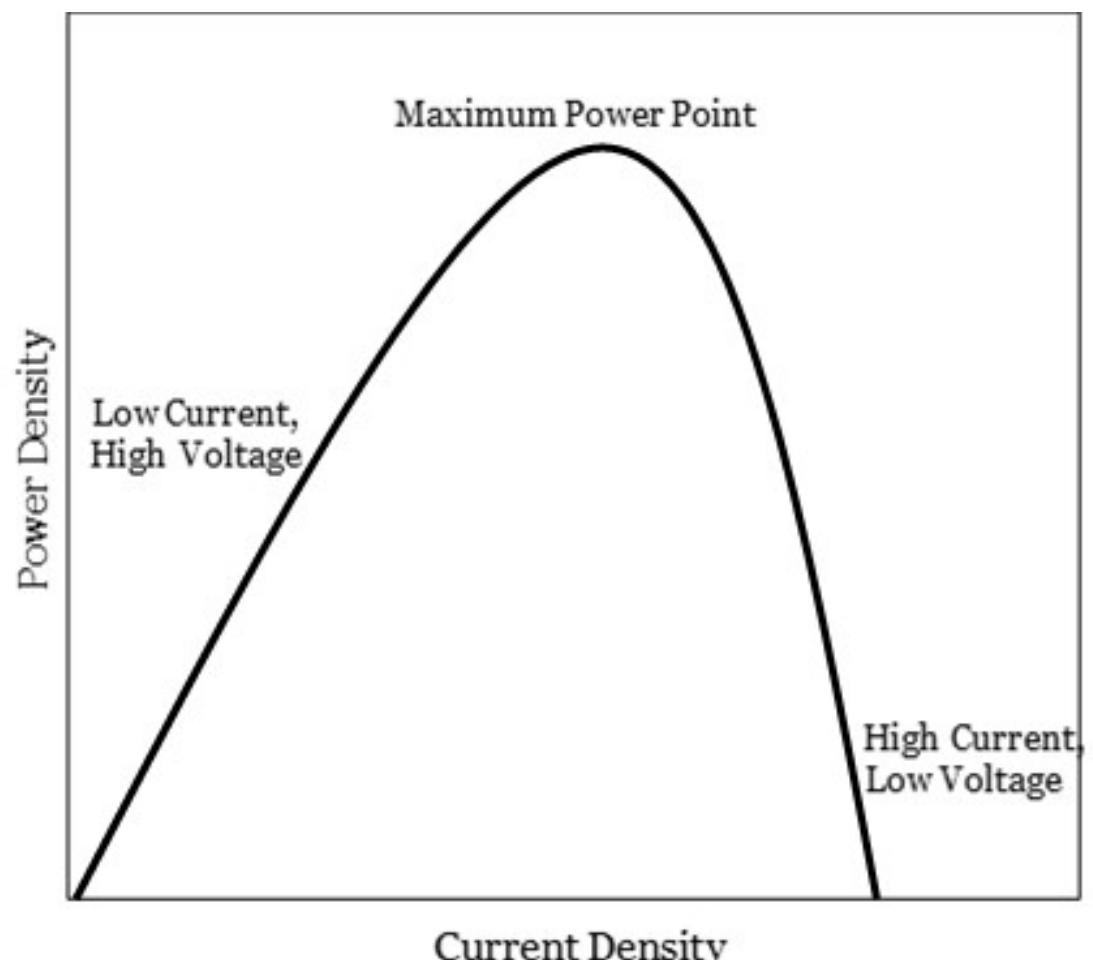

Figure 2.8: Idealized relationship between power density and current density for a typical MFC. Adapted from Wang et al [6o].

Figure 2.8 illustrates that power density in a MFC reaches a maximum at an intermediate current density and then drops off. According to fuel cell theory, power 
density reaches its peak when total internal resistance $\left(R_{\text {int }}\right)$ is equal to the applied external resistance $\left(R_{\text {ext }}\right)$ [20, 88]. Because the $R_{\text {ext }}$ that is applied when maximum power is achieved is known, analysis of power density curves like that shown in Figure 2.8 can be used to estimate the internal resistance of a MFC. Operating MFCs at the maximum power point keeps the power output from dropping considerably [89, 90]. Therefore, for this study, the power curves and total internal resistance were used to determine the external resistance for optimal power production.

In practice, MFCs cannot operate at the theoretical maximum potential or corresponding power output due to voltage losses in the MFC. These include losses due to activation, bacteria metabolism, ohmic resistance, and mass transport [20, 67, 91]. Activation losses occur when electrons are transferred from the electron donor to the anode and from the cathode to the electron acceptor. These losses occur mainly at low current densities, as illustrated in Figure 2.9, and can be limited by maximizing electrode surface area, using a catalyst at the cathode, enriching certain bacteria on the anode, and other measures $[66,91]$. Bacteria metabolism losses represent the energy captured by the bacteria for growth (Figure 2.7). These losses occur at all current densities. Ohmic losses refer to the resistance to electron flow through the medium in the anode chamber and through the electrical circuit (including electrodes), and the resistance to ion transport across the PEM. They occur within a large range of current densities, and can be minimized by reducing electrode spacing, assuring proper contact between the electrodes and the external circuit, and choosing high-performance electrode materials [66, 91]. Mass transport losses, also known as concentration losses, occur when the electron flow is limited due to inadequate mass transport to the anode and mainly occur at high currents [91]. A typical polarization curve showing the dominant losses occurring at various current densities is shown in Figure 2.9. Thus, polarization curves provide another means of estimating internal resistance in a MFC. The slope of the most linear section of polarization curves, which is presumably dominated by ohmic resistance (Figure 2.9), is the total internal resistance in the MFC, as described by Ohm's Law (Equation 2.3). 


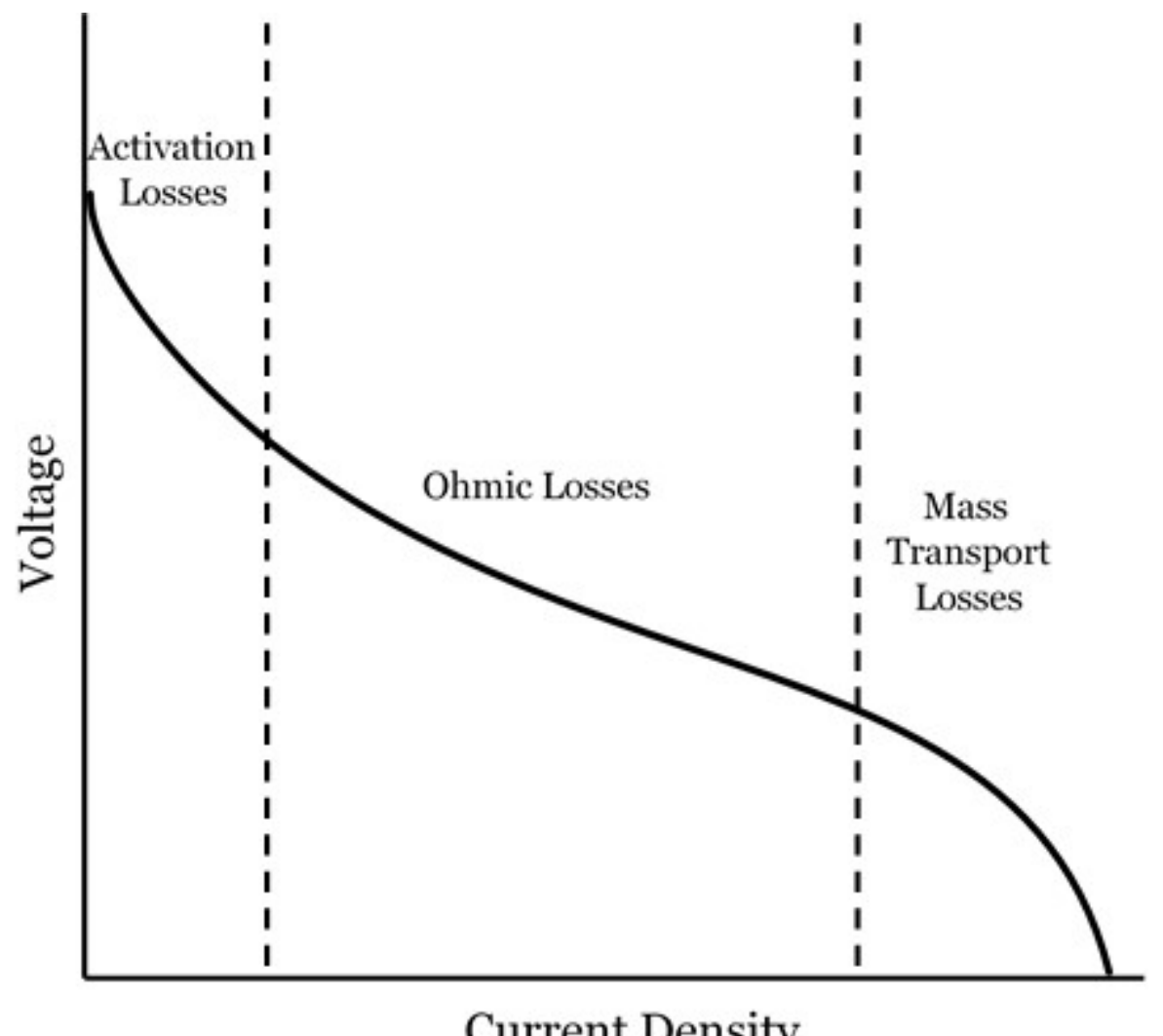

Figure 2.9: Categories of voltage losses on a voltage vs. current density polarization curve.

Figure 2.9 shows a typical polarization curve of an MFC where voltage non-linearly decreases with increasing current density. In the low current density zones, where voltage is high, activation losses dominate in the MFC. In the middle current density zone, where voltage more linearly decreases with increasing current, losses are mainly due to ohmic losses. At high current densities, near to a short-circuit condition, more of the losses within the MFC are mass transport voltage losses. 


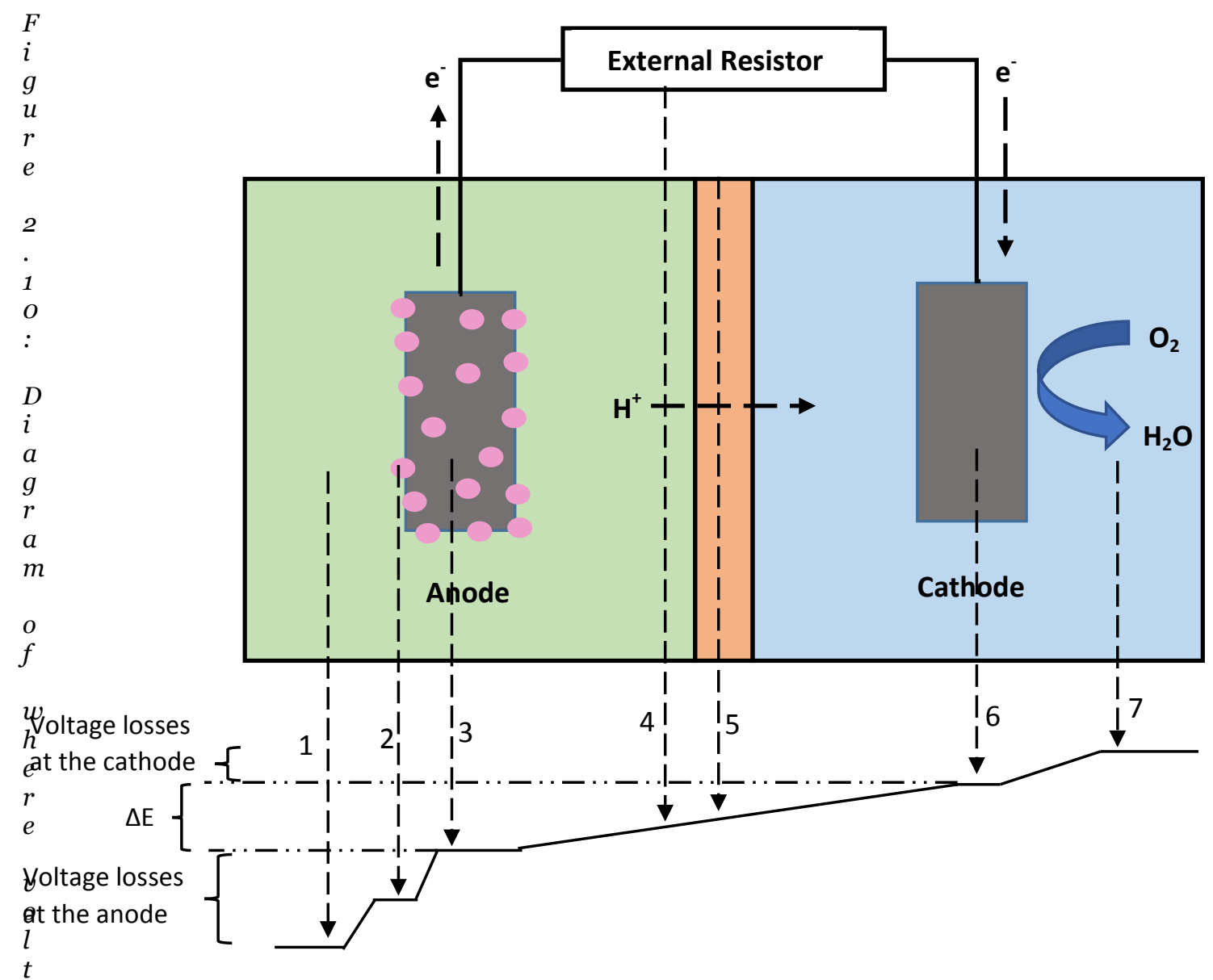

age losses occur within the MFC. 1. Anodic activation losses and mass transport losses. 2. Bacteria metabolism losses. 3. Ohmic losses at the anode. 4. Voltage drop from external resistor. 5. Ohmic losses at the PEM. 6. Ohmic losses at the cathode. 7. Activation and ohmic losses from oxygen reduction. Adapted from Rabaey and Verstraete [67].

Figure 2.10 illustrates how internal resistances and various losses within an MFC decrease the useful voltage.

Coulombic efficiency (CE) can be found using Equation 2.9.

$$
C E=\frac{M \int_{0}^{t} I d t}{F b V_{A n} \Delta C O D}
$$

where $\mathrm{M}$ is the molecular weight of oxygen gas (32 g/mole), $\mathrm{b}$ is the number of electrons conserved in the reduction of $\mathrm{O}_{2}$ to $\mathrm{H}_{2} \mathrm{O}(4), \mathrm{V}_{\mathrm{An}}$ is the volume of substrate in the anode 
chamber of the MFC, and $\triangle \mathrm{COD}$ is the change in chemical oxygen demand (COD) of the substrate over the time period [20].

The other aforementioned measures of MFC performance will be used along with coulombic efficiency to determine how the performance of the MFC in this study compares to other MFCs in research.

\subsection{Microbial Fuel Cell Construction}

\subsubsection{MFC Configurations}

A wide variety of batch and continuous-flow MFC configurations are currently being used in laboratory-scale research. Common configurations include H-type, air cathode, cube, tube, three-chamber (one anode and two cathode chambers), and stacked MFCs [20]. Air cathode MFCs are a simple design with little need for ongoing maintenance or cathode aeration. They also generally achieve higher power densities and are relatively low-cost; consequently, they are seen as the future of scaled-up microbial fuel cells [20, $73,76,92]$. For these reasons, this study focused on air cathode MFCs only.

Air cathode MFCs can be made in a variety of architectures. Although there are many differences in appearance in these MFCs, all air cathode MFCs have a cathode exposed to air, rather than a cathode that is exposed to $\mathrm{O}_{2}$ by submerging it in aerated water, and an anode chamber containing substrate. Various architectures of air-cathode MFCs include the cube reactor (Figure 2.11), bottle reactor (Figure 2.12), and tube reactor with different cathode configurations (Figure 2.13). There are many variations on these basic configurations that are not discussed at length in this thesis.

The cube architecture (Figure 2.11) is a simple design and is used widely in laboratory studies. The anode is generally either a carbon cloth attached to one side of the cube or a graphite brush suspended on the inside of the anode chamber. Bottle reactors use a bottle designed specifically for testing MFCs in the laboratory. In the MFC shown in Figure 2.12, there is a carbon cloth anode suspended in the bottle and a treated carbon cloth cathode at the opening of the bottle. A tubular MFC configuration like that shown in Figure 2.13 A was used in this study, as described in detail below. 


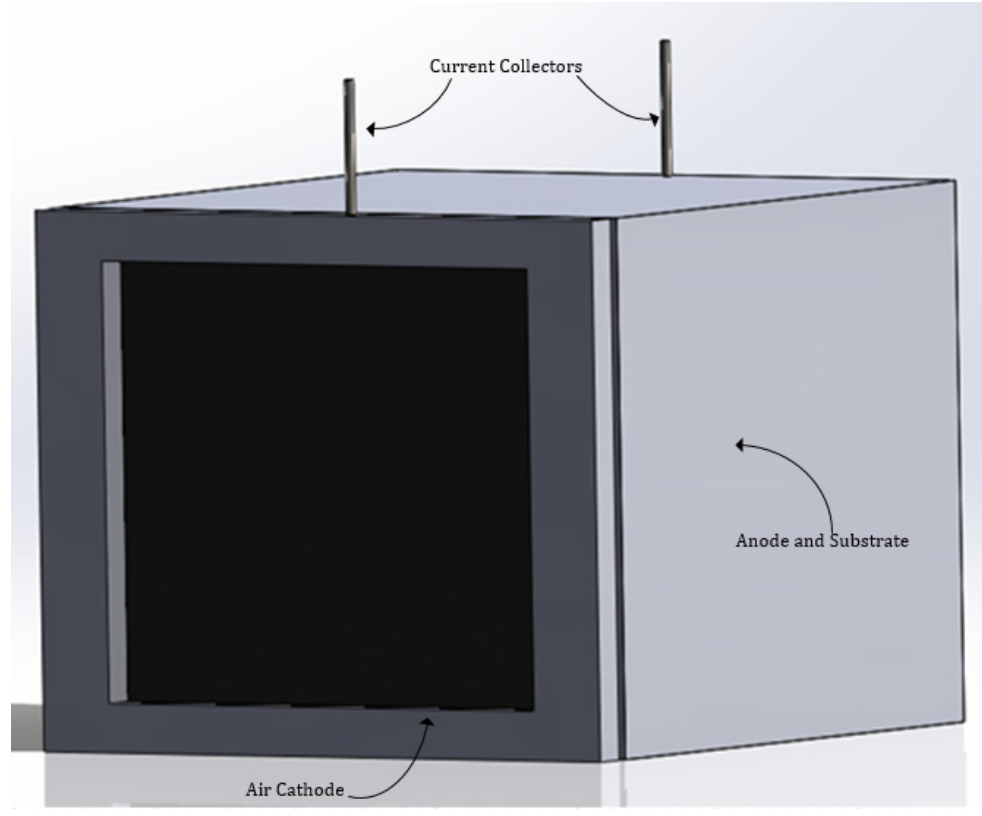

Figure 2.11: Diagram of a cube MFC

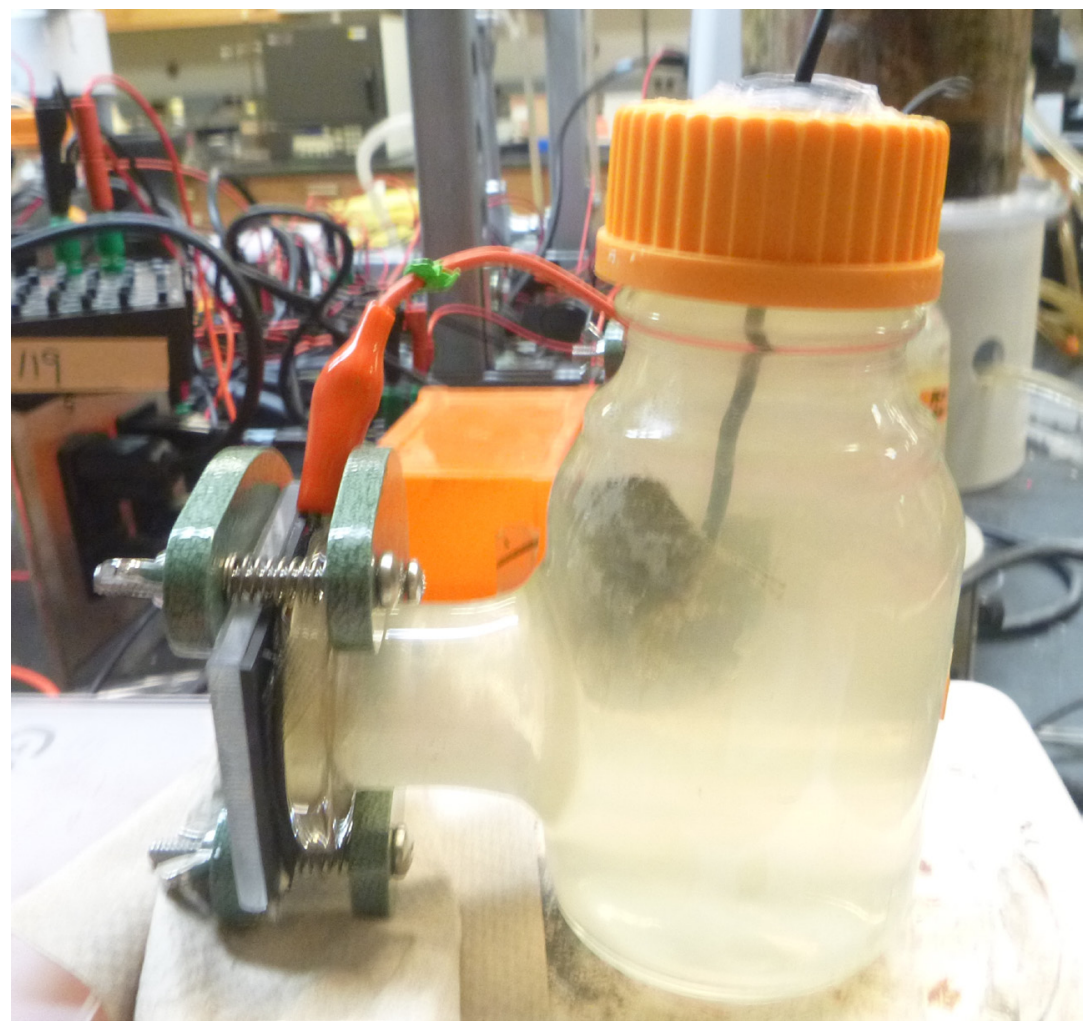

Figure 2.12: Photograph of a typical air cathode bottle reactor (Photo by author). 


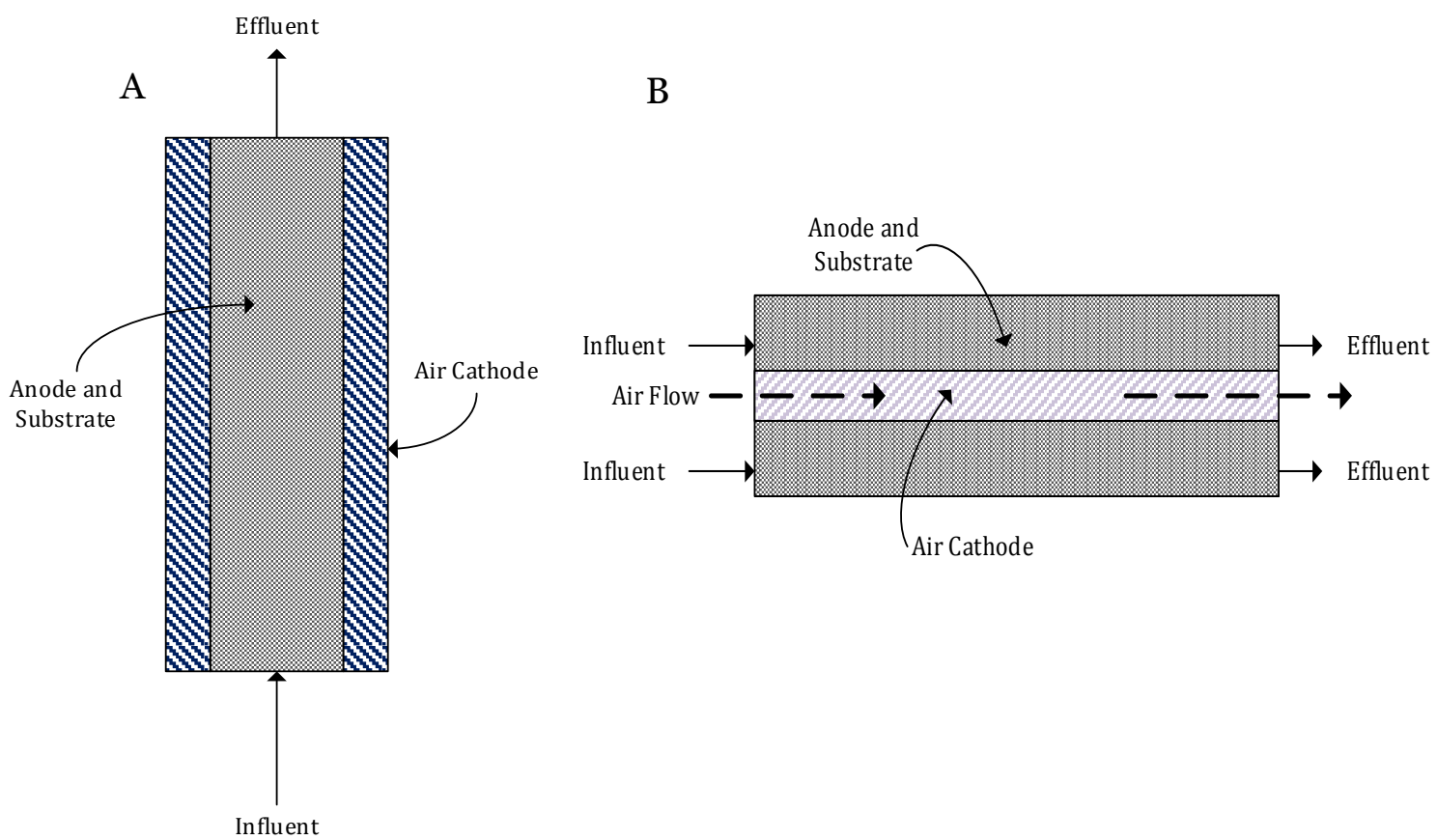

Figure 2.13: Tubular MFC configurations with (A) cathode wrapped around the exterior of the anode and (B) cathode in the center of the MFC (adapted from Liu et al. and Scott et al. [26, 93]).

\subsubsection{MFC Materials}

Studies have found that the materials used in MFCs for electrodes, catalysts, proton exchange membranes, and current collectors influence the internal resistance and overall performance of MFCs.

\subsubsection{Electrodes}

Electrodes provide an electrical connection between the electron donor, electron acceptor, and the external circuit in a MFC. The anode is the negative terminal and the cathode is the positive terminal. Electrodes must be electrically conductive, corrosionresistant, mechanically strong, and have a large surface area. Anodes must also support development of biofilms [20]. Anodic biofilms, which contain electrochemically active bacteria, are important for electrochemical performance of the MFC. Carbon-based electrodes are highly conductive, noncorrosive, support biofilm development, and are widely used as electrode materials in MFCs [11, 94]. For both anodes and cathodes, a variety of carbon-based materials such as graphite rods, graphite brushes, carbon cloth, carbon felt, carbon paper, and granular activated carbon have been widely used in MFC research. 


\subsubsection{Cathode Catalysts}

At the cathode, it is recommended to use a catalyst to aid in the reduction of dissolved oxygen in water or atmospheric oxygen in an air cathode configuration [95]. Platinum is the most common cathode catalyst, and it has shown to help increase power output and coulombic efficiency of the MFC [65, 96-99]. Platinum is expensive, however, and therefore it is not sustainable, especially in larger MFCs or in MFCs in industry or the home. Typical platinum loading on MFC cathodes is $0.5 \mathrm{mg} / \mathrm{cm}^{2}$, but to lower costs it is possible to reduce the platinum loading to $0.25 \mathrm{mg} / \mathrm{cm}^{2}$ with only a small drop in performance $[97,100]$. Omitting the catalyst completely reduces MFC performance by up to $95 \%$. Therefore, it is important to consider other catalyst alternatives [65]. Some potentially viable alternatives to platinum include compounds containing transition metals, activated carbon, carbon nanotubes, and cathodic biofilms. These platinum alternatives may become feasible at a larger scale in the future. Nevertheless, platinum is still the most widely used catalyst in MFC research.

\subsubsection{Proton Exchange Membranes}

Proton exchange membranes (PEMs) are thin, cloth-like membranes that allow protons and other cations to pass from the anode to the cathode and simultaneously inhibit other compounds, especially $\mathrm{O}_{2}$, to pass from one chamber to the other [20]. Nafion ${ }^{\circledR}$ membranes are commonly used in research.

Depending on the reactor configuration, PEMs can be attached to the cathode or placed in between the anode and cathode chambers. Membrane PEMs help to minimize substrate loss from the anode and oxygen permeation into the anode chamber, both of which allow the MFC to reach higher coulombic efficiencies $[67,76]$. Research has shown, however, that in some MFCs, $\mathrm{O}_{2}$ permeation of Nafion ${ }^{\circledR}$ PEMs is significant and the expected increase in MFC performance is not realized. In fact, in air cathode MFCs in particular, it has been found that MFCs without PEMs perform better than MFCs with PEMs [76].

Nafion ${ }^{\circledR}$ PEMs are also relatively expensive, ranging from $\$ 34$ to $\$ 90$ for a $10 \mathrm{~cm}$ by 10 cm square, and are not cost-effective at a large scale [101]. Low-cost alternatives for PEMs include gelatin-based salt bridges, clay pots, glass wool, porous fabrics, activated carbon, cathodic biofilms, and PEM-less MFCs [96, 102-111]. These PEM alternatives 
may have potential in the future of MFCs, but have not yet been widely adopted in research.

\subsubsection{Conductive Materials}

Current collectors attach the electrodes to the external circuit. Due to the nature of MFCs, current collectors have to be corrosion-resistant, yet electrically conductive. The most commonly used current collector, copper, is not a practical current collector for MFCs due to its low resistance to corrosion. Corrosion leads to rust, which can produce a false current in an MFC [112]. Both stainless steel and titanium are used as current collectors in MFCs mainly in the form of wires and meshes [113-115]. Although stainless steel and titanium are less electrically conductive than copper, they are both significantly less corrosive and therefore a more practical option for use in MFCs [116, 117].

\subsection{Utilization of MFCs in Practice}

\subsubsection{Scaled-up MFCs}

Large-scale MFCs have the potential to treat substantial amounts of waste while producing electricity. However, large-scale MFCs have been limited by low power densities, compared to laboratory-scaled MFCs [118-120]. This is mainly due to the high internal resistance and uneven current distributions observed in larger MFCs [115, 121]. The high internal resistance that has been observed in scaled-up MFCs can be attributed in part to a large space between electrodes. Larger distances between electrodes increases the internal ohmic resistance in the MFC and, as a result, decreases the power density $[96,122-124]$. Therefore reducing the electrode spacing in scaled up MFCs can lower internal resistance and increase overall power output.

Other methods to increase performance in scaled-up MFCs include using multiple anodes and connecting MFCs in series or parallel. The use of multiple anodes can help increase the power density by reducing electrode spacing and lowering contact resistance in the MFC [122, 125-129]. Connecting MFCs in series or parallel is known as MFC stacking and can theoretically increase the overall voltage or current of the MFC. In practice, however, MFC stacking can lead to voltage reversal and lower power densities [130-134]. 


\subsubsection{Use of Energy Harvesting Systems}

Due to the unreliability of using multiple anodes and cathodes or stacking MFCs in order to increase the MFC voltage, more reliable options must be considered. Recently, several research groups have been studying the possibility of using energy harvesting systems and DC/DC boost converters in conjunction with MFCs to increase the voltage to a usable level. There are several ways that energy harvesting systems can work to optimize voltage and power output. A commonly used energy harvesting system uses super capacitors to store energy from the MFC, and then uses one or more DC/DC boost converters to increase the voltage of the outgoing energy $[135,136]$.

Currently, energy harvesting systems are designed on an individual basis. Consequently, there are no defined requirements for MFC performance or standard outputs from the energy harvesting system. Most studies conducted on energy harvesting systems have designed them for use with various sensing equipment which requires only short bursts of energy [137-140]. In general though, the MFCs with voltages of between 0.3 and 0.45 $\mathrm{V}$ were able to power the energy harvesting systems, which had an output of approximately $3.3 \mathrm{~V}[88,141,142]$. It has also been found that supercapacitors used in energy harvesting systems are charged most optimally at $0.3 \mathrm{~V}$, and several charge pumps need a minimum of $0.18 \mathrm{~V}$ to operate [136, 142]. Therefore, MFC working voltages of 0.18 to $0.45 \mathrm{~V}$ should be sufficient for operating energy harvesting systems.

\subsection{Manure as an MFC Fuel Source}

Few studies have evaluated the use of manure as a fuel for MFCs, despite its potential for use in developing countries where manure is often a relatively abundant source of organic matter. The first study to demonstrate that manure could fuel a MFC was conducted by Yokoyama et al. [6o]. Later, Wang et al. [143] proved that it was possible to use low-moisture dairy manure as a substrate. Power densities achieved with cow manure are lower than with other organic matter sources [27, 93]. However, an advantage of cow manure is that it can sustain power production for over 140 days [61]. The MFC research with manure as a fuel has been summarized briefly in Table 2.1. 
Table 2.1: Summary of studies conducted on MFCs using manure as a fuel source

\begin{tabular}{|c|c|c|c|c|c|c|}
\hline MFC Type & $\begin{array}{c}\text { Manure } \\
\text { Concentration }\end{array}$ & OCV (V) & $\begin{array}{c}\mathbf{P}_{\mathrm{An}} / \mathbf{P}_{\mathbf{C a}} \\
\left(\mathbf{m W} / \mathbf{m}^{2}\right)\end{array}$ & $P_{V}\left(W / \mathbf{m}^{3}\right)$ & CE (\%) & Reference \\
\hline Tubular air cathode & $\begin{array}{c}1.25 \mathrm{~g} \text { manure } / \mathrm{mL} \\
\text { water }\end{array}$ & 0.51 & 2.5 & NR & NR & [93] \\
\hline $\begin{array}{l}\text { Single chamber cube air } \\
\text { cathode }\end{array}$ & NR & 0.4 & 189 & NR & $11.7 \%$ & {$[27]$} \\
\hline Two-chamber & $\begin{array}{l}\text { 20:80 manure: } \\
\text { water }\end{array}$ & 0.41 & 4 & NR & NR & {$[144]$} \\
\hline Two-chamber & $\begin{array}{c}68 \mathrm{~g} / \mathrm{L} \\
37.9 \mathrm{~g} / \mathrm{L}\end{array}$ & $\begin{array}{c}0.3 \\
0.26\end{array}$ & $\begin{array}{l}36.6 \\
25.6\end{array}$ & $\begin{array}{l}0.21 \\
0.15\end{array}$ & NR & {$[145]$} \\
\hline Two-chamber & $\begin{array}{l}24.5 \mathrm{~g} / \mathrm{L} \\
13.5 \mathrm{~g} / \mathrm{L}\end{array}$ & $\begin{array}{l}0.32 \\
0.37\end{array}$ & $\begin{array}{l}39 \\
53\end{array}$ & NR & NR & {$[145]$} \\
\hline Three-chamber & $\begin{array}{l}\text { 2:5(v/v) manure: } \\
\text { distilled water }\end{array}$ & 0.8 & NR & 14.11 & $14.91-18.65 \%$ & {$[61]$} \\
\hline Three-chamber & $\begin{array}{c}2 \% \text { manure solids } \\
\text { to } 10 \% \text { manure } \\
\text { solids }\end{array}$ & $1.04^{\mathrm{c}}$ & NR & $15 \cdot 5^{\mathrm{c}}$ & $\begin{array}{l}39.8 \%^{d} \\
17.3 \%^{c}\end{array}$ & [62] \\
\hline $\begin{array}{l}\text { Single chamber air } \\
\text { cathode cube }\end{array}$ & $\begin{array}{l}\text { 1:9 manure: } \\
\text { distilled water }\end{array}$ & 0.015 & 136 & NR & $0.22 \%$ & {$[60]$} \\
\hline
\end{tabular}

${ }^{a} \mathrm{P}_{\mathrm{An}} / \mathrm{P}_{\mathrm{Ca}}$ is power density normalized to the anode or cathode surface area and $\mathrm{P}_{\mathrm{V}}$ is power density normalized to the anode chamber volume.

${ }^{b}$ Not Reported

c Measured at 6\% manure solids

d Measured at $2 \%$ manure solids 
Yokoyama et al. also compared the fertilizer characteristics of manure slurry before and after use in an MFC [6o]. It was found that the values for nitrogen, phosphorus, and potassium did not change significantly after being used in a MFC [60]. Also, fecal coliforms in manure fertilizer can contaminate the plants, especially fruits and vegetables. Ingesting contaminated crops can lead to gastrointestinal illnesses, including diarrhea, which is currently the second leading cause of death of children under 5 years of age worldwide $[146,147]$. It is therefore important to determine if MFCs can also help to reduce presence of fecal coliforms in cattle manure. A summary of several characteristics, including $\mathrm{pH}, \mathrm{COD}, \mathrm{BOD}_{5}$ (biochemical oxygen demand after 5 days), total and volatile solids, and the previously discussed fertilizer characteristics of fresh manure that have been characterized is shown in Table 2.2.

Table 2.2: Composition of fresh cattle manure

\begin{tabular}{|c|c|c|}
\hline Characteristic & Average Value & References \\
\hline $\mathrm{pH}$ & $7-8.4$ & \\
\hline Total COD & $149,000 \mathrm{mg} / \mathrm{L}$ & \\
\hline Total $\mathrm{BOD}_{5}$ & $16,100 \mathrm{mg} / \mathrm{L}$ & \\
\hline Total Solids & $15.4 \%(\mathrm{w} / \mathrm{w})$ & \multirow{2}{*}{ [6o, 61, 93, } \\
\hline Volatile Solids & $86.2 \%(\mathrm{w} / \mathrm{w})$ & $148]$ \\
\hline Total Carbon & $413 \mathrm{~g} / \mathrm{kg}$ dry manure & \\
\hline Total Nitrogen & $28 \mathrm{~g} / \mathrm{kg}$ dry manure & \\
\hline Ammonia Nitrogen & $5.8 \mathrm{~g} / \mathrm{kg}$ dry manure & \\
\hline Total Phosphorus & $16 \mathrm{~g} / \mathrm{kg}$ dry manure & \\
\hline Total Potassium & $6.5 \mathrm{~g} / \mathrm{kg}$ dry manure & \\
\hline
\end{tabular}

The high concentrations of biodegradable organic matter in the cow manure (indicated by the high $\mathrm{BOD}_{5}$ concentration) explain why cow manure can be used as a sources of fuel in a MFC, and the retention of $\mathrm{N}, \mathrm{P}$, and $\mathrm{K}$ during treatment preserve its qualities as a plant fertilizer. 


\section{Chapter 3: Methods and Materials}

This chapter describes the methods used for both the cultural and technical aspects of the project. The methods for conducting and analyzing interviews with local Tanzanians are described in Section 3.1. Methods for designing and constructing the MFC prototype can be found in Sections 3.2 and 3.3, respectively. MFC operation, including sampling and data analysis methods, is described in Section 3.4.

\subsection{Interview Methods}

The social aspect of this study documented the thoughts, experiences, and perceptions that local residents of the Hanan'g district had about electricity, TANESCO, livestock manure, and the use of manure. While in Tanzania, I (author) conducted interviews in three sites in and nearby the site where I served as a Peace Corps Volunteer. The interviews were semi-structured, in-depth, qualitative interviews concerning electricity needs and use, light sources, TANESCO, as well as livestock manure use and general perceptions about manure. These interviews were used, along with field observations, literature, and recent census data to help determine the feasibility of introducing microbial fuel cells as a new electricity generation technology to the Hanan'g district of Tanzania in the future.

Prior to conducting interviews, human subject research approval was acquired from the Institutional Review Board (IRB) at Michigan Tech (Appendices A and D). After this, a specific protocol was followed in order to get informal consent from the interviewees to participate. Before the interviews started, the interviewees were given either an oral or written explanation of the research and the interview that was to follow. If they agreed to participate, they were interviewed and recorded for use in this research, provided that their identities be kept confidential. The participants were also asked if they could be photographed and if the photographs could be used in comparing housing materials and livestock to what was recorded in the interviews. The consent forms can be found in Appendices B and C. All 19 invited interviewees agreed to be interviewed, recorded, and photographed. The interviews loosely followed a set of questions in three separate sections: general (home characteristics and demographics), electricity use, and microbial fuel cell feasibility (livestock ownership and manure perceptions). English translations of 
the interview questions can be found in Appendix E. The interviewees were encouraged to elaborate on any thoughts or ideas whenever possible.

All writing and speaking was conducted in Swahili, which is the most widely spoken language in the three interview sites as a whole. In the interview site of Bassotughagn, the residents mainly speak their local language of the Iraqw ethnic group, although they all speak Swahili as a second language. A colleague from the Iraqw ethnic group accompanied me to the interviews to translate when necessary to and from Swahili and the Iraqw language. Otherwise, the interviews were conducted by me (the author) in Swahili.

One round of interviews was conducted in June and July of 2014, and then a second round of interviews was conducted in February of 2015. In the first round of interviews, 15 participants were interviewed with questions about electricity use, livestock, and manure perceptions. The second round of interviews was conducted to include an extra question for the original interviewees concerning their preference of two microbial fuel cells, one being less expensive and higher maintenance, and one being more expensive and lower maintenance. The second round of interviews also included four extra interviews, all of which included the additional question, of women in the two village interview sites of Bassotughagn and Endaiswold in order to get a better representation of women in the interview pool.

The interview participants were identified and chosen for several different reasons. Firstly, they were identified because I had a social connection to them personally or through one of the two Peace Corps Volunteers located in Bassotughagn and Endaiswold villages. I believed that interviewing people that I already had a connection with would be more likely to give me real and honest answers. Also, the people who were invited to interview were chosen to have a diverse set of thoughts and opinions, as well as diverse backgrounds. I chose people to invite for interviews to try to achieve this diversity. Before selecting people to invite for interviews, I looked at which households had electricity, which households had livestock, and the housing conditions for the households. Having a livestock, electricity, and house with corrugated metal roofs and brick or concrete walls is considered an indication of wealth and progress [6, 37]. A summary of these selection variables can be found in Table 3.1. 
Of the 19 people interviewed, 7 of them come from a town and 12 come from rural villages that are off of the electricity grid. The interview participants come from varying levels of relative wealth and poverty, as Table 3.1 illustrates. Approximately half of those interviewed are farmers and livestock keepers and half work in various other jobs and in the home. With respect to gender, 9 men were interviewed and 10 women were interviewed. All those interviewed were adults.

Table 3.1: A summary of selection variables for interview participants in each study site

\begin{tabular}{|c|c|c|c|c|}
\hline & & \multicolumn{3}{|c|}{ Number of Participants } \\
\hline & & Bassotughagn & Endaiswold & Katesh \\
\hline \multirow{2}{*}{ Gender } & Male & 3 & 3 & 3 \\
\hline & Female & 3 & 3 & 4 \\
\hline \multirow{3}{*}{ Housing Material } & Mud and Sticks & 6 & O & o \\
\hline & Mud Bricks & O & 6 & 3 \\
\hline & Concrete Bricks & o & o & 4 \\
\hline \multirow{2}{*}{ Roofing Materials } & Iron Sheets & o & 5 & 7 \\
\hline & Thatch & 6 & 1 & o \\
\hline \multirow{2}{*}{ Livestock Present } & Yes & 3 & 6 & 4 \\
\hline & No & 3 & o & 3 \\
\hline \multirow{2}{*}{ Electricity Present } & Yes & o & 0 & 5 \\
\hline & No & 6 & 6 & 2 \\
\hline
\end{tabular}

All interviews were transcribed in Swahili by me with occasional input, such as identifying colloquial words and phrases and translating various words, from local Tanzanian residents. The interviews were then analyzed. For the questions that resulted in structured answers, the answers were tabulated and compared to other known data. The less structured questions were analyzed using coding and memoing. Following the guidelines from Corbin and Strauss [149], codes were given to answers from any interview participant that had a certain theme and were then grouped together. For example, many interview participants discussed at length the benefits of making their own low cost MFC, resulting in the code group "Low Cost Microbial Fuel Cell" and the codes being each expressed benefit (Table 3.2). Benefits of the low cost MFC included its low fabrication cost, the trade skills and training acquired through making the MFC, 
money making possibilities from making MFCs, and a lower dependence on TANESCO. Interview participants also expressed their concern with various issues with using microbial fuel cells in the home. Each expressed issue was coded individually and together they comprised the code group "Problems with Microbial Fuel Cells in the Home." Issues included a potential smell and dirtiness that was associated with manure, the possibility of the MFC breaking from children playing in the home and of the MFC being stolen from the home, as well as any potential issues with the difficulty in wiring a home for electricity.

Table 3.2: Examples of codes and code groups used in the qualitative analysis of the interviews.

\begin{tabular}{|l|l|}
\hline $\begin{array}{l}\text { Code Group: Low Cost Microbial } \\
\text { Fuel Cell }\end{array}$ & $\begin{array}{l}\text { Code Group: Problems with } \\
\text { Microbial Fuel Cells in the Home }\end{array}$ \\
\hline Code: Low cost & Code: Manure Smell \\
\hline Code: Trade Skills & Code: Manure Dirtiness \\
\hline Code: Microbial Fuel Cell Training & Code: Breaking MFC \\
\hline Code: Money Making & Code: Stolen MFC \\
\hline $\begin{array}{l}\text { Code: Lower Dependence on } \\
\text { TANESCO }\end{array}$ & Code: MFC Short/Home Wiring \\
\hline
\end{tabular}

After the data was coded and grouped, trends and anomalies were found in the data by grouping the codes together and memoing. In memoing, I looked at the interview participants' answers and wrote notes about observations and trends with the data as well as about observations I had while conducting the interview and through interactions with locals outside of the interviews. These notes were grouped together with a descriptive code and used in the analysis of results. Throughout results analysis, quotations from the interviews were extracted and used to emphasize points that the interviewees were making. These quotations were all translated by me. They were used, along with codes and notes from memoing, to more clearly illustrate the views of the interviewees and the issues that they raised about electricity and manure use. 


\subsection{Microbial Fuel Cell Design}

\subsubsection{Sizing}

Sizing a MFC is relatively difficult, as there are no consistent empirical or theoretical bases for selecting a size, and MFC performance is not always correlated with size. As discussed in Section 2.5.1, small MFCs often can achieve higher power densities than large MFCs. However, power production of larger MFCs can be increased as we improve our understanding of how to optimize electrode spacing and the use of multiple electrodes. For the purpose of this study, the goal was to produce sufficient power and voltage to operate a theoretical energy harvesting system.

To come up with an appropriate size for the cow manure-powered MFC used in this study, information from many studies comparing small and large MFCs was considered, along with data from studies using manure for the MFC fuel. Based on the studies comparing the effect of size on power production, the highest power outputs were with MFCs that had anode chamber volumes of approximately $600 \mathrm{~mL}[61,62], 1400 \mathrm{~mL}$ [122], or $1600 \mathrm{~mL}$ [92]. It was also noted that the $1600 \mathrm{~mL}$ volume MFC was also a tubular air cathode MFC. These volumes represent the fraction of the MFC filled with the fuel or substrate. Therefore, the MFC used in this study has a larger total volume to account for the volume of the brush anode, and to provide headspace to minimize pressure buildup due to gas production. Initially, a total volume of 3.0 L was used. This was later reduced to approximately $2.0 \mathrm{~L}$, as described below. The volume occupied by diluted manure was $1.6 \mathrm{~L}$.

\subsection{Microbial Fuel Cell Construction and Materials}

For this study, a tubular air cathode MFC was designed and constructed. This design is simple and requires few materials. However, the initial prototype MFC leaked and so the design and cathode preparation techniques were modified as described below.

\subsubsection{Original MFC Design}

The original MFC design was $36.8 \mathrm{~cm}$ in height and had a total volume of 3.75 liters (Figure 3.1). The reactor housing was constructed with PVC pipe, $11.4 \mathrm{~cm}$ OD and $0.6 \mathrm{~cm}$ wall thickness. Holes $(1 \mathrm{~cm})$ were drilled in staggered rows around the pipe to facilitate proton transfer between the anode and cathode [93]. The holes were drilled $4 \mathrm{~cm}$ apart (from center to center) around the pipe and $2 \mathrm{~cm}$ apart (from center to center) along the 
length of the pipe (Figure 3.2). To close the ends of the pipe, two $11.4 \mathrm{~cm}$ ID $(12.8 \mathrm{~cm}$ OD) female pipe thread (FPT) adapters were placed and glued onto the ends of the pipe, and two $11.4 \mathrm{~cm}$ diameter male pipe thread (MPT) plugs were screwed into the adaptors. Holes (1/8" NPT pipe thread) were incorporated into the top and bottom end caps for sampling and maintenance of the anode compartment. A $1 / 8$ ” Mininert valve $(\mathrm{P} / \mathrm{N}$ 631204, Valco Instruments Co. Inc., Houston, TX) was threaded to an NPT/Swagelok compression fitting which was connected to a 4 " piece of copper piping and then threaded into the top end cap for collection of headspace samples for analysis of methane. A polycarbonate stopcock valve with a leur connection (P/N EW-30600-02, Cole Parmer, Vernon Hills, IL) was attached to the bottom end cap for liquid sampling during operation.

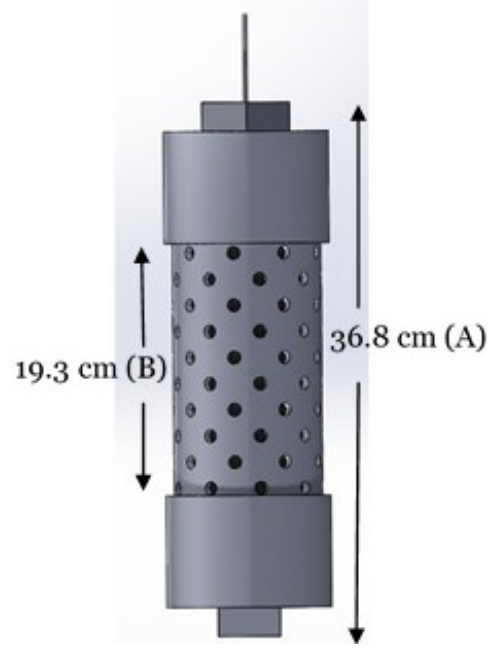

Figure 3.1: The reactor housing for the MFC consisted of $P V C$ pipe with $1 \mathrm{~cm}$ diameter holes and two caps at each end. Dimension A was $36.8 \mathrm{~cm}$ (14.5 inches) and dimension B was $19.3 \mathrm{~cm}$ (7.6 inches) for the original design and dimension $A$ was $24.9 \mathrm{~cm}$ (9.8 inches) and dimension $B$ was $7.6 \mathrm{~cm}$ (3.0 inches) for the modified design as described in the text.

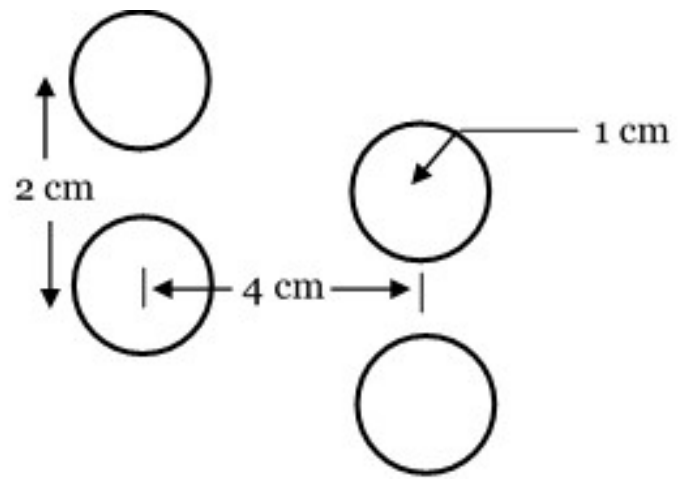

Figure 3.2: Diagram of the holes drilled into the reactor housing. 
A graphite fiber brush anode (Mill-Rose, Mentor, $\mathrm{OH}$ ) was used as the anode because of its high surface area, which has been found to promote biofilm growth on the anode [68]. The brush was 13 inches $(33 \mathrm{~cm})$ high and 4 inches $(10.16 \mathrm{~cm})$ in diameter, was secured to a 17.5-inch $(44.45 \mathrm{~cm})$ \#11 titanium wire for current collection. The anode consisted of 400,000 fibers/inch of brush length and fibers are 0.0003 inches in diameter, according to the manufacturer. Therefore, the projected surface area was 19,780 square inches $\left(12.76 \mathrm{~m}^{2}\right)$. Before use, the anode was heated for 30 minutes at $450^{\circ} \mathrm{C}$ to increase usable surface area and decrease the oxygen content in the fibers [150]. The anode is shown in Figure 3.3.

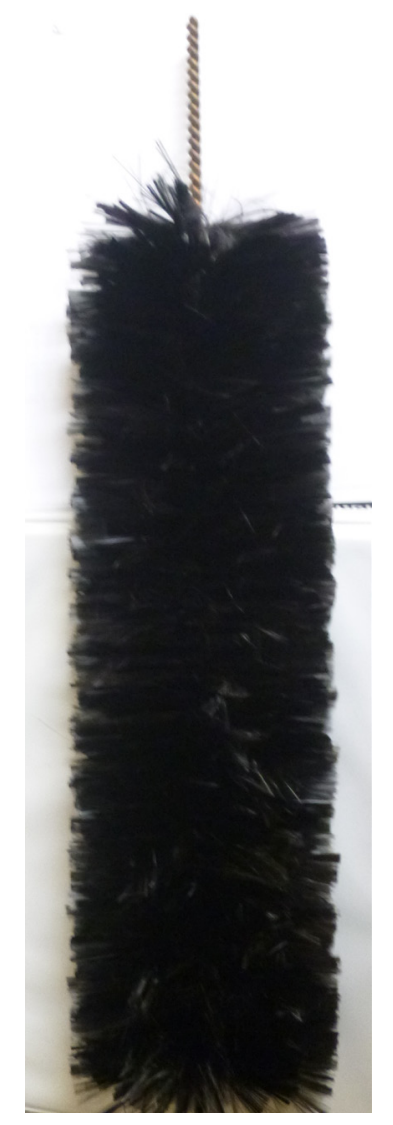

Figure 3.3: Photograph of graphite fiber brush and titanium wire (Photo by author).

A piece of plain carbon cloth (Fuel Cell Earth, Woburn, MA) was wet-proofed and treated to be used as the cathode (Figure 3.4). Wet-proofing the cloth helps to minimize leaking of water and dissolved substrate out of the anode chamber. For the original design, the cloth was wet-proofed by air brushing several layers of a solution of $30 \%$ polytetrafluoroethylene (PTFE Preparation 60 wt \% dispersion in water, Sigma Aldrich, 
St. Louis, MO) in DI water, allowing it to dry completely, and then baking it at $370^{\circ} \mathrm{C}$ for 30 minutes in a muffle furnace. The carbon cloth was then treated using a modified method from Cheng et al. [23] and Middaugh et al. [151]. First, a carbon layer was applied to the air-facing side of the cathode. The carbon layer helps to further minimize substrate loss, reduce oxygen diffusion into the anode chamber, and to facilitate the reduction of oxygen, all of which increases both $\mathrm{CE}$ and power output [112]. The carbon layer consisted of $1.56 \mathrm{mg}$ carbon black powder (Vulcan XC 72R, Fuel Cell Store, Woburn, MA) per $\mathrm{cm}^{2}$ of carbon cloth, mixed with 40\% PTFE solution and isopropyl alcohol, which helps with the application of the layer. After applying the carbon layer, the cloth was dried completely and baked for 30 minutes at $370^{\circ} \mathrm{C}$ in a muffle furnace. On top of the carbon base layer, 4 diffusion layers of 60\% PTFE solution were applied with an airbrush to further decrease substrate loss. After the application of each layer, the carbon cloth was dried completely and then baked for 15 minutes at $370^{\circ} \mathrm{C}$ in a muffle furnace.

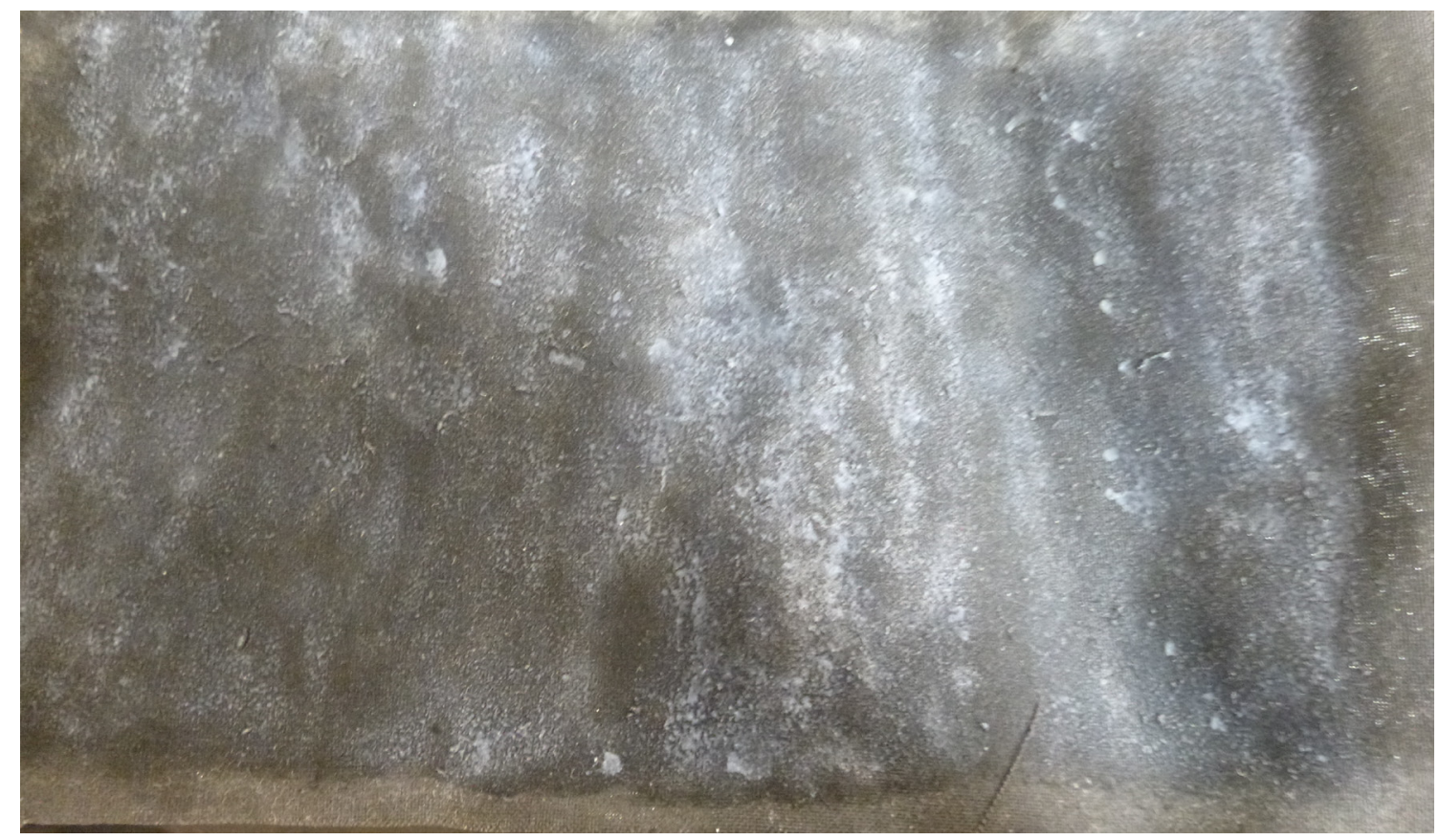

Figure 3.4: Photograph of the side of the carbon cloth after the carbon base layer and 4 diffusion layers were applied (Photo by author).

A catalyst layer was then applied with an air brush to the opposite, anode-facing side of the MFC to aid in the oxygen reduction reaction (Figure 3.5). The catalyst was applied as a solution of $20 \%$ by weight platinum in carbon powder (PTC20, Fuel Cell Earth, 
Woburn, MA) mixed with 5\% by weight Nafion solution (LQ-1105, Ion Power Inc., New Castle, DE) in DI water to act as a binder and isopropyl alcohol to aid in the application of the layer. The mixture applied consisted of $950 \mathrm{mg}$ platinum in carbon powder, 0.9 $\mathrm{mL}$ of DI water, $6.4 \mathrm{~mL}$ of $5 \%$ Nafion solution, and $5 \mathrm{~mL}$ of isopropyl alcohol. The target platinum loading was $0.5 \mathrm{mg} \mathrm{Pt} / \mathrm{cm}^{2}$. However, the actual amount of platinum applied to the carbon cloth was lower $\left(0.3 \mathrm{mg} \mathrm{Pt} / \mathrm{cm}^{2}\right)$ due to losses with the air brush.

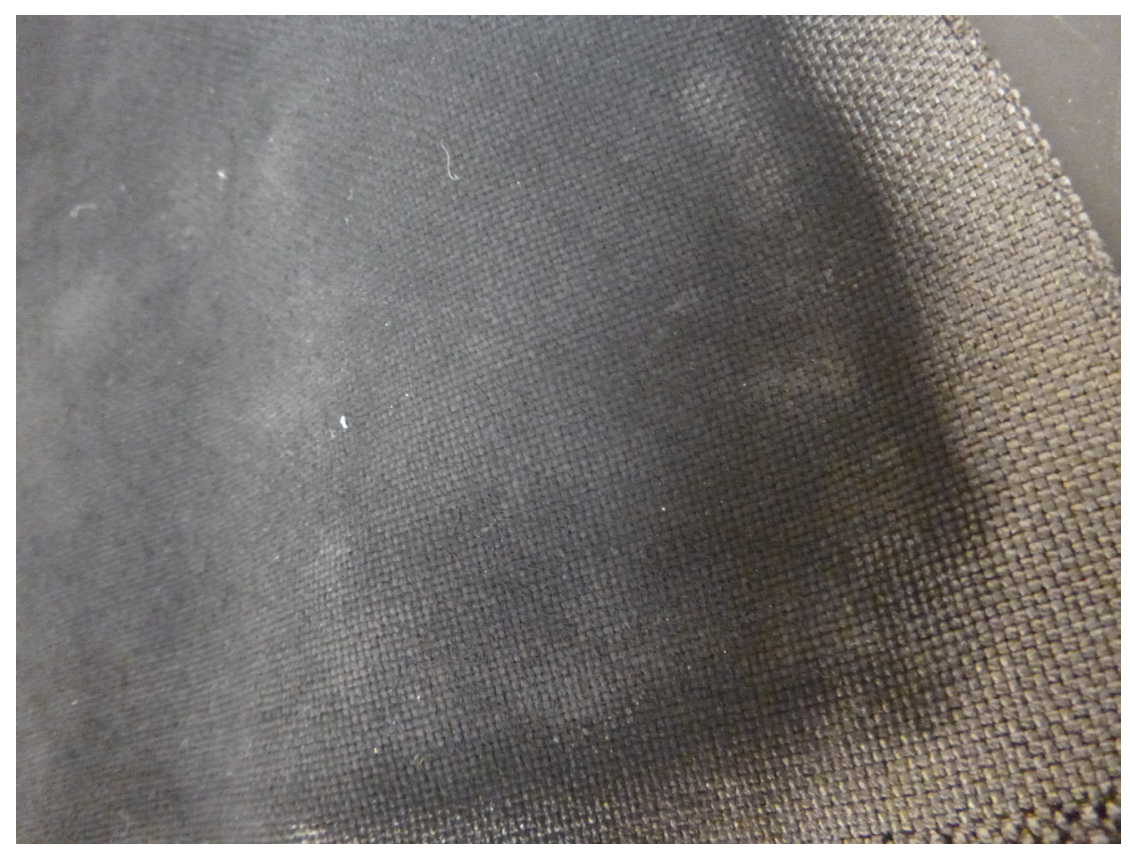

Figure 3.5: Photograph of the anode side of the cathode showing the layer of platinum and carbon (Photo by author)

The cloth was then dried and sealed onto the PVC pipe using silicone sealant $100 \%$ Clear Silicone, General Electric Company, Schenectady, NY). A silver conductive epoxy (8331 Silver Conductive Epoxy, MG Chemicals, Surrey, British Columbia, Canada) was used to seal the seams of the cloth together. The conductive epoxy has a resistivity of $0.017 \Omega-\mathrm{cm}[152]$.

\subsubsection{Modified MFC Design}

After constructing the original MFC, it was leak-tested. It quickly became apparent that excessive leaking was occurring through the carbon cloth. Leaking continued until the water level in the anode chamber dropped approximately 5 inches. Therefore, it was thought that the hydrostatic pressure inside the anode chamber was too high. To reduce hydrostatic pressure on the carbon cloth, the MFC was disassembled and cut to a shorter 
height $(24.9 \mathrm{~cm})$, the anode was shortened $(20 \mathrm{~cm})$, and the cathode was also shortened $(7.6 \mathrm{~cm})$ and resealed (Figure 3.6).

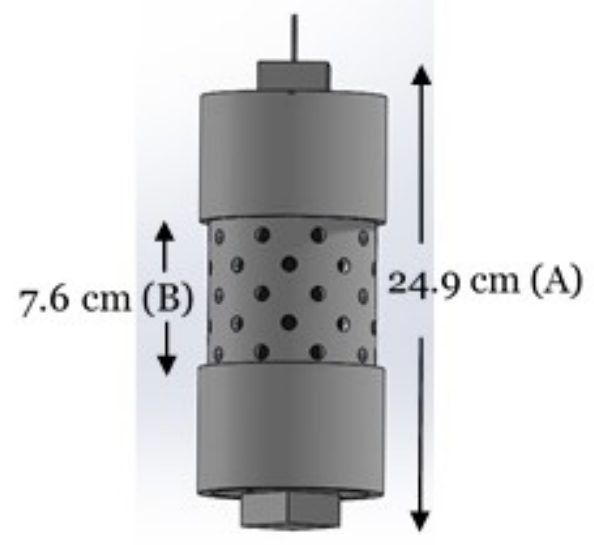

Figure 3.6: A diagram of the shorter MFC.

Throughout the startup process, the cathode exhibited excessive leaking. Therefore, a new cathode was prepared. During this time, the anode was stored in a 4 L Erlenmeyer flask filled with $1 \mathrm{~g} / \mathrm{L}$ sodium acetate solution. The new cathode was prepared following the procedure from Cheng et al. [23] and Middaugh et al. [151] and several key changes were made to the procedure used to prepare the first cathode. First, waterproofing was accomplished by soaking the cloth in an aqueous 30\% PTFE solution for one hour instead of airbrushing the PTFE solution on. It was also dried completely and baked at $370^{\circ} \mathrm{C}$ for 30 minutes in a muffle furnace. Second, layers were applied using a paintbrush instead of an airbrush. Due to the minimal loss of the platinum, carbon, and Nafion mixture in application, the platinum loading was approximately $0.5 \mathrm{mg} / \mathrm{cm}^{2}$ across the carbon cloth. Like with the original design, the carbon cloth was then sealed onto the outside of the MFC using an aquarium-grade water-tight $100 \%$ silicone sealant (DAP, Baltimore, MD). The assembled MFC is shown in Figure 3.7.

After assembling the MFC, alligator-to-banana cables (Elenco, Wheeling, IL) were connected to the anode (black) and cathode (red) and both were then connected to an external resistor box (Elenco, Wheeling, IL), which was operated in parallel with a digital multimeter (2000 series, Keithley, Cleveland, OH) (Figure 3.8). 


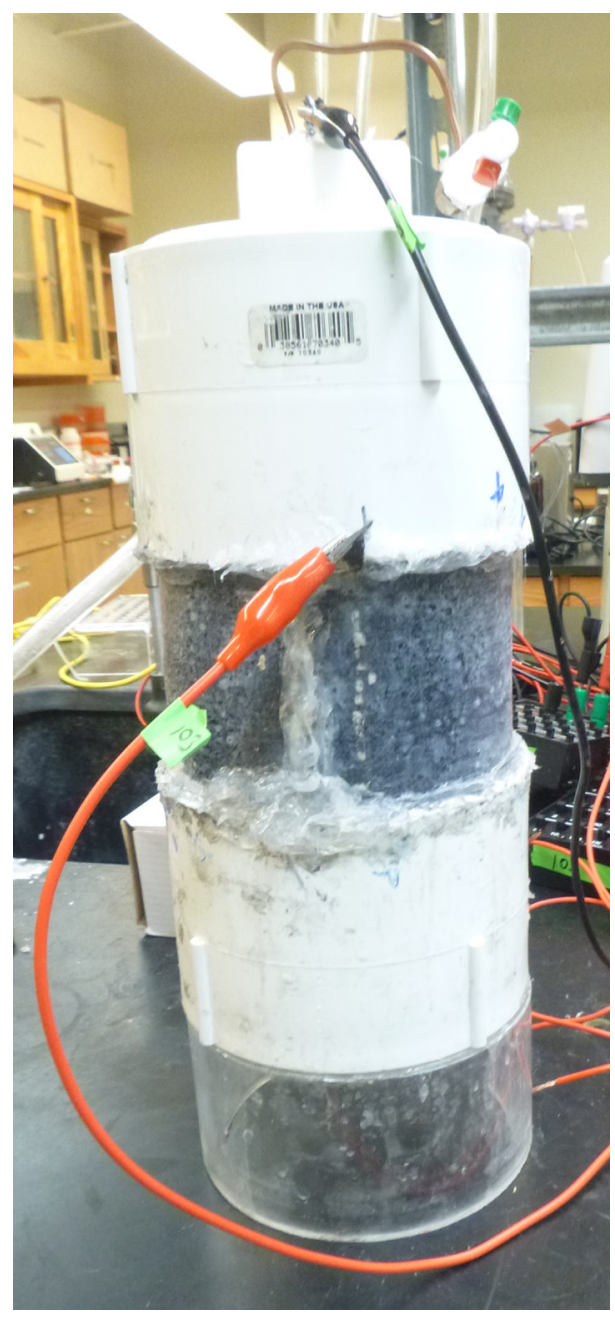

Figure 3.7: Photograph of the assembled MFC (Photo by author).

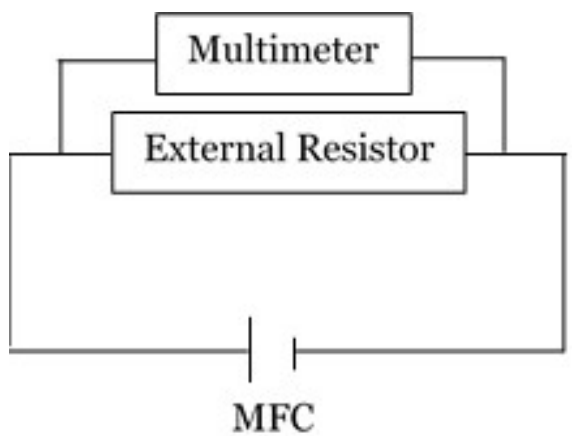

Figure 3.8: Simple circuit diagram showing the MFC circuit setup. 


\subsection{Microbial Fuel Cell Operation}

\subsubsection{Inoculation and Startup}

To develop a robust, acetate-utilizing, anode-respiring biofilm on the anode, previously reported inoculation procedures were adapted. This procedure involved filling the anode compartment with a mixture of 50\% effluent and bacteria from a working MFC and 50\% sodium acetate [129, 153-156].

Approximately 50, 3-inch carbon fibers were clipped from a "mother" MFC that has been actively producing electricity for several years and thus are presumably coated with electrochemically active bacteria. The fibers were stored in the MFC effluent while being flushed with $\mathrm{N}_{2}$ gas until added to the MFC. A sodium acetate feed solution contained 1 $\mathrm{g} / \mathrm{L}$ sodium acetate $\left(\mathrm{CH}_{3} \mathrm{COONa}\right)$, a salt solution, $12.5 \mathrm{~mL} / \mathrm{L}$ mineral solution, and 12.5 $\mathrm{mL} / \mathrm{L}$ vitamin solution. The recipe and procedure for preparing the feed solution can be found in Appendix F. $800 \mathrm{~mL}$ of the acetate feed solution were combined with $800 \mathrm{~mL}$ of effluent from the MFC and the mixture was transferred to the anode compartment. During the transfer procedure, both the anode compartment and the inoculation/feed solution were sparged continuously with $\mathrm{O}_{2}$-free $\mathrm{N}_{2}$ gas. The anode compartment was then sealed, the external circuit was closed and operated with an external resistance of $1000 \Omega$, and voltage was monitored continuously.

The anode compartment was drained and refilled with 100\% sodium acetate feed solution when the voltage dropped to $100 \mathrm{mV}$. This was repeated once. After replacing the leaking cathode (described above), the MFC was fed the acetate feed solution a third time. Thereafter, the MFC was fed with diluted manure as its fuel source (described below), and the external resistance was reduced to $100 \Omega$.

\subsubsection{Substrate Preparation}

Cattle manure was chosen for the MFC fuel source because of its high energy content and widespread availability in the Hanan'g district. For the study, cattle manure was collected from Palosaari's Rolling Acres Dairy Farm in Chassel, Michigan. The manure was collected from a mix of grass-fed dairy and steer cattle manure collected from the cow barn. This manure was chosen to simulate the manure produced by cattle in the Hanan'g district of Tanzania, where both dairy and steer cattle are fed mainly grass and occasionally corn. Cattle manure has an average total chemical oxygen demand (TCOD) 
of 149,000 mg/L [148], and was diluted to obtain a COD loading that was high enough to generate electricity but small enough to keep a short period of time for utilization in the MFC. A dilute substrate can allow for greater biofilm accumulation on the graphite brush anode [155]. However, high substrate COD levels have been correlated with lower internal resistance, higher power densities, and lower coulombic efficiencies in MFCs [126]. To optimize testing time and electrochemical performance, a COD of $1000 \mathrm{mg} / \mathrm{L}$ was chosen. This was achieved by diluting the manure to a $1 \%(\mathrm{v} / \mathrm{v})$ solution using DI water.

Before being diluted for use in the MFC, the raw manure was also tested for its total solids and volatile solids content. It was found that the manure contains $20.4 \%$ total solids and $80.4 \%$ of these solids are volatile, which is consistent with literature on cattle manure $[62,157,158]$.

For use in the MFC, 2 liters of $1 \%$ manure slurry was prepared. After thoroughly mixing the slurry using a stir bar and stir plate, $\mathrm{pH}$ and COD of the manure were analyzed. COD was measured to be $904 \mathrm{mg} / \mathrm{L}$. The slurry was then sealed in a container for 7-10 days to allow aerobic bacteria to deplete oxygen. $\mathrm{COD}$ and $\mathrm{BOD}_{5}$ (biochemical oxygen demand after 5 days) were tested before loading the slurry into the MFC.

\subsubsection{MFC Performance Monitoring}

The MFC was monitored at regular intervals to characterize its chemical and electrochemical performance. The anode liquid was sampled for analysis of $\mathrm{COD}, \mathrm{BOD}_{5}$, $\mathrm{pH}$, volatile fatty acids (VFAs), and fecal coliforms. The anode headspace was sampled for analysis of methane. Electrochemical performance was evaluated through the measurement of working voltage, open circuit voltage, and internal resistance.

\subsubsection{Chemical Sampling and Analysis}

To evaluate the chemical performance and treatment quality of the MFC, the COD, $\mathrm{BOD}_{5}$, and fecal coliforms of the manure slurry were tested before and after use in the MFC.

COD. Total COD of the anode chamber liquid was tested before loading into the MFC and after MFC operation. $0.3 \mathrm{~mL}$ of the liquid sample was added to a COD reagent vial (TNT823, HACH, Loveland, CO), which was heated at $150^{\circ} \mathrm{C}$ for 2 hours in a COD reactor (DRB 200, $\mathrm{HACH}$ ). After cooling to room temperature, the reagent vial was 
measured for COD concentration in a spectrophotometer (DR 2000, $\mathrm{HACH}$ ), which measures COD concentration with a $250 \mathrm{~nm}$ wavelength.

$\mathrm{BOD}_{5}$. Liquid samples were tested for $\mathrm{BOD}_{5}$ concentration before and after MFC operation as well. In order to measure $\mathrm{BOD}_{5}, 95 \mathrm{~mL}$ of the liquid sample and a $\mathrm{BOD}$ nutrient buffer pillow were added to $500 \mathrm{~mL}$ bottles. After capping the bottles, two pieces of potassium hydroxide were added to each cap. The bottles were placed on the BODTrak II respirometric BOD apparatus (P/N 2952400, HACH), sealed, and allowed to react for 5 days at the $700 \mathrm{mg} / \mathrm{L}$ BOD concentration setting. After 5 days of oxygen consumption, the $\mathrm{BOD}_{5}$ concentration was determined from the data output.

VFAs. Volatile fatty acids (VFAs) were measured in the diluted manure before and after each feed cycle to determine the concentration of acetic acid, propionic acid, and butyric acid in the substrate. These VFAs are easily consumed within the MFC. $1 \mathrm{~mL}$ samples of diluted manure were taken and frozen until measured. A high pressure liquid chromatography (HPLC) system (HP Agilent 1100 HPLC, Hewlett-Packard, Palo Alto, CA) was used to measure VFAs in the samples. The HPLC was used with an Agilent ChemStation software (110o Series, Agilent, Santa Clara, CA) for operation and analysis.

Each set of liquid samples was measured alongside a set of standards so that a unique calibration curve could be created for each test. For each set of measurements, a 1\% (v/v) phosphoric acid in Millipore water solution was used for the HPLC eluent, which flowed at $1.0 \mathrm{~mL} / \mathrm{min}$ during the test. The HPLC was operated with a column temperature of $50^{\circ} \mathrm{C}$ (Shodex KC-811 column). Each sample was injected 3 times, and each time a $30 \mu \mathrm{L}$ volume was taken for measurement. The samples were measured using a detector at a $205 \mathrm{~nm}$ wavelength. Each sample was measured for approximately 18 minutes, and any VFAs detected during this time in the samples were shown as peaks. Each peak area was calculated by a valley-to-valley integration method. VFAs for each sample were analyzed by comparing the peak areas and retention times to those of the measured standards. Concentrations for acetic acid, propionic acid, and butyric acid in each sample were calculated with the calibration curve created from standards data.

Fecal Coliforms. Fecal coliforms in the diluted manure were tested through fermentation tests of dilutions of the manure and analyzed with the MPN method. Fecal coliforms were measured before and after every feed cycle. For the test, 5 dilutions were made 
from the $1 \%(\mathrm{v} / \mathrm{v})$ diluted manure in DI water. The first dilution was made by adding 12 $\mathrm{mL}$ of the $1 \%(\mathrm{v} / \mathrm{v})$ diluted manure to $88 \mathrm{~mL}$ autoclaved DI water in order to obtain the correct dilution. Every subsequent dilution used $10 \mathrm{~mL}$ of the less diluted solution and $90 \mathrm{~mL}$ of autoclaved DI water. In triplicates for each dilution, $2 \mathrm{~mL}$ of A-1 medium and $10 \mathrm{~mL}$ diluted manure were mixed in a glass vial. Each vial contained a small inverted glass vial to contain any bubbles produced during fermentation. The vials were first incubated at $35^{\circ} \mathrm{C}$ for 3 hours and then at $45.5^{\circ} \mathrm{C}$ for 21 hours. At the end of this incubation, each vial was examined for bubbles in the small inverted vial. The presence of bubbles indicated a positive result for fecal coliforms.

Results for fecal coliform tests were obtained from the USDA Most Probable Number (MPN) tables [159]. In the tables, the combination of positive and negative test results from the triplicate samples give statistical probabilities for the number of fecal coliform cells in the samples. From MPN tables, the results were reported as MPN/mL, yet results needed to be converted to MPN/g dry manure (Equation 3.1) in order to compare the results to the regulations for Class A and Class B biosolids and organic manure compost $[160,161]$.

$$
\frac{M P N}{\text { gdry manure }}=\frac{M P N}{m L} * \frac{m L}{g \text { total manure solids }} * \frac{g \text { total manure solids }}{\text { gdry manure }} \quad \text { Equation } 3.1
$$

Methane. Methane concentration and amount were also measured on the final day of MFC operation and as necessary to understand what was occurring within the MFC and to troubleshoot any issues with performance. A gas chromatograph (GC) (HP 6890 series, Hewlett-Packard) was used to measure methane in $1 \mathrm{~mL}$ gas samples from the MFC headspace. The GC was used with an Agilent ChemStation software (6890 series, Agilent) to analyze the results. The GC was operated with an inlet temperature of $200^{\circ} \mathrm{C}$, and oven temperature of $150^{\circ} \mathrm{C}$, and a flame ionization detector (FID) temperature of $250^{\circ} \mathrm{C}$. For the inlet, the carrier gas was helium, which flowed at a rate of $40 \mathrm{~mL} / \mathrm{min}$. For the FID, $\mathrm{H}_{2}$ gas was used at a flow rate of $40 \mathrm{~mL} / \mathrm{min}$ and compressed air was used at a flow rate of $400 \mathrm{~mL} / \mathrm{min}$.

A set of standards was prepared by filling a gas bag with $99 \% \mathrm{CH}_{4}$ gas and filling subsequent bags with a ration of $\mathrm{N}_{2}$ and $\mathrm{CH}_{4}$ gases. Gas bags were prepared with 
concentrations from 50.2 to $40,206.8 \mu \mathrm{mol} / \mathrm{L}$. Three samples of $1 \mathrm{~mL}$ of each standard gas bag were injected into the GC. Peaks were obtained from the data and peak areas were found with valley-to-valley integration. Peak areas and methane standards concentrations were recorded and calibration curve was created. All subsequent headspace samples were analyzed using this calibration curve.

Methane concentration in the headspace was calculated with the volume of headspace and amount of methane in the headspace sample in $\mu$ moles. Volume of headspace was calculated by taking the mass of the MFC at the time of sampling, subtracting the empty MFC mass to obtain liquid mass. Liquid density was calculated before loading into the MFC, therefore liquid volume was able to be calculated. Headspace volume was found by subtracting liquid volume from total MFC volume. Amount of methane in the headspace sample was calculated by taking the peak area and retention time results provided by the GC and comparing them to the previously described standards curve. From the curve, it was possible to determine the amount of methane in the sample. This sample concentration was then used to determine methane concentration in the headspace.

All analyses of the results were used to evaluate the performance of the MFC. However, electrochemical analysis, coulombic efficiency, and fecal coliform reduction were especially important in MFC evaluation and were used in conjunction with interview results analysis to determine the feasibility of introducing MFCs into Tanzania.

\subsubsection{Electrochemical Sampling and Analysis}

Working voltage was measured across the external resistor with the digital multimeter and recorded every hour. The OCV was tested weekly by disconnecting the external circuit for at least 2 hours and recording the voltage, using a potentiostat (5000 series, Gamry Instruments, Warminster, PA). The potentiostat was operated using a currentcarrying lead and a voltage measuring lead connected to both the anode and the cathode. $\mathrm{R}_{\text {int }}$ in the MFC was measured weekly by conducting a linear sweep voltammetry (LSV) test on the MFC at its OCV using the potentiostat. The test varies MFC voltage and records the resulting current. For these tests, the voltage varied between OCV and short circuit conditions (o V, o $\Omega \mathrm{R}_{\text {ext }}$ ). The voltages varied at a rate of $0.2 \mathrm{mV} / \mathrm{s}$. From the LSV

data, $R_{\text {int }}$ is calculated using Equation 2.3 from the slope of the linear section of the current vs. voltage plot similar to Figure 2.9. 
Detailed information about internal resistance was found through the electrochemical impedance spectroscopy (EIS). This test uses a frequency response analyzer with a potentiostat to operate the MFC with an applied sinusoidal voltage, and measures impedance between the electrodes at varying frequencies of the sinusoidal voltage [162]. It can indicate where the internal resistances occur within the MFC. For these tests, the frequency was varied from $1 \mathrm{mHz}$ to $100 \mathrm{kHz}$ with a $10 \mathrm{mV}$ AC voltage applied. Following each EIS test, a Nyquist plot is generated and can be used to simplify data analysis. A common Nyquist plot and Bode from an EIS test (Figure 3.9) were used to guide in interpreting EIS data.

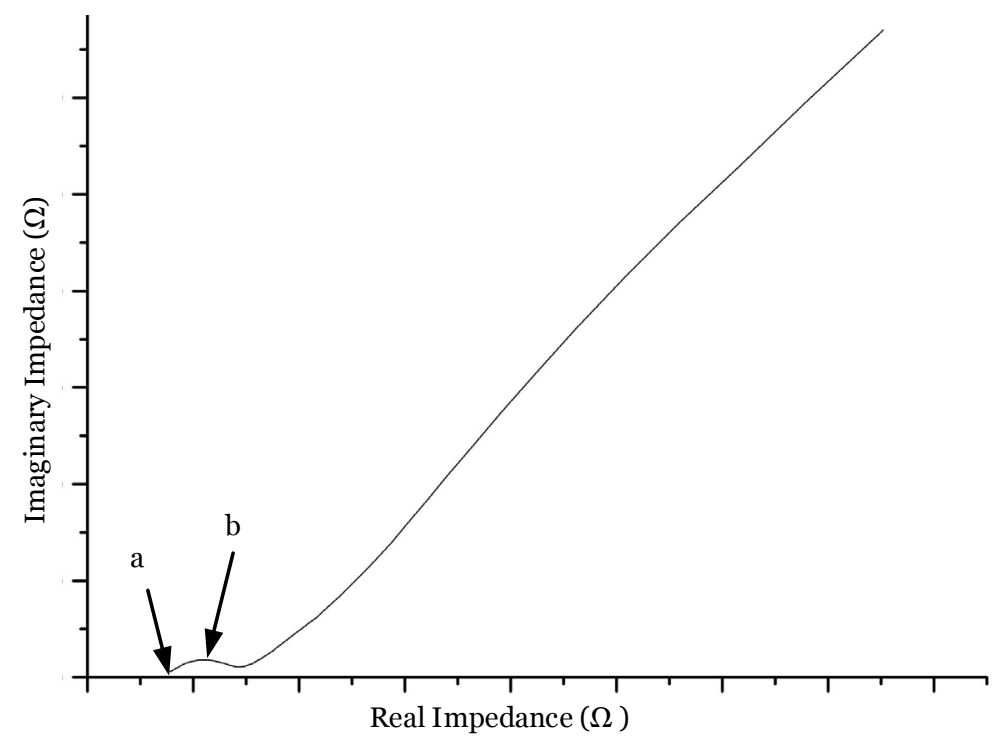

Figure 3.9: Typical electrochemical impedance spectroscopy Nyquist curve for MFCs.

The EIS Nyquist plot can be analyzed to find ohmic resistance (a) and charge transport resistance (b). Ohmic resistance is the point at which the curve intercepts the $\mathrm{x}$-axis [22, 163]. Charge transport resistance can be found by fitting a circle to the curve at section (b) and measuring its diameter [164]. Diffusion resistance is grouped with other internal resistances and is calculated by subtracting ohmic and charge transport resistances from total internal resistance [94, 165]. 


\section{Chapter 4: Results}

This chapter includes results from the interviews conducted with Tanzanians (Section 4.1) and from the tests conducted on the MFC prototype (Section 4.2). Analyses of the results are also discussed in this chapter.

\subsection{Interview Results and Analysis}

Interviews, observations, and informal discussions with local Tanzanians in the Hanan'g area were grouped into categories and analyzed. The results shown in this section are from these formal and informal interactions with locals and were used to determine the feasibility of introducing microbial fuel cells as an electricity source in the household.

Before the start of each interview there were informal discussions and observations at the interviewees' homes. This was conducted for 15 interview participants in round 1 of interviews, and for 4 interview participants in round 2 of the interviews. From these discussions and observations, the following were determined: housing material, roofing material, if livestock were present or owned by the interviewee, and if the interviewee's house had electricity. These results were compared to the initial information I gathered about the interviewees to confirm or contradict these indicators of wealth and socioeconomic status, and in order to fit this data into a census category, they were then compared to the census data for rural Tanzania, urban Tanzania, and all of the Manyara Region, which is where the area of study is located (Table 4.1) [4]. For all results reported in this section, the villages of Bassotughagn and Endaiswold are categorized as rural, and the town of Katesh is categorized as urban, as per census categories [166]. Relevant data from the 2012 Tanzanian census can be found in Appendix G.

\subsubsection{Electricity Use and TANESCO}

Living without electricity presents many challenges for the entire household. The interviews conducted allowed for collecting more in-depth information about the challenges that families deal with and the adaptations they have to make from living 
Table 4.1: Interview indicators pre-interview and post-interview, compared to census data

\begin{tabular}{|c|c|c|c|c|c|c|c|c|}
\hline & & \multicolumn{2}{|c|}{ Pre-Interview $^{\mathbf{a}}$} & \multicolumn{2}{|c|}{ Post-Interview $^{b}$} & \multicolumn{3}{|c|}{ Tanzanian Census Data [4] } \\
\hline & & Rural & Urban & Rural & Urban & Rural & Urban & $\begin{array}{l}\text { Manyara } \\
\text { Region }\end{array}$ \\
\hline \multicolumn{2}{|c|}{ Total Number of Participants } & 12 & 7 & 12 & 7 & $6,192,303$ & $3,084,694$ & 271,050 \\
\hline \multirow{2}{*}{ Gender } & Male & 6 & 3 & 6 & 3 & & & \\
\hline & Female & 6 & 4 & 6 & 4 & & & \\
\hline \multirow{3}{*}{$\begin{array}{l}\text { House } \\
\text { material }\end{array}$} & Mud and sticks & 6 & O & 4 & $\mathrm{O}$ & $32 \%$ & $7 \%$ & $50 \%$ \\
\hline & Mud bricks & 6 & 3 & 8 & 2 & $60 \%$ & $38 \%$ & $42 \%$ \\
\hline & Concrete bricks & O & 4 & O & 5 & $5 \%$ & $52 \%$ & $3 \%$ \\
\hline \multirow{2}{*}{$\begin{array}{l}\text { Roof } \\
\text { materials }\end{array}$} & Iron sheets & 4 & 5 & 6 & 5 & $53 \%$ & $91 \%$ & $53 \%$ \\
\hline & Thatch & 8 & $\mathrm{O}$ & 6 & $\mathrm{O}$ & $35 \%$ & $59 \%$ & $28 \%$ \\
\hline \multirow{2}{*}{ Livestock } & Have livestock & 12 & 2 & 10 & 1 & $36 \%$ & $6 \%$ & $56 \%$ \\
\hline & No livestock & 0 & 5 & 2 & 6 & $64 \%$ & $94 \%$ & $44 \%$ \\
\hline \multirow{2}{*}{ Electricity } & Have electricity & 0 & 5 & $\mathrm{O}$ & 5 & $8 \%$ & $49 \%$ & $12 \%$ \\
\hline & No electricity & 12 & 2 & 12 & 2 & $92 \%$ & $51 \%$ & $88 \%$ \\
\hline
\end{tabular}

${ }^{a}$ Indicates perceptions of interview participant indicators before interviews.

b Indicates interview participant indicators confirmed after the interviews took place. 
without electricity. All 15 interview participants interviewed in round 1 of interviews, and all 4 additional participants interviewed in round 2 of interviews discussed their electricity use or plans for use in the home, as well as difficulties with lack of electricity or with TANESCO. Table 4.1 shows that the majority of interview participants and Tanzanians in general live without electricity. All interviewees had school-age children at home and those without electricity all expressed concern about a lack of light for studying at night due to the limited number of lights available. One of the greatest limitations for children at home is that they are expected or required by their mothers to help cook and clean before they can study. For the women of the house, this allows them to use a light source for cooking and to complete the housework more quickly. Once the women's main duties have been completed, the children are allowed to use the lights. Other families have adapted in other ways to having few light sources. One man interviewed lives near several other homes where there are several children of the same age. The children form groups in the evenings so they can study together, requiring only one light source and having the opportunity to help each other through the learning process. He explained:

[Other children] that have no light, they study together [with my children]. They study in a group when there is not enough light... They like working in a group because if one of them gets the answer, they are happy and others can get the answer too.

The main issues from living without electricity that families experience in the Hanan'g area include difficulty in cooking and doing household chores in the evening, cleanliness, and safety. Many women in the rural villages cook inside their homes and have very little light in their cooking area. Likewise, those that cook outside of their homes have little to no light for cooking after sunset. The majority of those interviewed have a dark area for cooking, which can greatly increase the difficulties in cooking. The interviewees also reported issues with maintaining cleanliness when going to the outdoor toilet in the dark. No interview participants have lighted toilet and bathing rooms, which can lead to issues with maintaining cleanliness in the evening and night time. In Tanzanian culture, cleanliness is very highly valued, as presenting a clean body, clean clothing, and a clean home can better a person's reputation. Another concern of interview participants was that the lack of light makes their home less safe. In small villages, generally the 
communities are close and there is little violent crime. Through observations and discussions with community members, it was found that the largest potential for crime in these villages is theft. Theft, including street theft and home burglary, is the main crime conducted in urban areas as well, although crime rates are generally higher in urban areas [167].

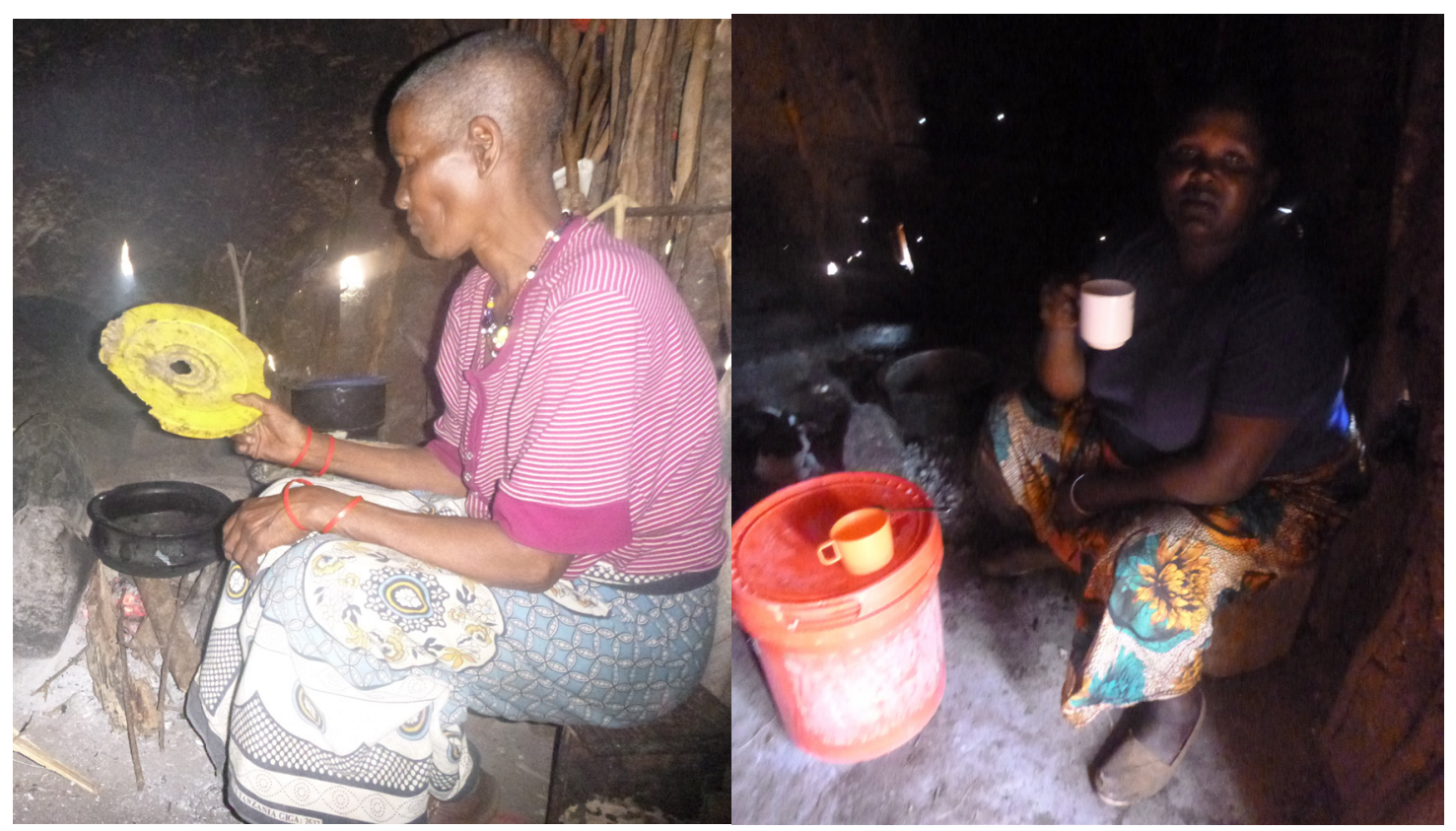

Figure 4.1: Women in rural Tanzania often cook inside the home and have little light for cooking (Photos by author).

Community members have been looking for reliable, low-cost lighting options for their homes to help reduce these observed difficulties. Small solar lights have become a popular source of light in the rural villages around the Hanan'g District without electricity. Most of those interviewed have at least one small solar light at home in addition to a kerosene lamp or a battery-powered flashlight as a backup, whereas the majority of rural Tanzanians use mainly kerosene or wick lamps and a small percentage of rural Tanzanians use flashlights or reusable solar lights (Figure 4.2) [4]. This discrepancy could potentially be due to localized aid, as it was found in the interviews that several interview participants were able to buy small solar lights at a discounted rate. As discussed previously, there are several NGOs that are working to provide and sell small solar lights to rural Tanzanian families. One of these NGOs, or a related organization may have introduced these small solar lights to the area. Although the use 
of solar lights is not the norm throughout Tanzania, their prevalence throughout the Hanan'g area may indicate that residents could be more likely to adopt a new electricity or lighting technology.

Interview participants with electricity reported to experience relatively frequent blackouts in the evening. During the blackouts, they primarily used candles as a light source (Figure 4.2). As previously discussed, candles are relatively expensive and lose their wax and wick within several hours. Therefore, all of the interview participants with electricity were open to learning about an alternative light source for use during blackouts.

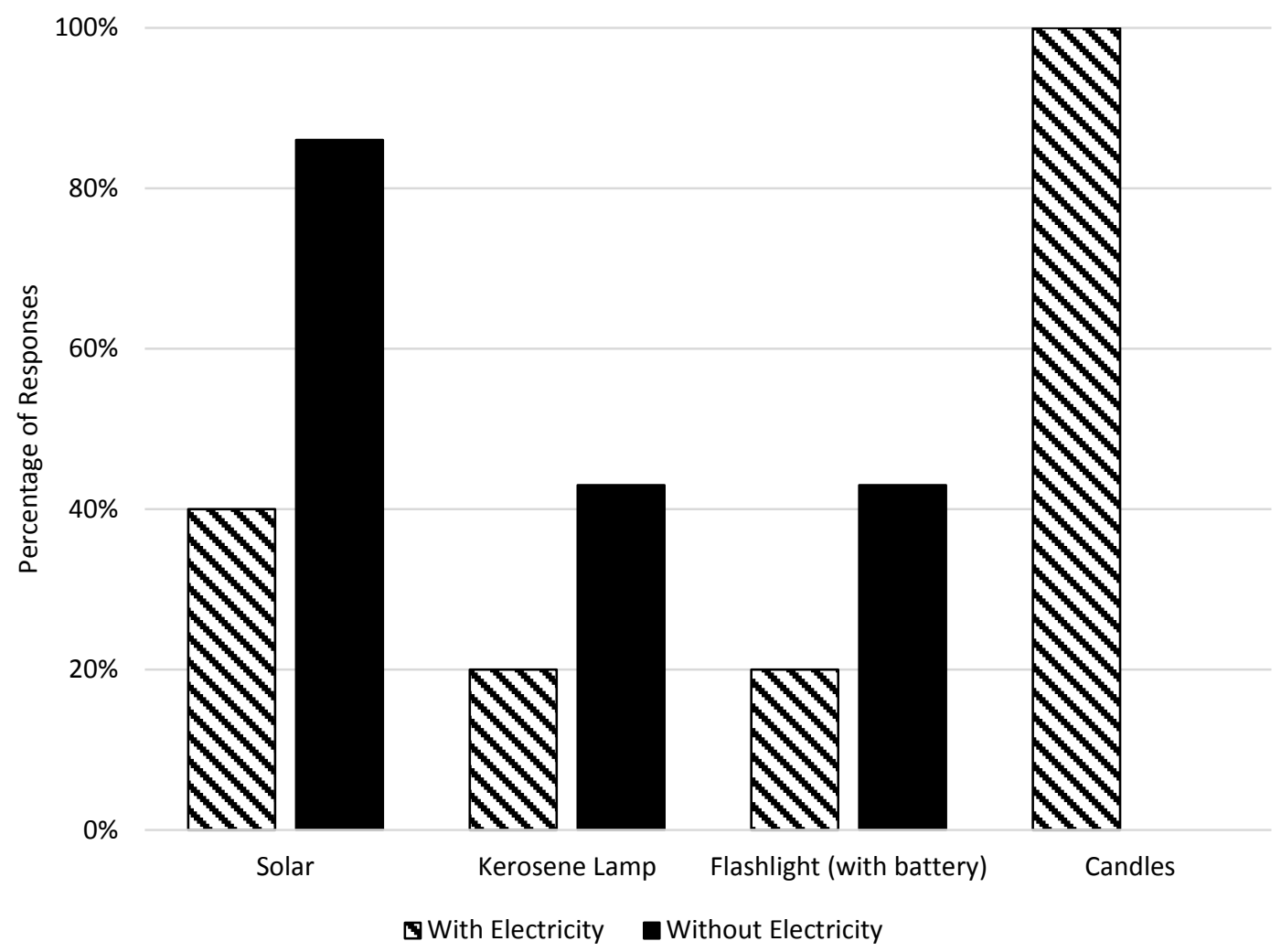

Figure 4.2: Plot of light sources used for nighttime use by those without electricity (black) and for use during blackouts by those with electricity (striped).

Having electricity can greatly increase people's quality of life, as well as their status within the community. From the interviews, it was found that lighting is the most important use of electricity, whether the light would be for children to study with, for completing household chores, or for the safety of the home. The second most important 
use of electricity was found to be mobile phone charging. Mobile phones have become nearly ubiquitous throughout Tanzania and are not only used for communication between family and friends, but also for economic transactions and income generating activities. Throughout the interviews, the interview participants also mentioned other potential uses for electricity, such as cooking, listening to the radio, watching television, using an electric iron, as well as running an electric corn grinder. Many of those interviewed expressed a desire to use electricity to help them start a business or to do another income generating activity. Those interviewed who currently have electricity use it for lighting their home, charging their mobile phone, watching television and listening to the radio, and ironing clothes (Figure 4.3). They reported to pay between $\$ 1.20$ and $\$ 14.40$ per month for electricity, and in the Manyara Region, the average person has approximately $\$ 41$ in monthly income [168]. Those interviewed without electricity plan to use it for light, specifically light for studying, phone charging, and cooking primarily (Figure 4.3). Although income was not discussed explicitly in the interviews, most of the people interviewed without electricity mentioned that there was little to no extra money in the household for them to invest in electricity for their homes.

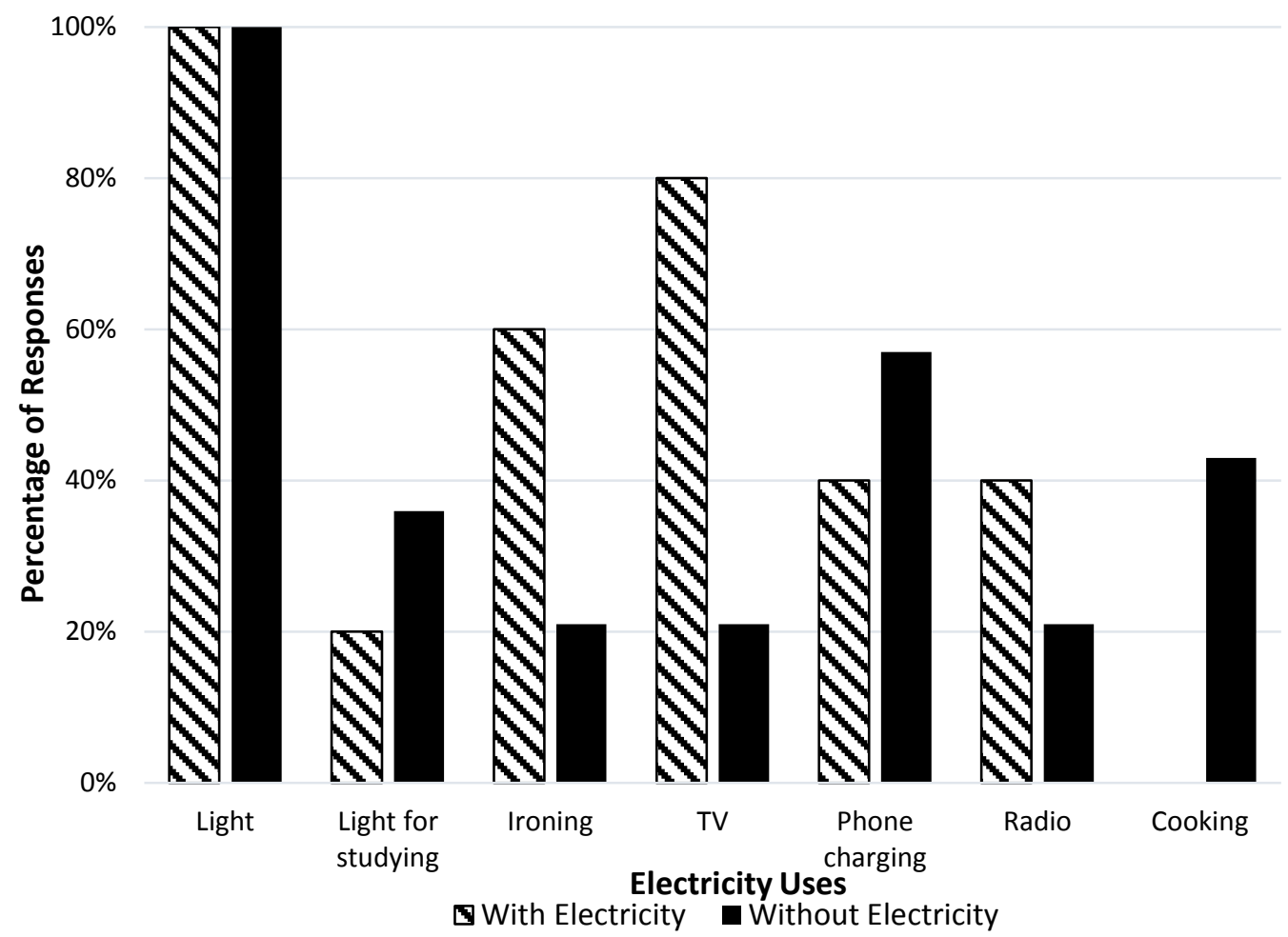

Figure 4.3: Interview participants' perceptions of current electricity use for those with electricity (striped) and plans for electricity use for those without electricity (black). 
TANESCO is the only grid electrical supply company in Tanzania, as discussed in section 2.2.3.1. For those looking to get electricity installed in their homes, they must choose between TANESCO and several off-grid options, such as solar photovoltaics, biogaspowered electricity, diesel generators, and wind power. Of those who have electricity in their homes, the vast majority are connected to the grid, although solar photovoltaics are increasing in popularity. TANESCO electricity is relatively cheap, but is increasing in cost to the users. The electricity rate increased in 2014 from $\$ 0.03 / \mathrm{kWh}$ to $\$ 0.05 / \mathrm{kWh}$ for domestic users using up to $75 \mathrm{kWh}$ per month and the rate increase from $\$ 0.13 / \mathrm{kWh}$ to $\$ 0.17 / \mathrm{kWh}$ for domestic users using more than $75 \mathrm{kWh}$ per month [169]. The increase was sharp and invoked anger and frustration in electricity users, as found from the interviews. The 'high-electricity' users now pay around five cents more per kilowatt hour than the U.S. residential average, and about six cents more per kilowatt hour than the majority of U.S. states [170]. The company is currently switching all of its users from a traditional meter-based system, where the user is billed after each month, to a voucherbased system called LUKU. This switch was most likely due to the lack of accountability of users to pay their bills on time. The LUKU system prevents any issues with late payments by having users pay upfront. This LUKU system is slightly more expensive than the metered system, and users are unreceptive to the continuous increases in price [171].

Of those interviewed, all current and past TANESCO users had issues with increasing rates for electricity, extra unexpected charges, and general lack of customer service. Users also had issues with the unscheduled power cuts. They are relatively infrequent, compared to previous years, but they are usually followed by power surges. The resulting power surges have been strong enough to break light bulbs and various appliances, making users angry and creating a climate of discontent. One informant said:

When [electricity] gets cut unexpectedly... the problems I have are that I get angry because some appliances break, but also because I am in the dark. Electricity is cut when I have no notice... so I cannot prepare for it.

Current user discontentedness allows for the possibility of changes to the electricity sources in Tanzania. As discussed previously, TANESCO is owned by the Tanzanian 
government, and effectively has a monopoly on the electrical supply and grid distribution market [11]. Some possible changes that could arise from this include adding more electrical supply companies as competitors and adding options for electricity besides traditional grid electricity. One informant compared the current state of TANESCO to Tanzania's previous national telephone company, TTCL (Tanzania Telecommunications Company Limited). He said:

We have one electrical company - TANESCO. So there is a monopoly. They set their own price, and if you don't pay that price, they cut off your electricity that day. So my thought was that there should be many electrical companies... I mean for competition like the phone companies. A while ago we only had only one phone company, TTCL... Now there are many phone companies. We have Vodacom, we have Airtel, people are not upset anymore. People make phone calls and the costs have decreased.

Although TANESCO has planned to allow for a free market with other electricity companies, customers generally believe that change will be slow to come. Therefore, an increase in interest of off-grid electricity has been observed, and was expressed by most interview participants.

Some off-grid electricity technologies like solar photovoltaics require a high upfront cost to purchase and install, however. To determine the relative importance of cost of these electricity technologies, in round 2 of the interviews, 16 interview participants were asked to choose between two electricity technologies: The first was a technology that would cost approximately $\$ 20$ but they would need to build themselves, take time to maintain it, and it would produce less light. The second was a technology that would cost approximately $\$ 8$ o but they would not have to build or maintain it, and it would produce more light than the other technology. Twelve interviewees chose the less expensive technology. The main reasons reported were the lower cost and the value of learning to build the technology. Some remarks from the informants about the technologies were:

I would choose to learn to make [the technology] myself. Because it costs less than the one you can buy... We [Tanzanians] like [to buy] inexpensive things. 
I would choose the [low cost technology] because I would make it myself, it has a low cost, and I can become good at making it with my own hands.

Of the participants that chose the low-cost, low-light option, two also chose the highercost, more-light option as an option that they would like to have in the future. Four participants chose only the higher-cost, more-light option. Their main reasons were the lower maintenance, and the potential for more light.

Also notable from the interviews was the expressed concern from those without electricity about the safety of electrical wiring within the home. As previously discussed, there have been several incidents in Tanzania where homes have been poorly wired and where illicit connections from homes to the electrical grid have been made, and several people have been killed because of these issues. Therefore, it was emphasized by several interview participants that safety in home wiring and in any electricity technology to be used inside the home was very important.

From these results, it was found that the majority of interview participants expressed that they would like the low-cost technology that they could make themselves in order to gain trade skills and make their own affordable light source. Therefore, when designing future technologies, MFCs in particular, cost and ease of fabrication are two very important factors in the success of the technology in Tanzania.

\subsubsection{Manure Perceptions and Use}

As explained in section 2.6, various studies have previously established that manure is a viable source of fuel for use in a microbial fuel cell and has potential to be a source of alternative energy in the future. Due to this possibility, I also investigated the feasibility of using manure for electricity as well as the perceptions people have of manure and its use during both rounds of interviews conducted. The area of study is heavily populated with livestock herders and livestock keepers. The Tanzanian National Bureau of Statistics defines livestock for the census data to be cattle, goats, sheep, and poultry [4]. The 2012 Tanzanian Census found that in the Manyara region, 52\% of the rural population keeps livestock, as compared to $36 \%$ of Tanzania's rural population as a whole [4]. Of the livestock keepers in Manyara, over 70\% of livestock keepers keep cattle 
and goats (Figure 4.4) [4]. The Iraqw and Barbaig ethnic groups that live in the Manyara region are known livestock keepers and keep their livestock in or near to their homes. A majority of those interviewed are from the Iraqw ethnic group. All those interviewed from the Iraqw ethnic group, along with an interviewee from the Chagga ethnic group of the Moshi region, grew up with livestock near their homes. Through the interviews, they showed that they are completely comfortable handling manure. Manure is a part of their everyday lives, as all interviewees reported to use manure for fertilizer in their fields, gardens, or even just for their banana plants. From the Tanzanian census, it was found that three-quarters of households in the Manyara region are engaged in agricultural activities [4]. If people do not live with livestock in the home, they have neighbors with livestock. Even in the more urban households of Katesh town, livestock manure is easy to come by if a home does not have livestock.

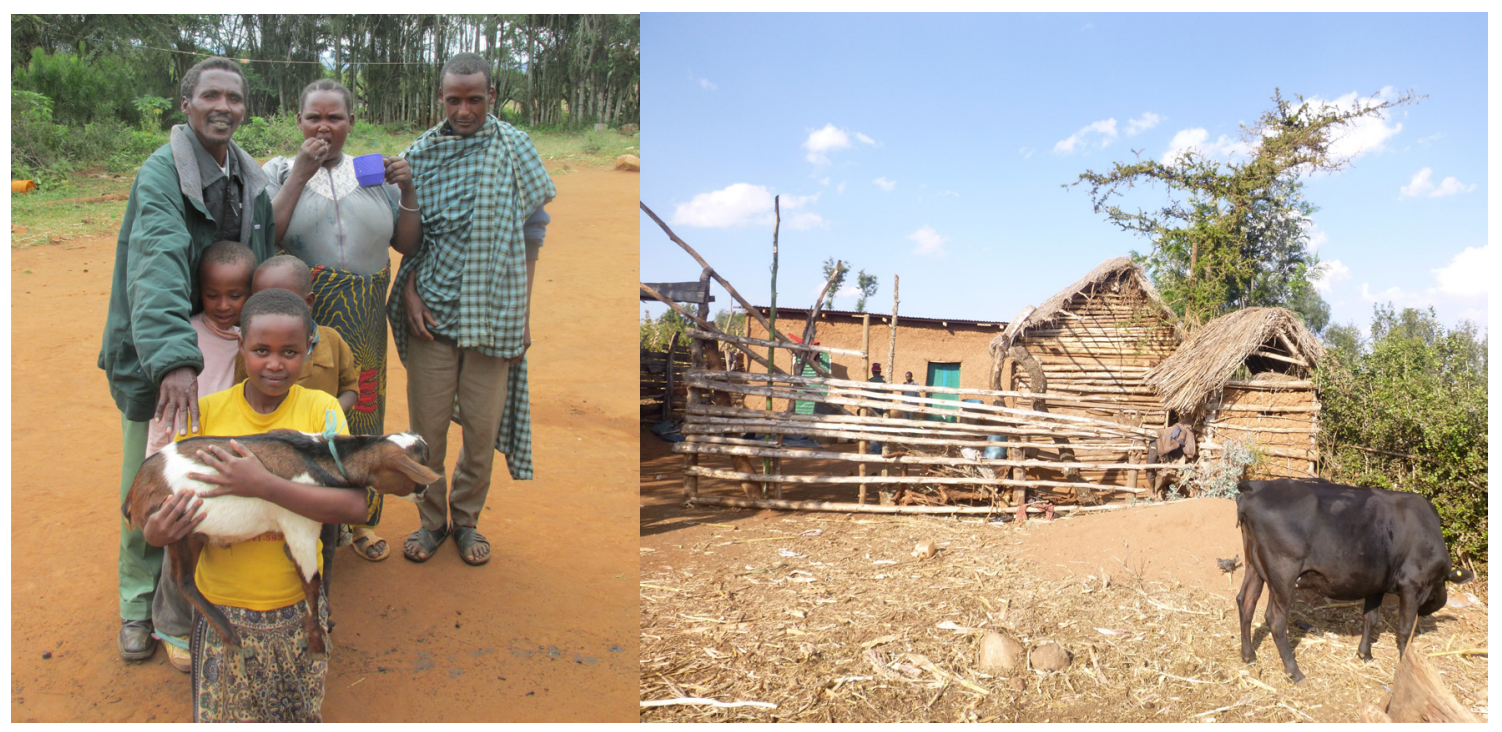

Figure 4.4: Many families in rural Hanan'g district live with livestock in and around their homes (Photos by author).

Interviews and observations revealed that manure is commonly handled and used by people in the study area. All those interviewed reported to use manure for fertilizer to aid in growing the corn, beans and other fruits and vegetables that comprise the majority of the food consumed by most households. Most of those interviewed said that they have an excess of manure, however those with no livestock have no excess. Despite this difference in access to manure, most interview participants expressed concern about having enough manure for both fertilizer and electricity generation. Their food security depends on the availability of manure to fertilize their fields, so if they use manure for a purpose other 
than fertilizer, they may be taking away some of their food security, especially for those with large fields of crops. It has already been determined that manure does not lose its fertilizing properties after use in a MFC, however it has not been determined if MFCs can help to reduce fecal coliforms in the manure [60]. As discussed in Section 2.6, this was the purpose of testing the cow manure for fecal coliforms before and after use in the MFC. If the manure slurry is absent of fecal coliforms after use in the MFC, it is a safer source of fertilizer for people to use in their fields. The reuse of manure as fertilizer after use in an MFC could allow MFCs to be used in a way that meets multiple needs of the rural Tanzanian end users.

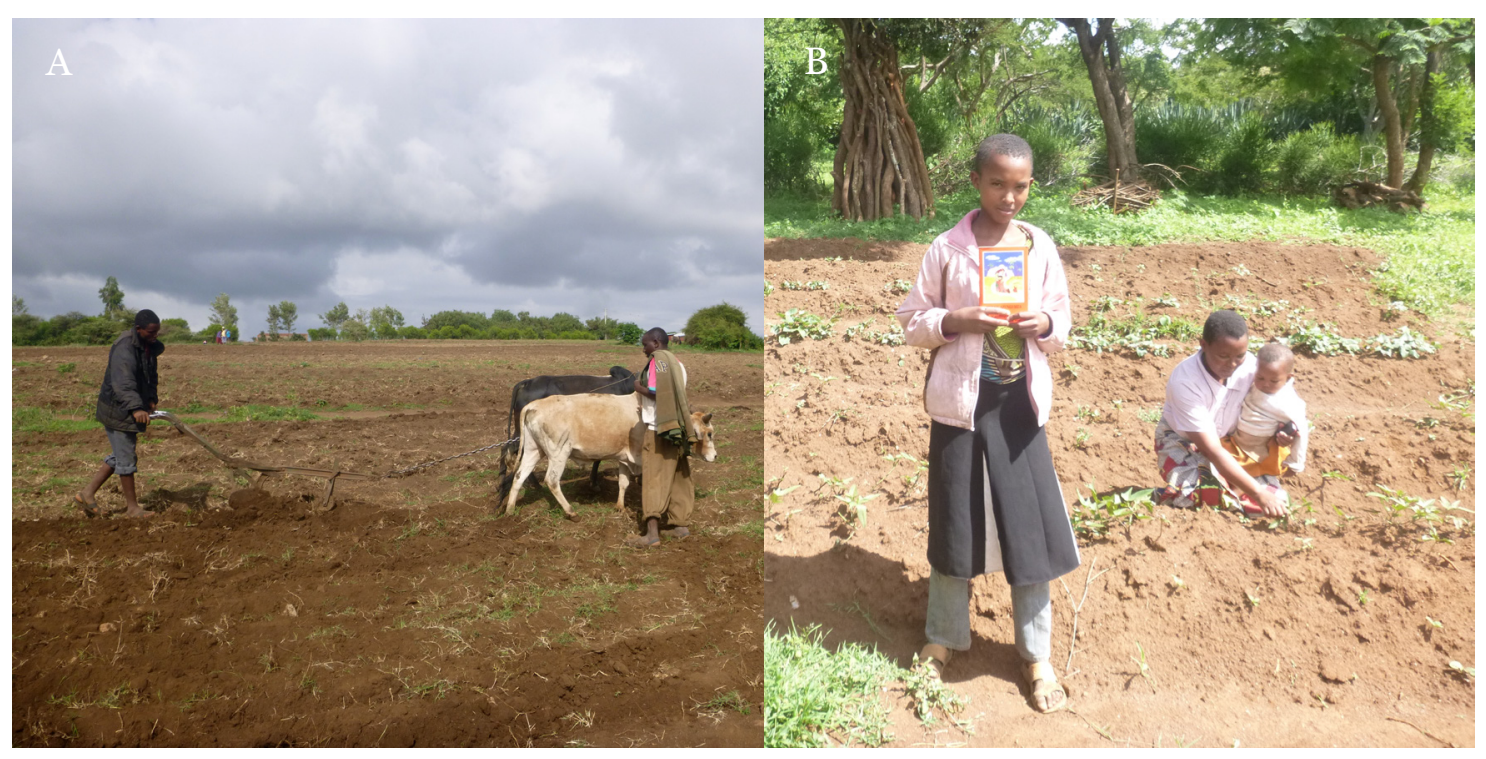

Figure 4.5: A. Farmers in the Hanan'g area usually use cattle to help with their farming and use the manure as fertilizer in the fields. B. Most residents of the Hanan'g district, especially those in rural areas, rely on small farms and gardens for their food (Photos by author).

Many rural Tanzanians interviewed also expressed concern with the potential unpleasant odors and dirtiness from having manure in the MFC in their home, so it is also important that MFCs can accommodate that issue. The women interviewed were concerned about the smell and dirtiness that the MFC could bring to the kitchen when they are cooking, the bedrooms when they are sleeping, and to the main sitting room when they have neighbors or friends visiting. 
If [the MFC] has a bad smell, why do you put it inside your home?... If there is a bad smell, this is a problem... If I have already finished cleaning my home very well, it can make [my home] dirty again.

The Muslim couple interviewed were concerned about the potential dirtiness of the MFC because they are not allowed to pray in a home that is dirty. Praying at home is very important for any Muslims in a Christian village, as there are no mosques to pray in. Therefore, microbial fuel cells would need to have little to no possibility of leaking and negligible smells in order for them to be considered acceptable to use in the home. A study conducted by Kim et al [172] found that MFCs can significantly reduce the chemicals and volatile organic acids in swine wastewater that are responsible for the unpleasant odors. Therefore, any odors from the MFC would most likely be greatly reduced after running the MFC with manure slurry. During loading of manure into the MFC, however, odors from the manure would still be present. The use of human waste was also suggested by two separate interview participants in both rural and urban households as a replacement for livestock manure in a microbial fuel cell. This could indicate a possibility of social acceptance for using a generally unused waste product for agriculture to power microbial fuel cells. With the reduction in odors and the potential ability to reuse manure as a fertilizer, microbial fuel cells could be a viable technology within the rural Tanzanian culture.

\subsection{Microbial Fuel Cell Results and Analysis}

\subsubsection{Electrochemical Performance during Startup}

The voltage monitored in the MFC with $\mathrm{R}_{\text {ext }}$ of $1000 \Omega$ during the startup phase is shown in Figure 4.6. The MFC was filled with a mix of 50\% sodium acetate solution and 50\% MFC effluent on day o and refilled with 100\% sodium acetate feed on days 7, 9, and 14 . The cathode was replaced on day 17 , and it was refilled with a sodium acetate feed again on day 24. Peak voltages for the batch cycles (points a, b, and c) ranged from 0.280 to $0.430 \mathrm{~V}$. The lowest peak voltage was attained in the last batch of the startup procedure, when cathode leakage was greater and more detrimental to MFC performance. Gaps in the plot data indicate a disconnect of the external circuit and voltage measurements for testing or loading the MFC. 
Cathode leakage during startup made running the MFC difficult and resulted in excessive loss of substrate from the MFC. This loss of substrate led to oxygen diffusion into the anode chamber and less usable substrate, both of which greatly decreased voltage and power production compared to points a and b (Figure 4.6). The MFC had to be reloaded with new sodium acetate solution every few days which led to less consistent data. Generally, MFC voltage increases until it plateaus, and then drops when much of the substrate has been utilized. Due to the loss of substrate through the leaking cathode, however, it was difficult to determine what was causing voltage decreases in the MFC used in this study.

In addition to voltage and power reduction from substrate loss and oxygen permeation, rust formed at the connection of the external circuit to the cathode. Rust was formed mainly from the leaking substrate coming in contact with the external circuit. Effects of rust on the circuit elements can be seen at point $d$ in Figure 4.6. The erratic jumps and decreases in voltage were found to be due in large part to rusting which resulted in an unreliable circuit connection.

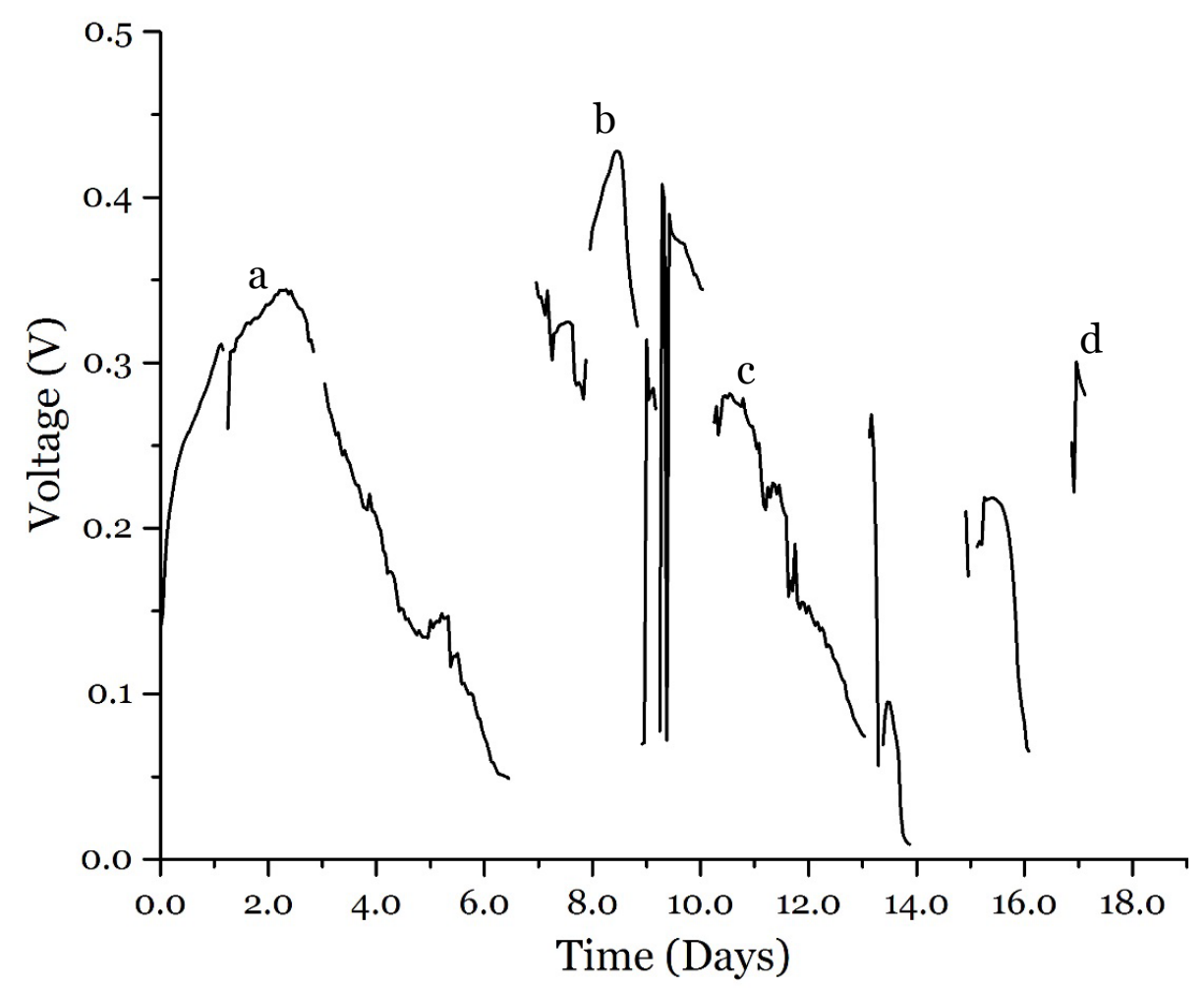

Figure 4.6: Voltage of the MFC during startup. Points $a, b$, and c show peak voltages for three batches. Point $d$ shows the effects of rusting on the circuit elements. 
The voltage data collected with a $1000 \Omega \mathrm{R}_{\text {ext }}$ were used to calculate current and power output. The maximum power density during the startup phase was $0.114 \mathrm{~W} / \mathrm{m}^{3}(6.786$ $\mathrm{mW} / \mathrm{m}^{2}$ ) and occurred during the second acetate feed cycle (point b). The cathode area was used to calculate current and power density because the cathode is generally the limiting electrode [22].

Two LSV tests were run on the MFC during startup. OCV, $\mathrm{R}_{\text {int, }}$ and maximum power density for both tests are summarized in Table 4.2. Polarization curves and power curves comparing the results from the two different tests are shown in Figures 4.7 and 4.8. As the results and plots indicate, MFC performance increased significantly from day 4 to day 11 of startup. $\mathrm{R}_{\text {int }}$ decreased and $\mathrm{OCV}, \mathrm{P}_{\mathrm{V}}$, and $\mathrm{P}_{\mathrm{Ca}}$ all increased throughout startup. The increase in performance indicates that the microbial community was developing on the anode throughout startup.

Table 4.2: Summary of electrochemical performance of the MFC during startup

\begin{tabular}{|c|c|c|c|c|}
\hline $\begin{array}{l}\text { Days (since initial } \\
\text { start-up) }\end{array}$ & $\operatorname{OCV}(\mathrm{V})$ & $\mathbf{R}_{\text {int }}(\boldsymbol{\Omega})$ & $\underset{\left(W / \mathbf{m}^{3}\right)}{\operatorname{Maximum}} P_{v}$ & $\begin{array}{l}\operatorname{Maximum} P_{\mathrm{Ca}} \\
\left(\mathbf{m W} / \mathbf{m}^{2}\right)\end{array}$ \\
\hline 4 & 0.389 & 230 & 0.097 & 5.8 \\
\hline 11 & 0.431 & 150 & 0.228 & 13.5 \\
\hline
\end{tabular}




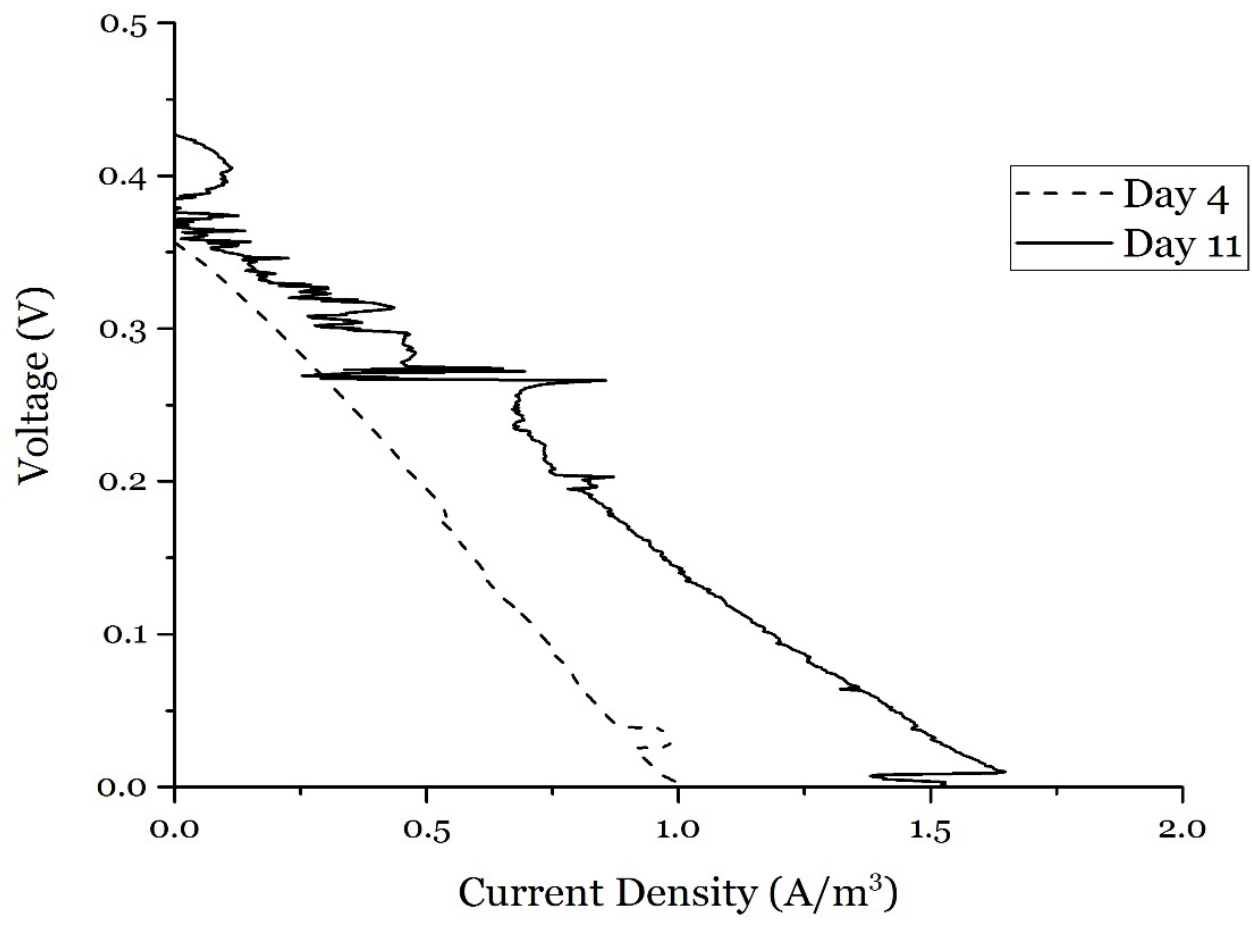

Figure 4.7: Polarization curves from the LSV test on days 3 and 10 of MFC operation during startup.

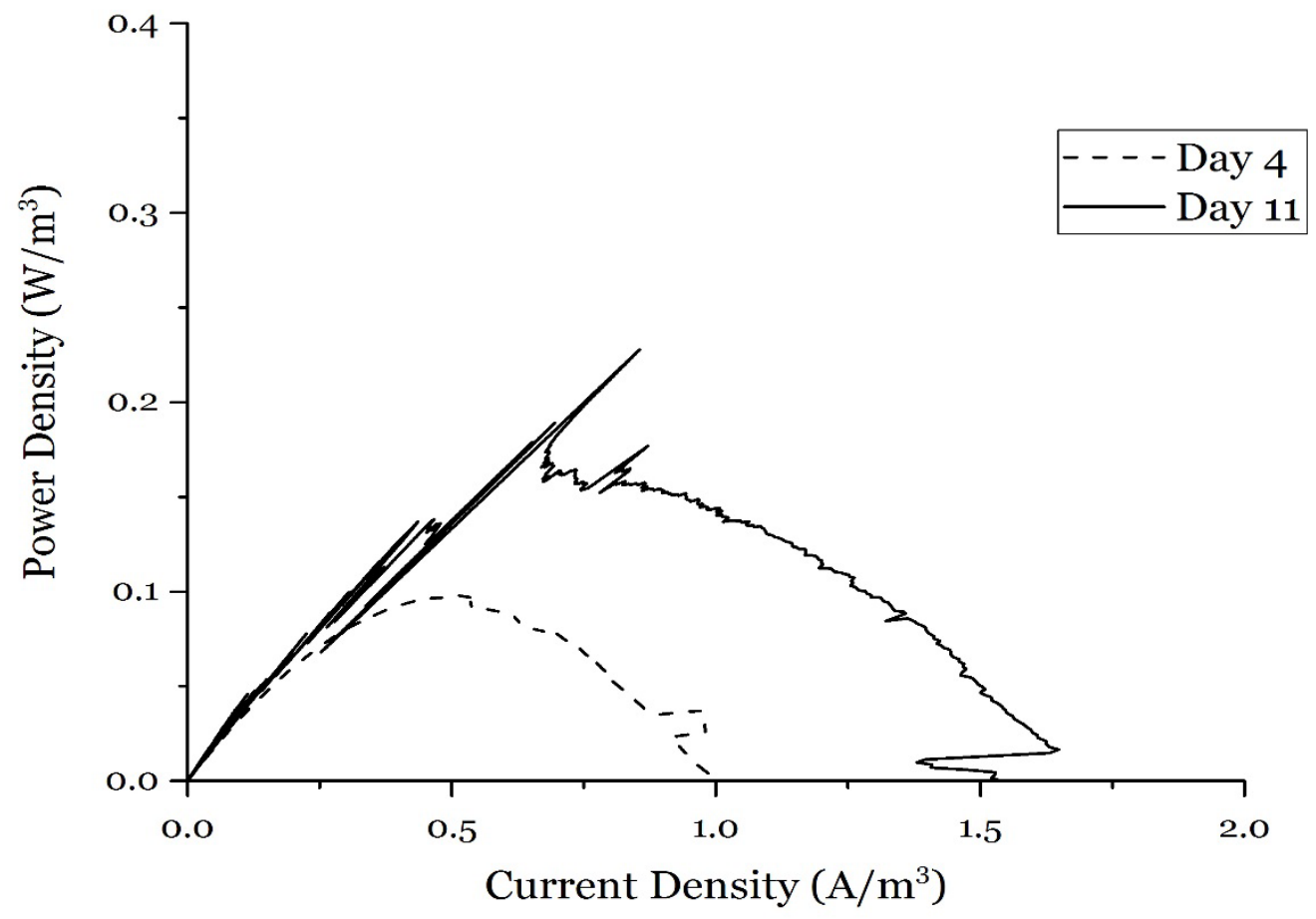

Figure 4.8: Power curves from LSV test on days 3 and 10 of MFC operation during startup. 


\subsubsection{Electrochemical Performance with Acetate Feed Cycle}

Due to the inconsistent MFC performance with the leaking cathode, the cathode was replaced as described in Section 3.3.2. After the MFC was reassembled with the new cathode and the anode was reinserted after having been stored in an acetate solution, the anode compartment was filled again with acetate feed solution to confirm that the activity of the bacteria associated with the anode had been preserved.

For this cycle (acetate feed cycle 3 ), $R_{\text {ext }}$ was kept at $1000 \Omega$. Working voltage initially decreased for approximately one day (Figure 4.9). This decrease was most likely due to the microbial population on the anode acclimating to the new environment. After reacclimation, voltage climbed continuously to a $0.63 \mathrm{~V}\left(0.249 \mathrm{~W} / \mathrm{m}^{3}, 14.8 \mathrm{~mW} / \mathrm{m}^{2}\right)$, where it stayed for over 6 days. During this steady voltage period, the MFC briefly peaked at $0.66 \mathrm{~V}\left(0.275 \mathrm{~W} / \mathrm{m}^{3}, 16.3 \mathrm{~mW} /{ }^{2}\right)$. These data showed that the MFC was able to obtain relatively high voltages and power densities under typical MFC operating conditions. Although the voltage was still high, at twelve days of operation with the acetate batch, the MFC was emptied and loaded with the manure slurry due to time constraints.

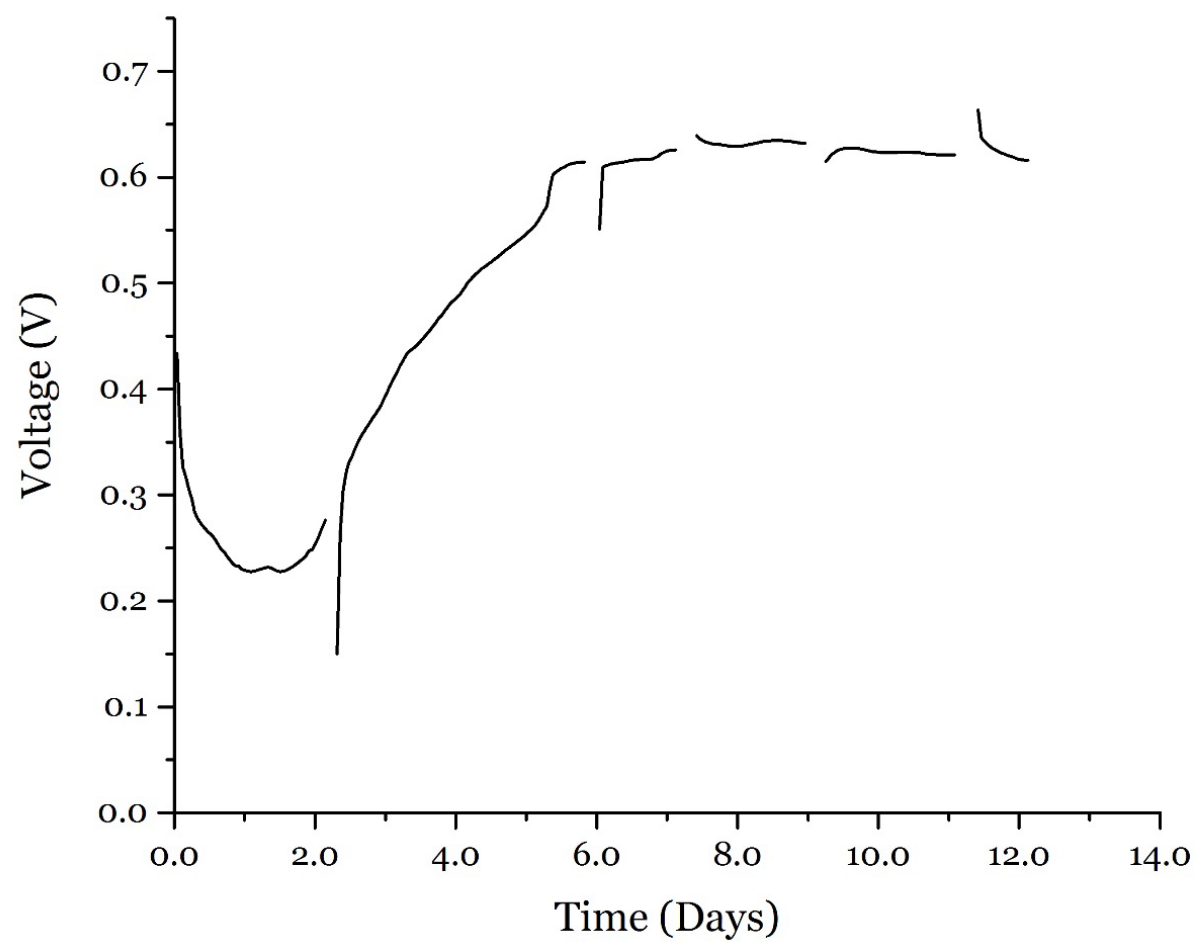

Figure 4.9: MFC voltage during operation with a batch of feed acetate solution (acetate feed cycle 3) immediately after replacing the leaking cathode.

63 
Three LSV tests were run on the MFC during the third acetate feed cycle. A summary of the results can be found in Table 4.3, polarization curves are shown in Figure 4.10, and power curves are shown in Figure 4.11. It can be seen that after day 3, the OCV, $\mathrm{P}_{\mathrm{Ca}}$, and $\mathrm{P}_{\mathrm{V}}$ increased, while the $\mathrm{R}_{\text {int }}$ decreased significantly. This can most likely be attributed to the MFC and anode re-acclimating after replacing the cathode. After the acclimation period, the MFC appeared to stabilize. On day 10, both a forward (OCV to short-circuit) and a reverse (short-circuit to OCV) LSV test were conducted on the MFC to confirm the reliability of the LSV results. Figure 4.12 shows the two curves. It can be seen that the two curves have a similar slope, indicating their similar $R_{\text {int }}$ values. The forward test yielded a $R_{\text {int }}$ of $100 \Omega$ and the reverse test yielded a $R_{\text {int }}$ of $105 \Omega$, confirming that the LSV test was reliable for this batch. Therefore, the forward results only were used to calculate power. The maximum power density for this test was $1.22 \mathrm{~W} / \mathrm{m}^{3}\left(72.1 \mathrm{~mW} / \mathrm{m}^{2}\right)$. On the reverse LSV test, current was initially very high due to operation at the short circuit conditions but dropped after resistance was increased.

Table 4.3: Summary of electrochemical performance from LSV tests on the MFC on days 3, 7, and 10 of the third acetate feed cycle.

\begin{tabular}{|c|c|c|c|c|}
\hline $\begin{array}{l}\text { Days (since start of } \\
\text { cycle) }\end{array}$ & OCV (V) & $\mathbf{R}_{\text {int }}(\boldsymbol{\Omega})$ & $\underset{\left(W / \mathbf{m}^{3}\right)}{\operatorname{Maximum}} \mathbf{P}_{V}$ & $\underset{\left(\mathbf{m W} / \mathbf{m}^{2}\right)}{\operatorname{Maximum} P_{\mathrm{Ca}}}$ \\
\hline 3 & 0.467 & 370 & 0.27 & 16.0 \\
\hline 7 & 0.689 & 101 & 0.85 & 50.16 \\
\hline 10 & 0.705 & 100 & 1.22 & 72.1 \\
\hline
\end{tabular}




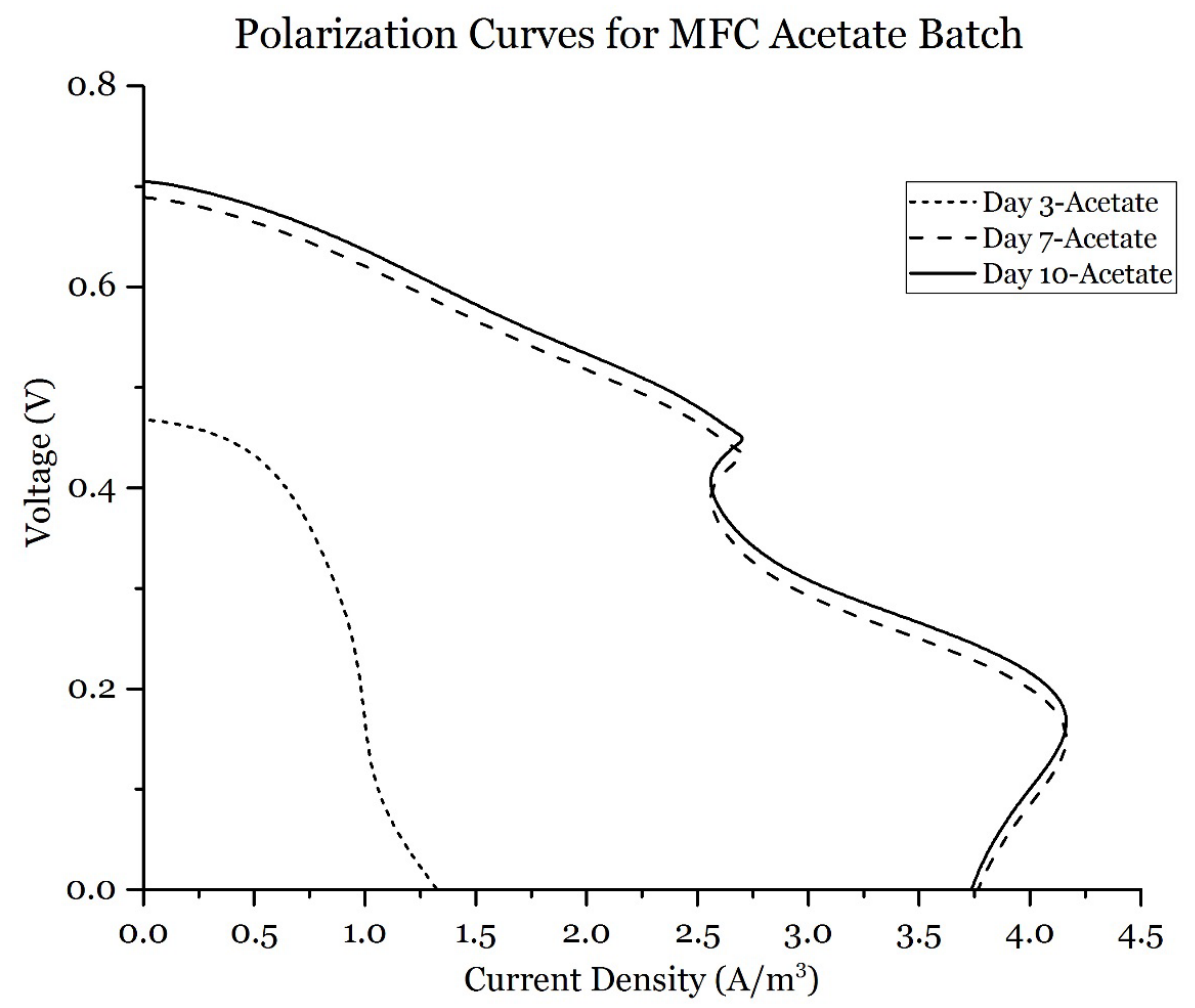

Figure 4.10: Polarization curves for days 3, 7, and 10 of operating the MFC during acetate feed cycle 3.

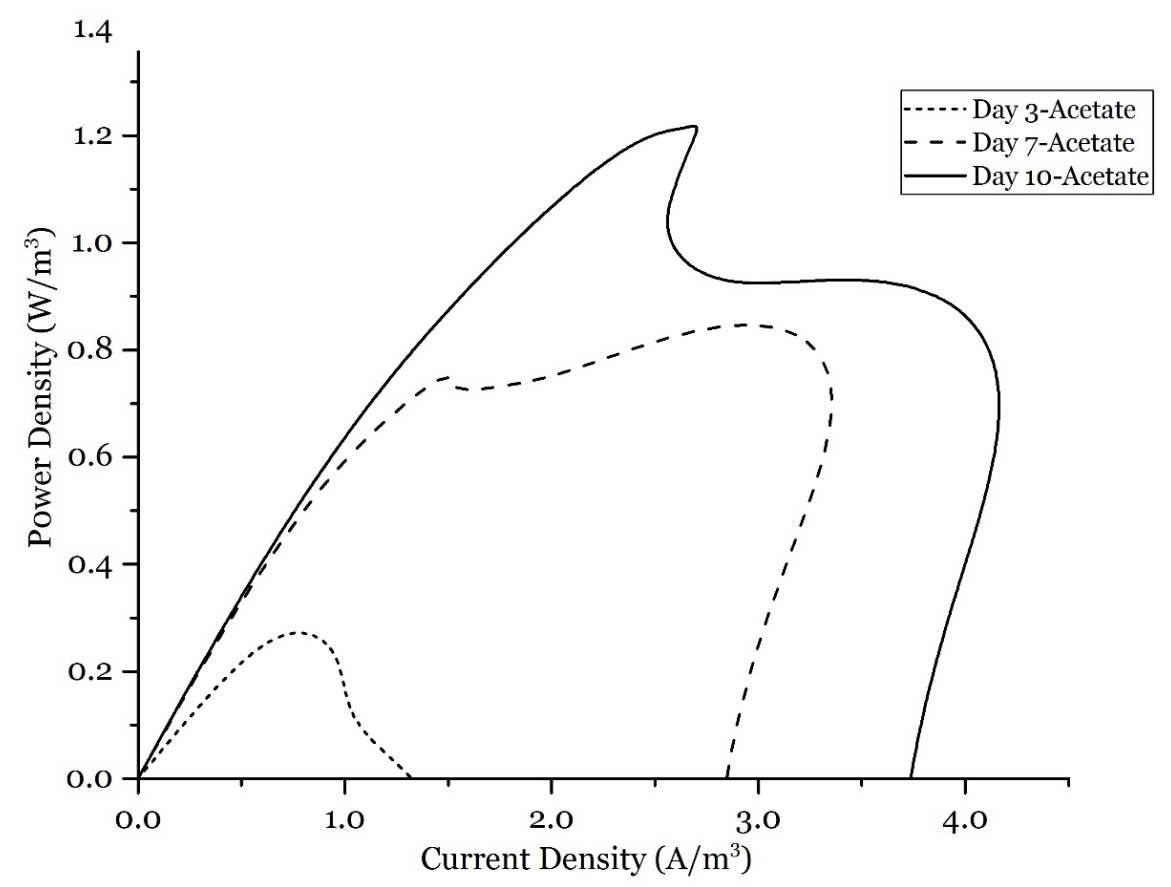

Figure 4.11: Power curves for days 3, 7, and 10 of operating the MFC during acetate feed cycle 3. 
The polarization and power curves obtained during acetate feed cycle 3 are shown in Figure 4.10 and Figure 4.11, respectively. Power overshoot can be seen on days 7 and 10. Power overshoot refers to the doubling back of voltage and power at high current density and low resistances. It is due to the lag in microbial response to low external resistances being applied to the MFC during LSV testing, and presumably occurred because the microbial population that developed on the anode during startup was acclimated to a high $R_{\text {ext }}[123,173-175]$. Power overshoot does not indicate any operational problems with the MFC, and acclimating the MFC to both high and low resistances to minimize power overshoot can change the microbial community on the anode, which is not desired for this test [176-178].

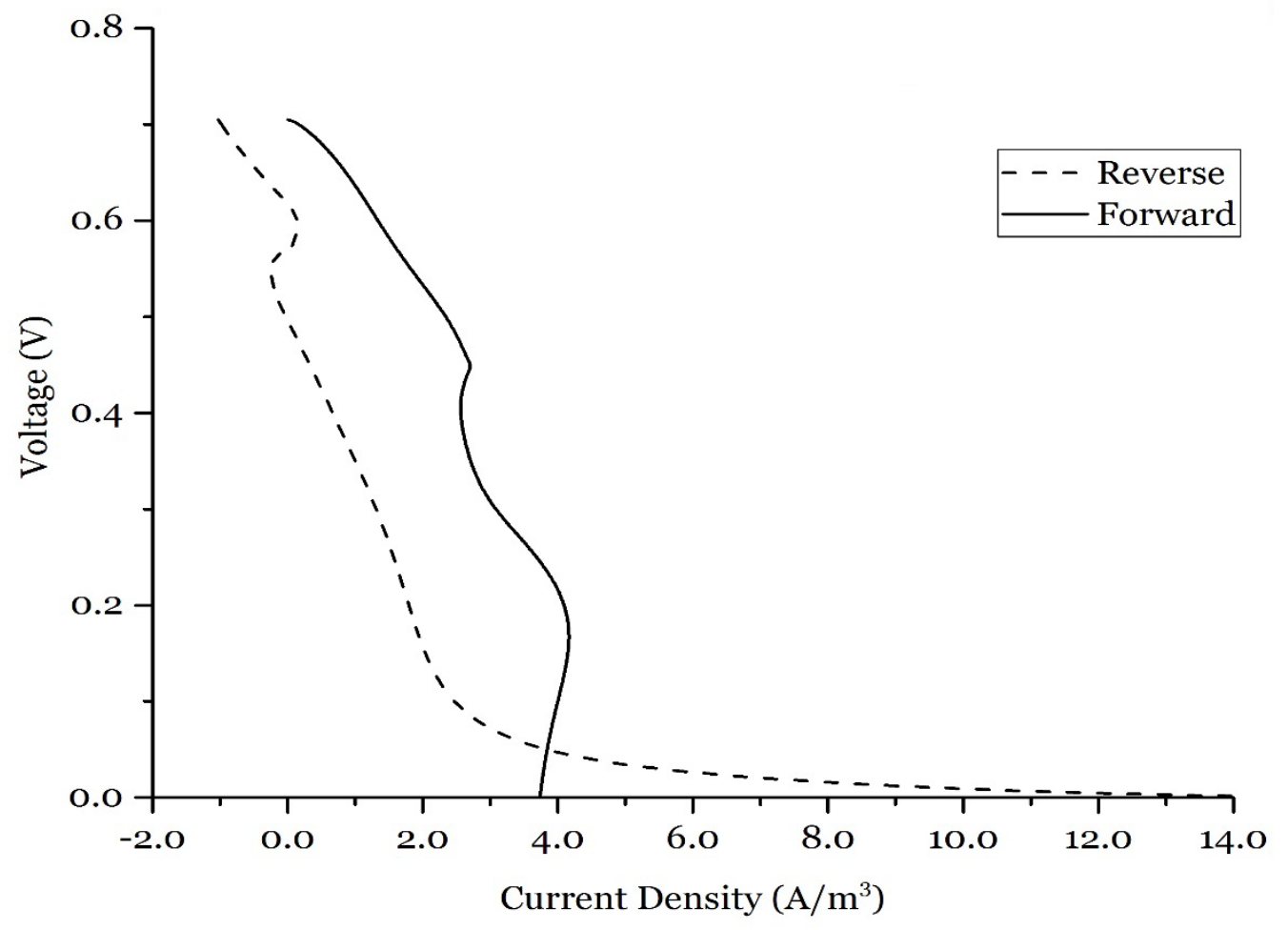

Figure 4.12: Polarization curves for forward and reverse LSV tests on the MFC during acetate feed cycle 3 on day 10 of operation.

An EIS test was performed on the MFC on day 8 of acetate feed cycle 3. The Nyquist plot is shown in Figure 4.13 A. From the Nyquist plot, the ohmic resistance (8.3 $\Omega$ ) was found where the curve intercepts the $\mathrm{x}$-axis. The charge transfer resistance was found from the circle-fit method in MATLAB by taking the diameter of the fitted circle, which was $0.6 \Omega$ (Figure 4.13 B). Subtracting ohmic resistance and charge transfer resistance from total 
internal resistance (101 $\Omega$ ) gives diffusion resistance and all other internal resistances $(92.1 \Omega)$.
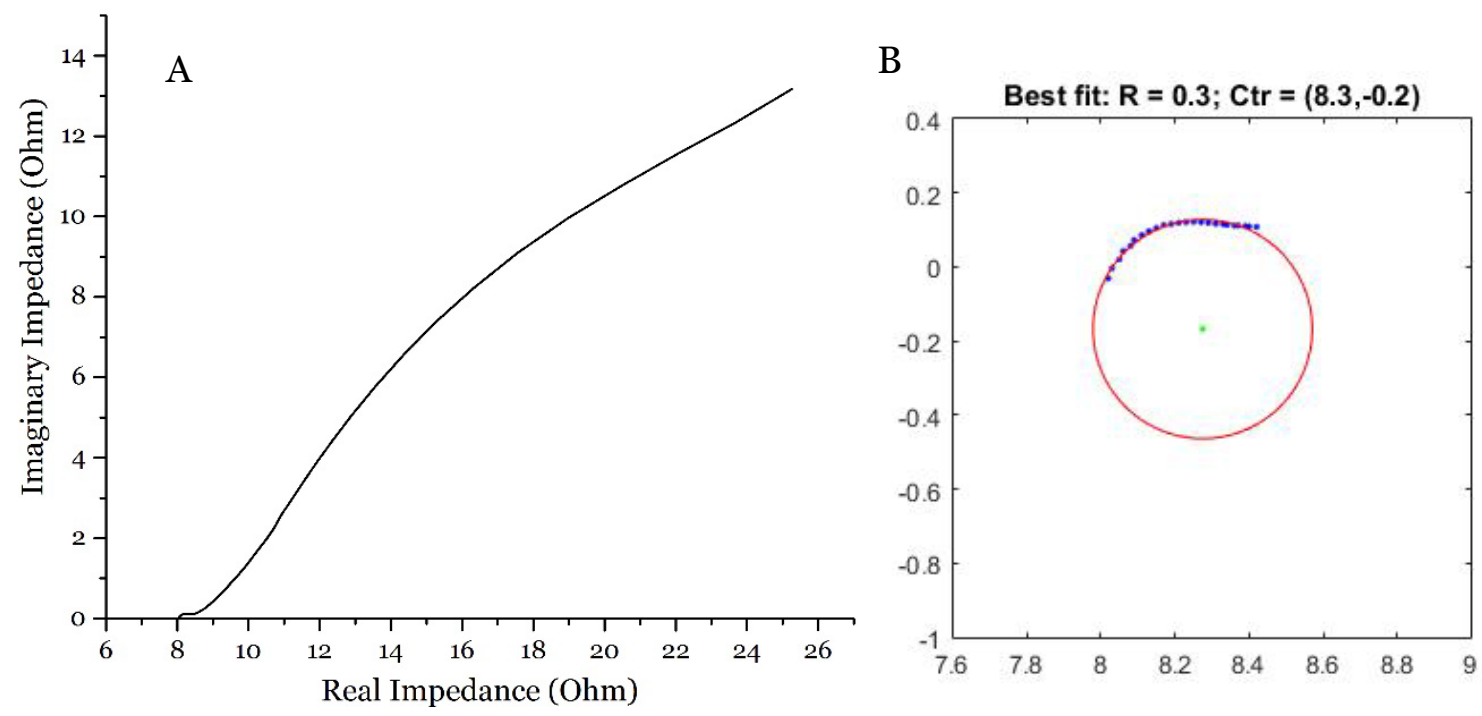

Figure 4.13: A. Nyquist plot obtained from an EIS test on the MFC on day 8 of acetate feed cycle 3. B. Circle fit on the curved section of the Nyquist plot to estimate charge transfer resistance.

\subsubsection{Electrochemical Performance during Manure Feed Cycle 1}

After the voltage began decreasing in acetate feed cycle 3, the MFC was loaded with an $\mathrm{O}_{2}$-depleted $1 \%$ volume diluted cattle manure in DI water, as previously described. The $\mathrm{pH}$ of the diluted manure was 7.68, which is near the ideal $\mathrm{pH}$ range of 8 to 10 for high current conduction $[179,180]$. The $\mathrm{pH}$ of the substrate can significantly affect voltage and power density of the MFC [179-181].

The duration of the first manure cycle was 13 days. The MFC achieved a maximum working voltage of $0.156 \mathrm{~V}$ with an external resistance of $100 \Omega$ after 19 hours (o.8 days) of operation. At this point, the power density was $0.151 \mathrm{~W} / \mathrm{m}^{3}\left(8.97 \mathrm{~mW} / \mathrm{m}^{2}\right)$. After reaching the peak voltage, the MFC dropped to a fairly stable working voltage of around $0.04-0.05 \mathrm{~V}$. Small variations in voltage were seen throughout the feed cycle, as can be seen in Figure 4.14. These small variations were mainly attributed to the variations in temperature within the laboratory from day and night hours. 


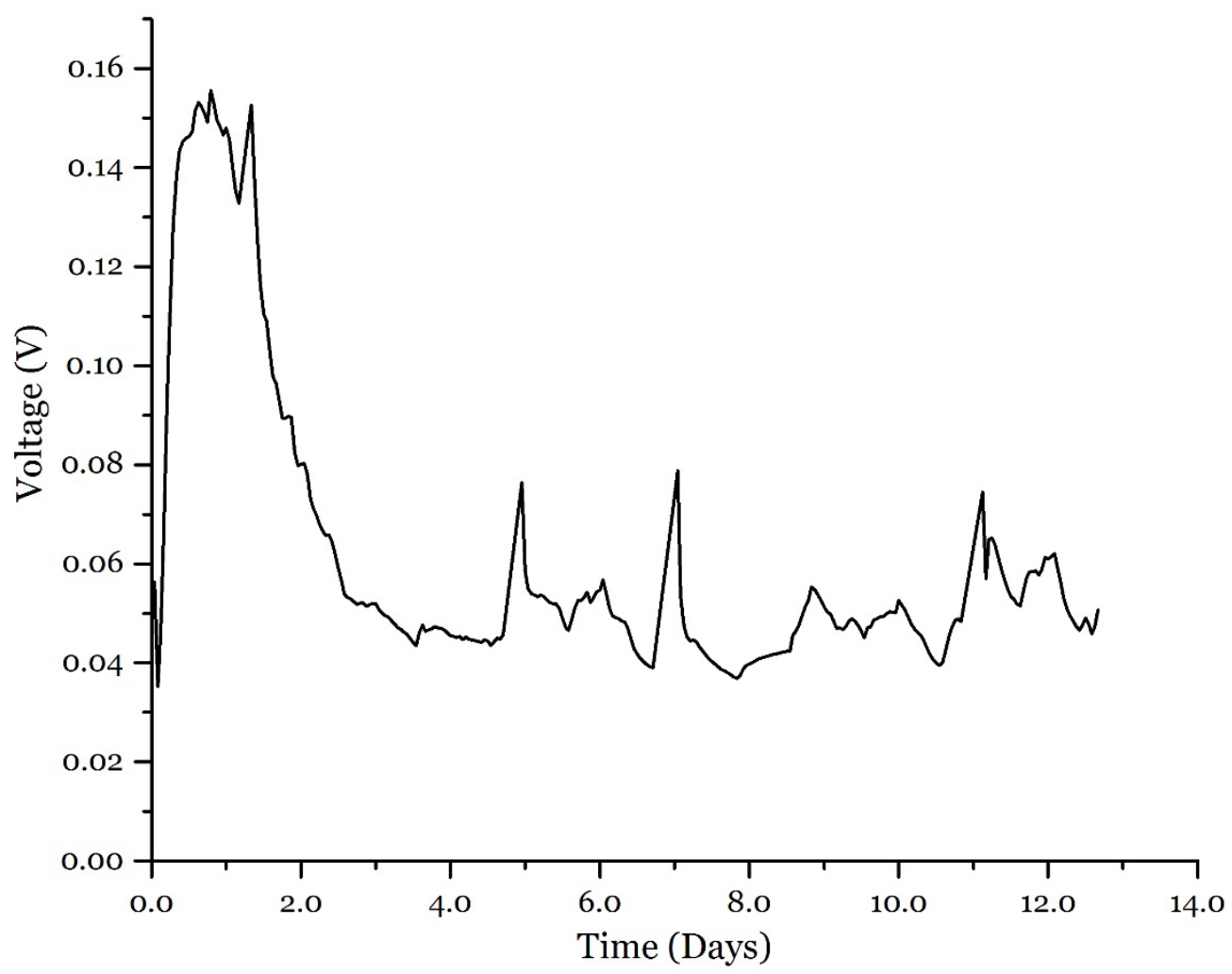

Figure 4.14: Working MFC voltage during manure feed cycle 1.

Three LSV tests were run on the MFC to measure internal resistance and maximum power density. Similarly to the working voltage data for manure feed cycle 1, performance peaked very early, and subsequently dropped off to a lower quasi-steady state performance. The performance of the MFC under peak conditions was lower for manure feed cycle 1 than for acetate feed cycle 3. Polarization curves and power curves for all LSV tests are shown in Figure 4.15 and Figure 4.16, respectively. A summary of the key values obtained from the LSV tests can be found in Table 4.4.

On day 6 of manure feed cycle 1, the LSV test was run both in forward and reverse modes. From Table 4.4 it can be seen that $\mathrm{R}_{\text {int }}$ for the forward test was $314 \Omega$. The reverse test resulted in a $\mathrm{R}_{\text {int }}$ of $298 \Omega$, which was fairly similar to the forward results, indicating relatively stable MFC operation. 
Table 4.4: Summary of electrochemical performance of the MFC from LSV tests on days 2, 6, and 12 of manure feed cycle 1.

\begin{tabular}{|c|c|c|c|c|}
\hline $\begin{array}{c}\text { Days (since } \\
\text { start of cycle) }\end{array}$ & $\operatorname{OCV}(\mathrm{V})$ & $\mathbf{R}_{\text {int }}(\Omega)$ & $\underset{\left(W / \mathbf{m}^{3}\right)}{\operatorname{Maximum}} P_{v}$ & $\begin{array}{l}\operatorname{Maximum} P_{C a} \\
\left(\mathbf{m W} / \mathbf{m}^{2}\right)\end{array}$ \\
\hline 2 & 0.655 & 260 & 0.402 & 23.85 \\
\hline 6 & 0.477 & 314 & 0.164 & 9.73 \\
\hline 12 & 0.433 & 316 & 0.143 & 8.48 \\
\hline
\end{tabular}

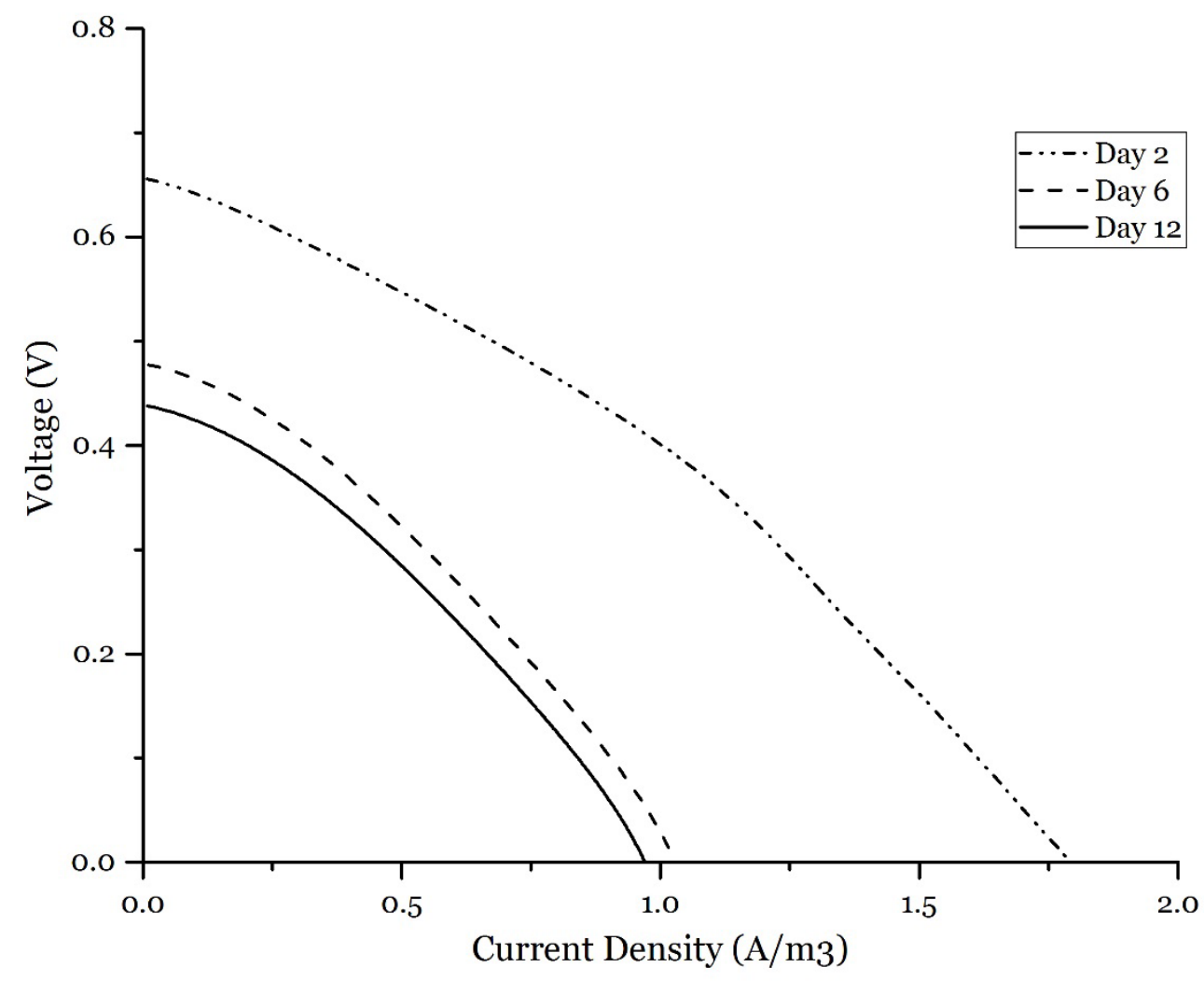

Figure 4.15: Polarization curves from LSV tests on days 2, 6, and 12 of manure feed cycle 1. 


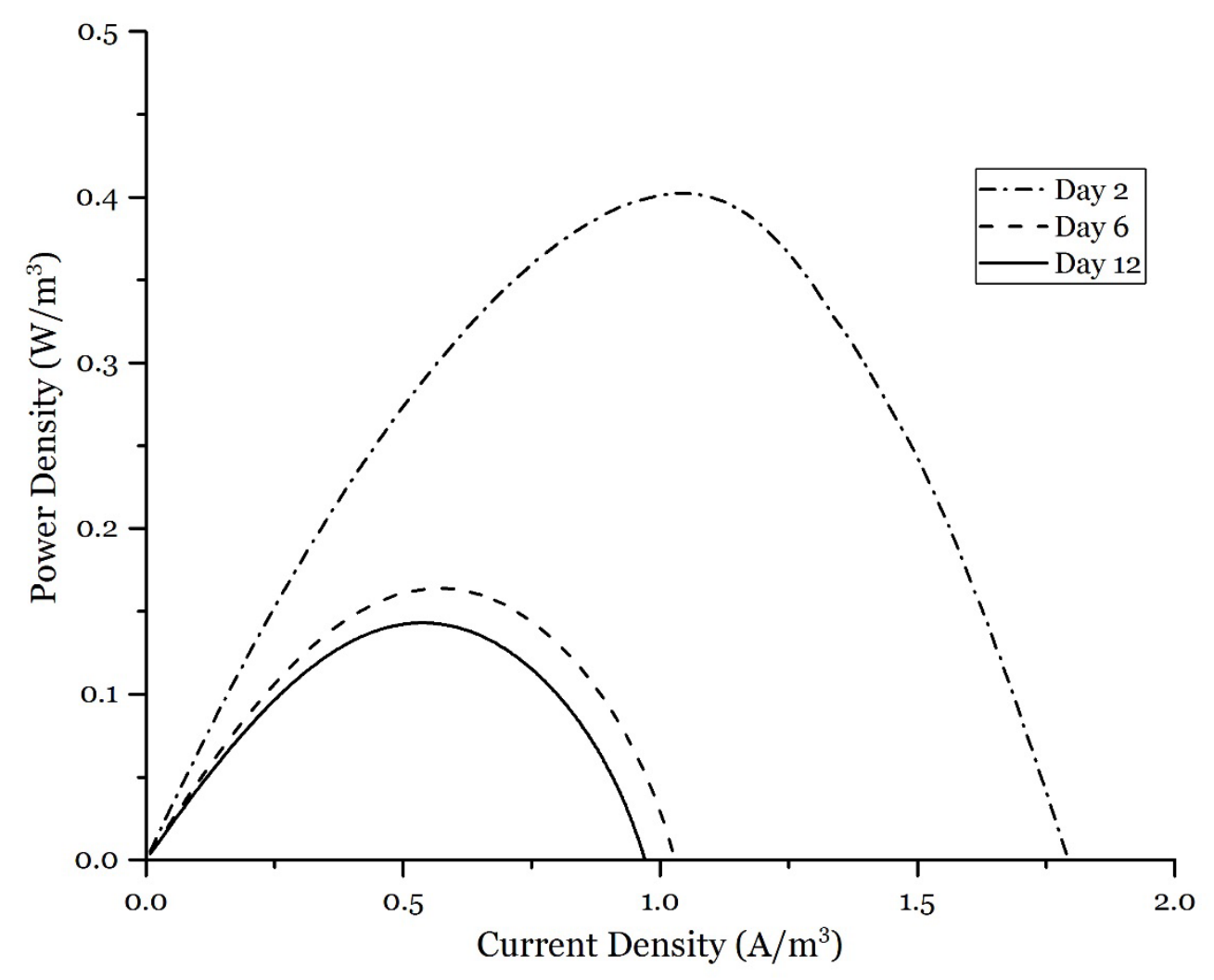

Figure 4.16: Power curves from LSV tests on days 2, 6, and 12 of manure feed cycle 1.

An EIS test was run on the MFC on day 8 of manure feed cycle 1. Figure 4.17 shows the Nyquist plot from the EIS data. From the Nyquist plot, ohmic resistance was determined to be $47.8 \Omega$ (Figure $4.17 \mathrm{~A}$ ) and charge transfer resistance was found to be $11 \Omega$ (Figure 4.17 B). Diffusion resistance and other internal resistances were found to be $255.2 \Omega$ from subtracting ohmic and charge transfer resistance from $\mathrm{R}_{\text {int }}$ on day 6 of manure feed cycle $1(314 \Omega)$. 

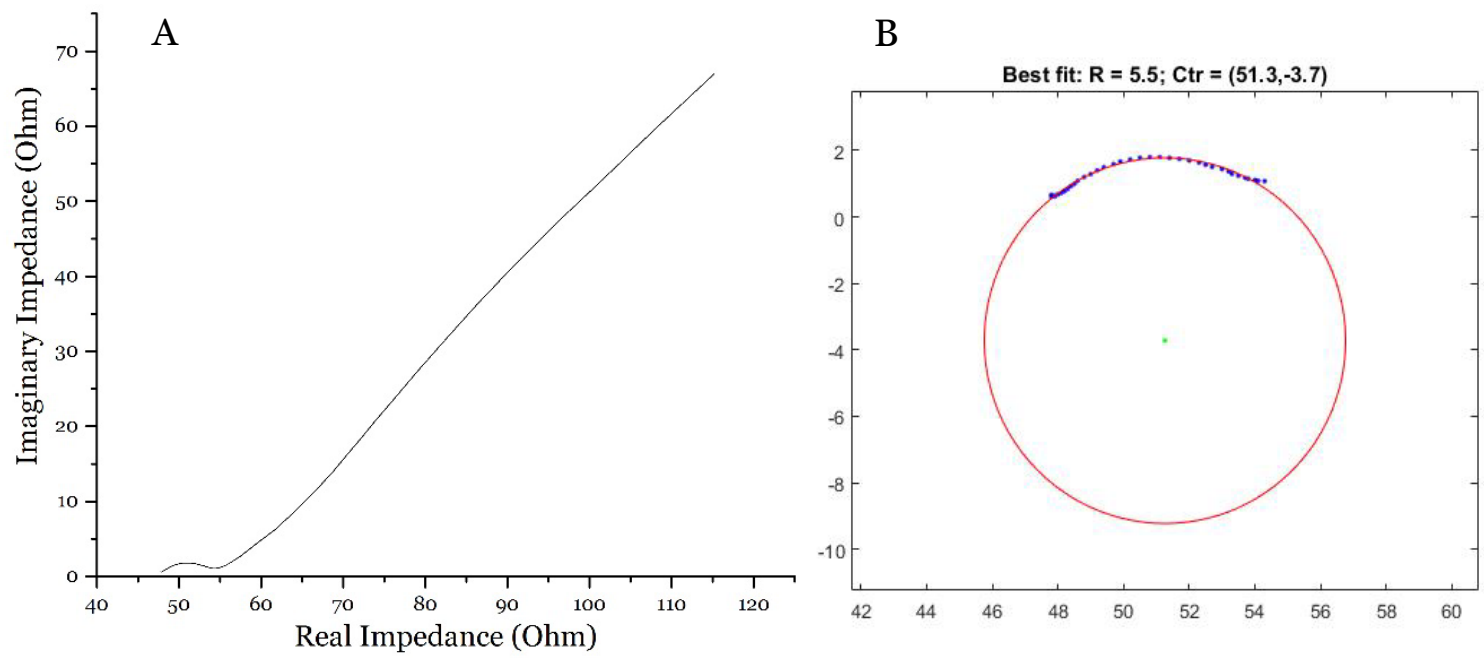

Figure 4.17: A. Nyquist Plot from EIS test of manure feed cycle 1 on day 8. B. Circle fit of Nyquist plot to estimate charge transfer resistance.

\subsubsection{Electrochemical Performance During Manure Feed Cycle 2}

After manure feed cycle 1, a manure feed cycle 2 was initiated with a fresh batch of $\mathrm{O}_{2}{ }^{-}$ depleted $1 \%$ diluted manure prepared with DI water. The working voltage data obtained during this cycle are shown in Figure 4.18. The MFC voltage initially rose rapidly, peaked at $0.17 \mathrm{~V}$ and then dropped off, similar to the initial pattern observed in manure feed cycle 1 . However, in general, the voltage was higher and much more variable in manure feed cycle 2 than in cycle 1 after the peak voltage was reached. Voltage variations due to laboratory temperature were also seen in manure feed cycle 2 , similar to those seen in manure feed cycle 1. 


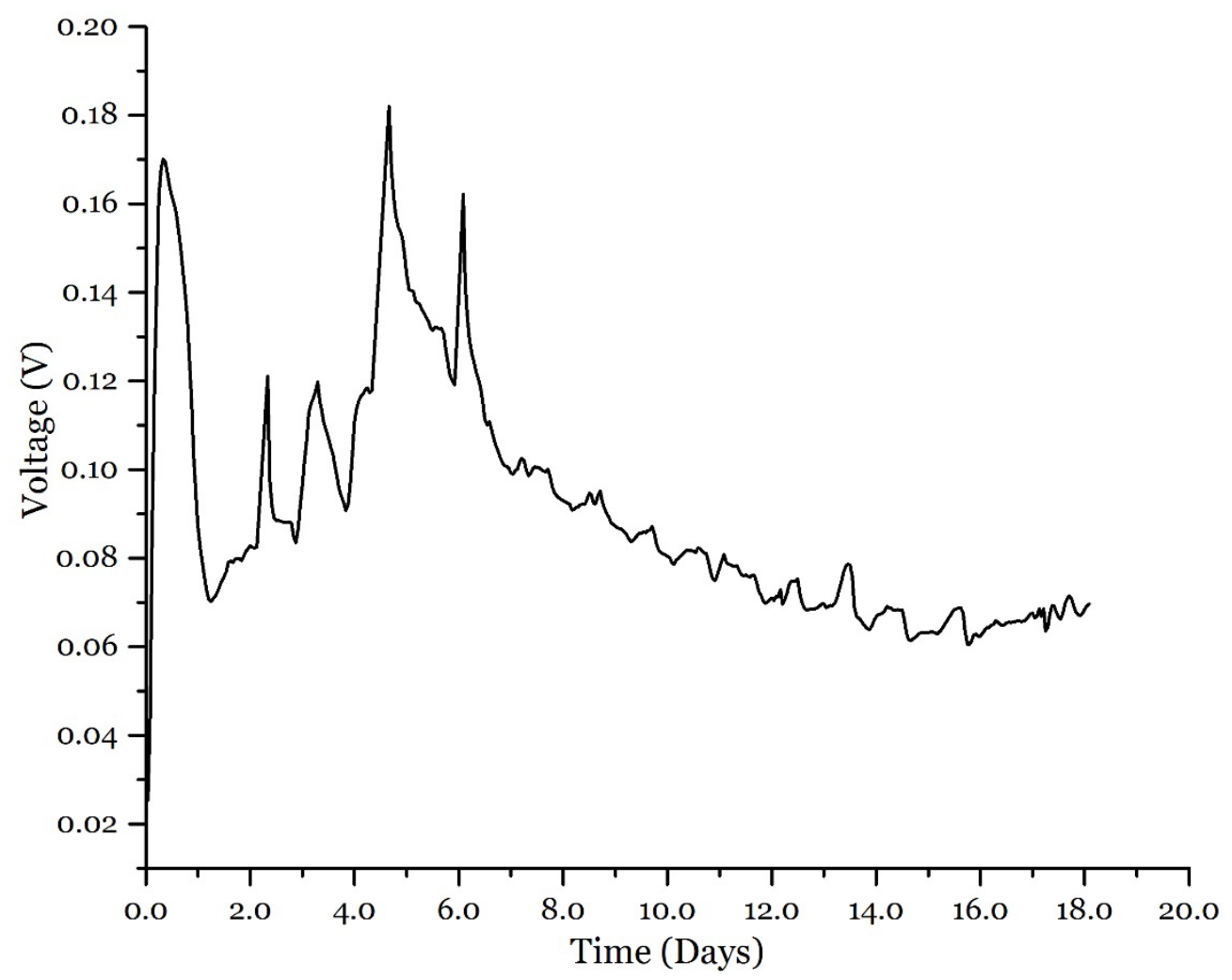

Figure 4.18: Working voltage of MFC during manure feed cycle 2.

LSV tests were run on the MFC on days 3, 7, and 12 of manure feed cycle 2. A summary of the LSV test results can be found in Table 4.5 and the polarization and power curves (Figure 4.19 and Figure 4.20, respectively). A reverse LSV test was also run on day 3. A $R_{\text {int }}$ of $399 \Omega$ was measured with the reverse test, compared to $349 \Omega$ for the forward test. The discrepancy in results could be due to the fluctuations in the working voltage at the time.

Table 4.5: Summary of electrochemical performance from manure feed cycle 2 LSV tests

\begin{tabular}{|c|c|c|c|c|}
\hline $\begin{array}{c}\text { Days (since } \\
\text { start of cycle) }\end{array}$ & $\operatorname{OCV}(\mathrm{V})$ & $\mathbf{R}_{\text {int }}(\boldsymbol{\Omega})$ & $\underset{\left(W / \mathbf{m}^{3}\right)}{\operatorname{Maximum}} P_{v}$ & $\begin{array}{l}\operatorname{Maximum} P_{\mathrm{Ca}} \\
\left(\mathrm{mW} / \mathrm{m}^{2}\right)\end{array}$ \\
\hline 3 & 0.567 & 349 & 0.195 & 11.5 \\
\hline 7 & 0.604 & 273 & 0.272 & 16.1 \\
\hline 12 & 0.523 & 342 & 0.180 & 10.7 \\
\hline
\end{tabular}




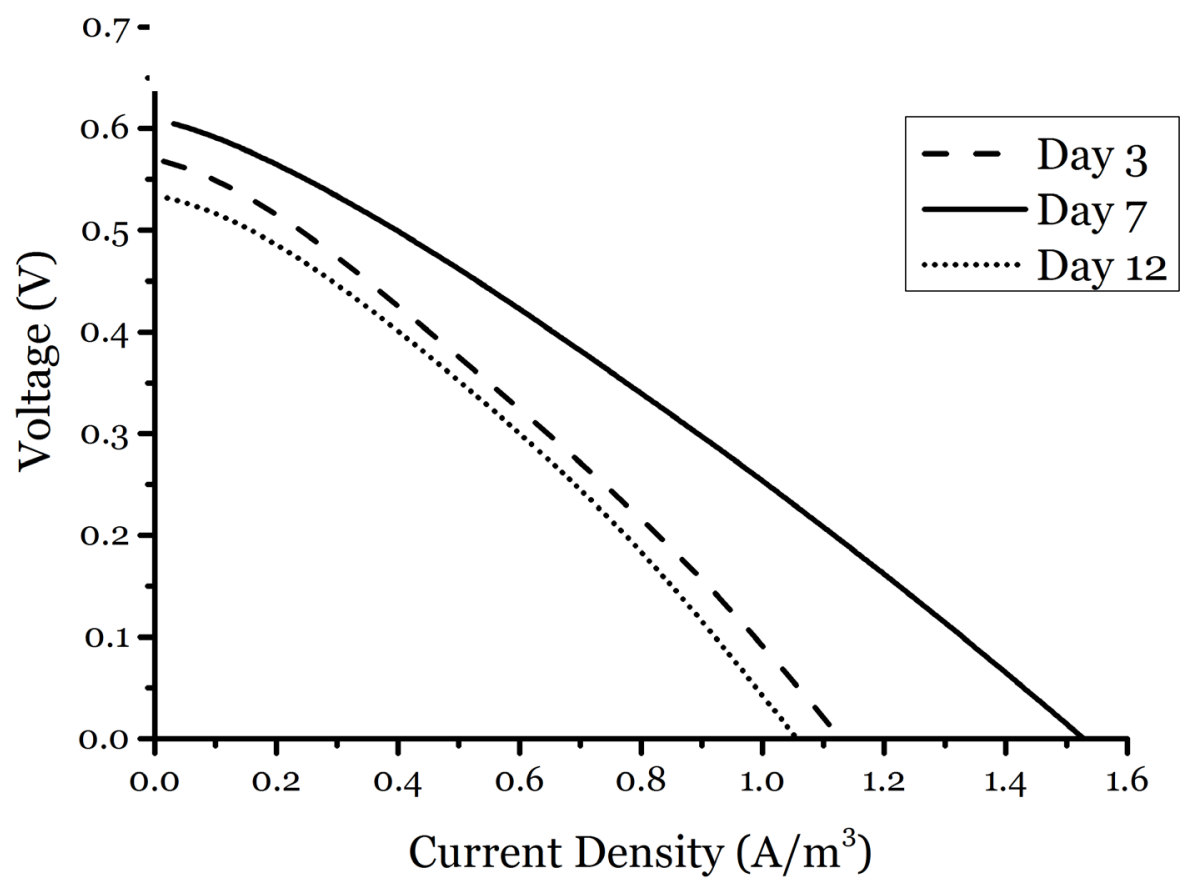

Figure 4.19: Polarization curves from LSV tests on days 3 and 7 of manure feed cycle 2.

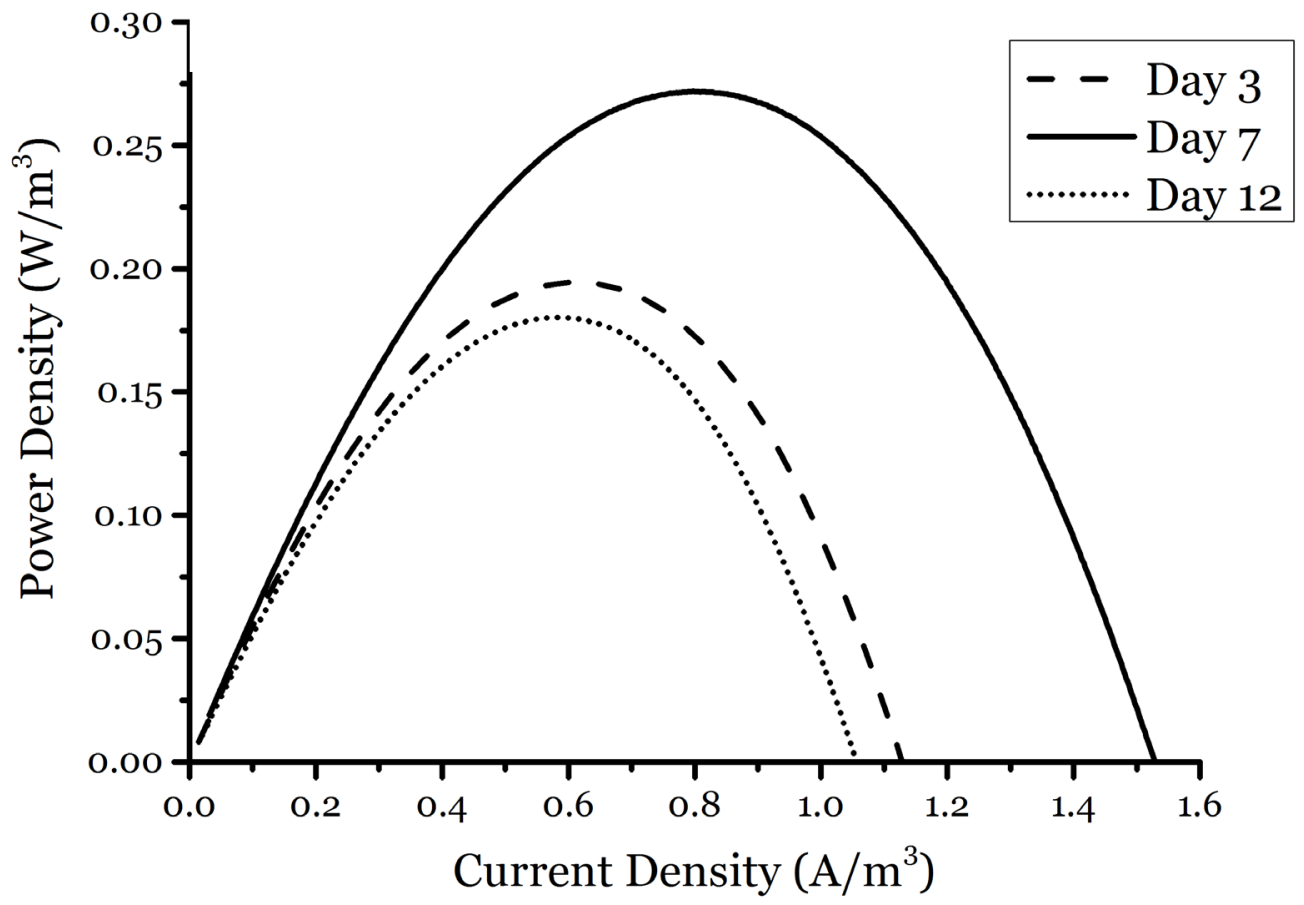

Figure 4.20: Power curves from LSV tests on days 3 and 7 of manure feed cycle 2. 
An EIS test was run on the MFC on day 5 of manure feed cycle 2, yielding a Nyquist plot (Figure $4.21 \mathrm{~A}$ ). From the Nyquist plot, ohmic resistance was determined to be $54.5 \Omega$ and charge transfer resistance was found to be $16 \Omega$ (Figure 4.21 B). Diffusion resistance was found to be $278.6 \Omega$ from $R_{\text {int }}$ on day 3 of manure feed cycle $2(349 \Omega$ ) minus ohmic and charge transfer resistances.
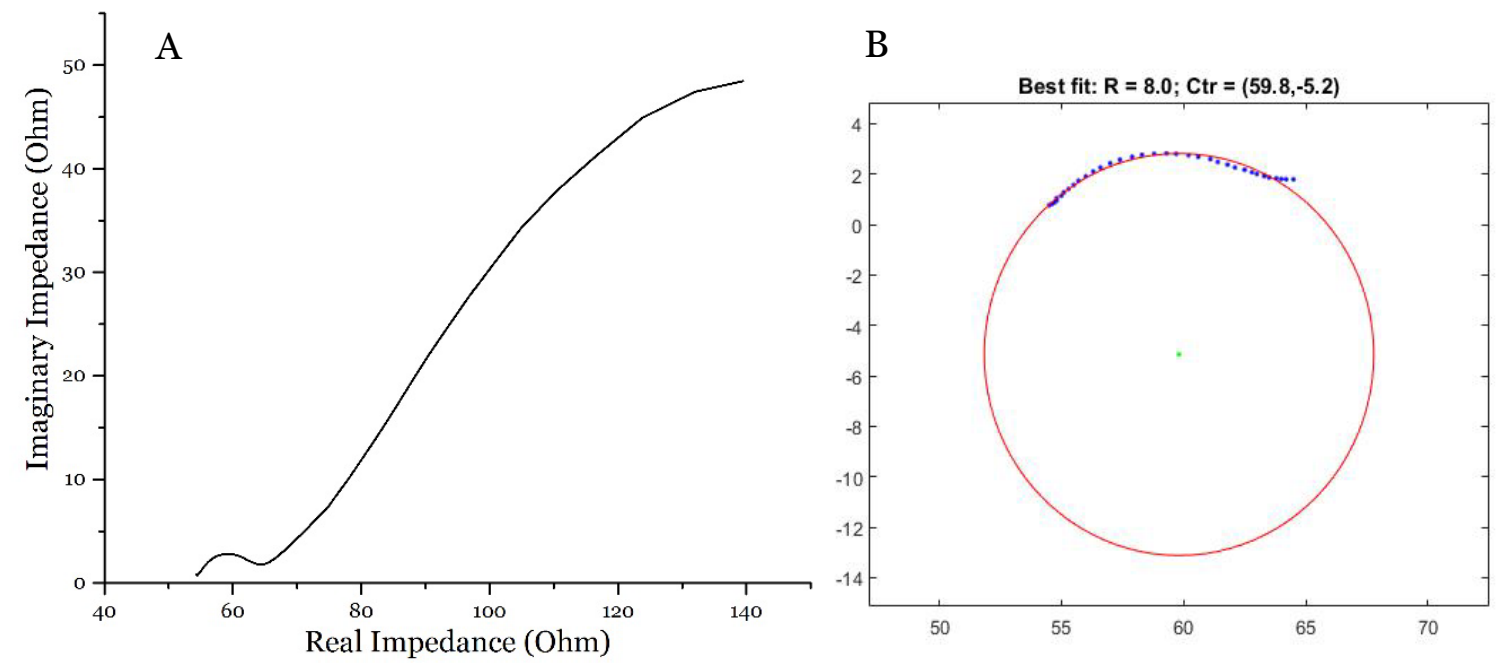

Figure 4.21: A. Nyquist plot from the EIS test on manure feed cycle 2. B. Circle fit of semicircle from Nyquist plot to determine charge transfer resistance.

\subsubsection{Summary of Electrochemical Performance}

The OCV, $\mathrm{R}_{\text {int }}$, and maximum power densities from the last day of operation for each feed cycle are summarized in Table 4.6.

Table 4.6: Summary of MFC electrochemical performance at the end of operation for each feed cycle

\begin{tabular}{|c|c|c|c|c|c|}
\hline MFC Cycle & $\begin{array}{c}\text { Days (since } \\
\text { beginning of } \\
\text { startup phase) }\end{array}$ & $\begin{array}{c}\text { OCV } \\
(\mathbf{V})\end{array}$ & $\begin{array}{c}\mathbf{R}_{\text {int }} \\
\mathbf{( \Omega )}\end{array}$ & $\begin{array}{c}\text { Maximum } \\
\mathbf{P}_{\mathbf{V}} \mathbf{( W / \mathbf { m } ^ { 3 } )}\end{array}$ & $\begin{array}{c}\text { Maximum } \\
\mathbf{P}_{\mathbf{C a}} \\
\mathbf{( m W / \mathbf { m } ^ { 2 }} \mathbf{~}\end{array}$ \\
\hline $\begin{array}{c}\text { Startup } \\
\text { Acetate Feed }\end{array}$ & 15 & 0.431 & 150 & 0.228 & 13.5 \\
\hline $\begin{array}{c}\text { Cycle 3 } \\
\text { Manure Feed }\end{array}$ & 40 & 0.690 & 100 & 1.22 & 72.1 \\
\hline $\begin{array}{c}\text { Cycle 1 } \\
\text { Manure Feed } \\
\text { Cycle 2 }\end{array}$ & 64 & 0.433 & 316 & 0.143 & 23.8 \\
\hline
\end{tabular}


From Table 4.6, it is clear that MFC performance (measured as OCV, $\mathrm{R}_{\text {int }}$, and maximum power density) improved considerably between the start-up phase and acetate feed cycle 3. This increase in performance was expected, because the leaking cathode was replaced. Performance decreased when the feed was then switched from acetate to manure. This decrease in performance was also expected, as manure-fed MFCs have been found to have a lower performance than easily consumed substrates such as acetate or glucose-fed MFCs. The lower performance of manure is likely due to several factors: (1) electrochemically active bacteria on the anode have a limited substrate range and use acetate as the primary electron donor. Low concentrations of acetate in the manure indicate that the substrate availability of the manure is low. (2) Manure lacks the optimal mix of nutrients and growth factors that the acetate contains. (3) Acetate is an easily consumed substrate and therefore all constituents are bioavailable. Manure is a more complex substrate and the constituents are not all bioavailable initially, yet they can degrade over time, becoming more bioavailable. (4) The manure dilution was not sparged with $\mathrm{N}_{2}$ gas before being loaded into the MFC, and therefore the manure may not have fully been $\mathrm{O}_{2}$-depleted. Nevertheless, MFC performance measures improved for manure feed cycle 2, relative to manure feed cycle 1. Presumably, this was the result of enrichment of populations that could biodegrade the manure constituents and/or further depletion of oxygen or other alternative electron acceptors.

\subsubsection{MFC Inputs and Operation}

During startup and the acetate and manure feed cycles, the MFC was weighed periodically to determine the amount of substrate lost due to evaporation through the cathode. If necessary, substrate or water could be added to the MFC during operation. This is important because if the level of substrate in the anode compartment gets too low, air can penetrate the anode, resulting in a drop in the potential between the anode and cathode and cessation of current. As previously discussed, during startup, the cathode was very leaky, and the feed solution had to be replenished every one or two days during this period. After replacing the cathode, however, leaking had stopped, and the MFC did not require addition of substrate or water during subsequent cycles (except when a new feed cycle was initiated). For example, during manure feed cycle 1 , only $22 \mathrm{~mL}$ of substrate was lost to evaporation over 13 days of operation. 


\subsubsection{BOD and COD removal}

COD and BOD of the manure feed solutions, and the COD of the acetate feed, were measured before and after treatment in the MFC to determine how much they were reduced (Table 4.7). Note that because acetate is completely biodegradable, the ultimate BOD equals the COD. This information is used to calculate CE (Equation 2.9). A reduction in the $\mathrm{BOD}$ represents a reduction in the available biochemical energy in the manure. Ideally, the BOD of the manure will be reduced significantly, and a high percentage of the biochemical energy will be converted to electrical energy. That is, the $\mathrm{CE}$ will be high. This would mean Tanzanians would derive the maximum benefit of the manure in terms of electricity production, while having a more stable fertilizer product.

Table 4.7: COD values for each MFC batch and COD removal efficiencies

\begin{tabular}{|c|c|c|c|c|c|c|}
\hline \begin{tabular}{|cc} 
& MFC \\
I & Feed \\
n & Cycle
\end{tabular} & $\begin{array}{c}\text { COD } \\
\text { Before } \\
\text { MFC }\end{array}$ & $\begin{array}{l}\text { COD } \\
\text { After } \\
\text { MFC }\end{array}$ & $\begin{array}{c}\text { \% COD } \\
\text { Remov } \\
\text { al }\end{array}$ & $\begin{array}{c}\text { BOD }_{5} \\
\text { Before } \\
\text { MFC }\end{array}$ & $\begin{array}{c}\text { BOD }_{5} \\
\text { After } \\
\text { MFC }\end{array}$ & $\begin{array}{c}\% \mathrm{BOD}_{5} \\
\text { Removal }\end{array}$ \\
\hline Acetate & 854 mg/L & $386 \mathrm{mg} / \mathrm{L}$ & $54.8 \%$ & . & . & . \\
\hline$t^{\text {Manure } 1}$ & $699 \mathrm{mg} / \mathrm{L}$ & $462 \mathrm{mg} / \mathrm{L}$ & $33.9 \%$ & $97 \mathrm{mg} / \mathrm{L}$ & $100 \mathrm{mg} / \mathrm{L}$ & $-3.1 \%$ \\
\hline Manure 2 & $1125 \mathrm{mg} / \mathrm{L}$ & $471 \mathrm{mg} / \mathrm{L}$ & $58.1 \%$ & $109 \mathrm{mg} / \mathrm{L}$ & 96 mg/L & $11.9 \%$ \\
\hline
\end{tabular}

In the current study, a lower percent reduction of acetate was achieved because acetate feed cycle 3 was ended prematurely so that the first manure feed cycle could be initiated. Much higher removal would presumably be achieved if the cycle had been run to completion. Manure feed cycle 1 was ended after the voltage dropped below $40 \mathrm{mV}$; therefore, it was expected that the COD and BOD removal would be higher. In retrospect, the manure contains complex and particulate organic matter that presumably was not mineralized within 13 days. However, at least some of the complex organic matter that was not biodegradable on day o was apparently converted to biodegradable substrates by day 13, which explains why the BOD increased during manure feed cycle 1. A greater BOD removal was seen in manure feed cycle 2, indicating that the biodegradable substrates were able to be reduced more sufficiently than in manure feed cycle 1 . It seems very likely that greater reductions in the COD and BOD would have been observed if manure feed cycles 1 and 2 had run for a longer period of time. 


\subsubsection{Coulombic Efficiencies}

CEs of $6.0 \%, 14.7 \%$, and $13.1 \%$ were calculated for acetate feed cycle 3 and manure feed cycles 1 and 2, respectively, using Equation 2.9. In comparison, the CE of manure feed cycles 1 and 2 fall within the typical range of values reported for manure-fed MFCs (10 20\%) [27, 61, 62], although a CE of $39.8 \%$ has also been reported [62].

These relatively low CE values suggest that electrons derived from oxidation of manure constituents were consumed in the reduction electron acceptors other than the anode. The high $\mathrm{R}_{\text {ext }}$ applied to the MFC during startup and acetate feed cycle 3 could have contributed to the low $\mathrm{CE}$ as well $[131,182]$.

\subsubsection{Volatile Fatty Acids in Manure Slurry Batches}

Samples of the manure slurry batches before and after MFC operation were tested for VFAs. Results are shown in Table 4.8.

Table 4.8: Summary of VFAs in manure slurry batches before and after MFC operation

\begin{tabular}{|c|c|c|}
\hline MFC Feed Cycle & Acetic Acid & Butyric Acid \\
\hline Manure 1 Pre-MFC & $4.72 \mathrm{mg} / \mathrm{L}$ & $33.24 \mathrm{mg} / \mathrm{L}$ \\
\hline Manure 1 Post-MFC & o mg/L & $36.17 \mathrm{mg} / \mathrm{L}$ \\
\hline Manure 2 Pre-MFC & $0 \mathrm{mg} / \mathrm{L}$ & $0 \mathrm{mg} / \mathrm{L}$ \\
\hline Manure 2 Mid-MFC & $45.34 \mathrm{mg} / \mathrm{L}$ & $37.53 \mathrm{mg} / \mathrm{L}$ \\
\hline Manure 2 Post-MFC & $10.88 \mathrm{mg} / \mathrm{L}$ & $41.22 \mathrm{mg} / \mathrm{L}$ \\
\hline
\end{tabular}

Acetic and butyric acids were initially present in the diluted manure used in feed cycle 1. They were undetected in the diluted manure used in feed cycle 2, however 6 days into feed cycle 2, another sample was taken which showed presence of both acetic and butyric acids. The presence of acetic and butyric acids is consistent with previous analyses of cow manure. The VFAs of fresh dairy cattle manure are dominated by acetic acid, but after approximately 10 days of fermentation, the VFAs in cattle manure slurries become dominated by butyric acid $[183,184]$. Thus, it is likely that some fermentation occurred in the manure while it was stored under sealed conditions to deplete $\mathrm{O}_{2}$. After 13 days of MFC operation for manure feed cycle 1 , acetic acid was depleted, but showed an increase in butyric acid. Similarly, after 19 days of manure feed cycle 2, acetic acid significantly decreased and butyric acid concentrations increased. The increase in butyric acid in the 
slurry after manure feed cycles 1 and 2 was expected and presumably was due to fermentation or hydrolysis of the diluted manure in the MFC.

\subsubsection{Fecal Coliform Reduction}

Fecal coliforms are a commonly used indicator of mammalian intestinal pathogens and were quantified in the manure slurries before and after treatment in the MFC. The fecal coliform concentration in the diluted manure prior to treatment in both manure feed cycle 1 and 2 was $2.82 \times 10^{5} \mathrm{MPN} / \mathrm{g}$ dry manure. This value meets the U.S. EPA fecal coliform requirements for Class B wastewater treatment biosolids $\left(<2.0 \times 10^{6} \mathrm{MFN} / \mathrm{g}\right.$ dry solids) [160]. This means that Class B biosolids are considered safe to land-apply to crops that are not consumed directly by humans or grazed, but human access to the land application sites. In contrast, Class A biosolids must have fecal coliform levels of $<1000$ MPN/g dry solids [160]. These biosolids can be land-applied without restrictions on crop production, grazing, or human access. In the U.S., organic farming standards allow application of untreated animal manure on land used for production of: (1) crops not intended for human consumption; (2) vegetable crops up to 120 days prior to harvest (if incorporated into the soil); or (3) vegetable crops like sweet corn for which the edible portion does not touch the soil or receive ground splash up to 90 days prior to harvest (if incorporated into the soil) $[159,161]$. Manure can be applied to vegetables within less than the 120 or 90 day periods only if it is composted at a high temperature $(131-170$ ${ }^{\circ} \mathrm{F}$ ) for 15 days, which will result in fecal coliform levels that meet the Class A biosolids standards. Therefore it would be desirable to achieve fecal coliform levels of $<1000$ MPN/g dry solids following treatment in the MFC.

After 13 days of treatment in manure feed cycle 1 , fecal coliforms were reduced $64.1 \%$ to 1.01X $10^{5} \mathrm{MPN} / \mathrm{g}$ dry manure. Although this is a significant reduction, clearly the Class A biosolids standard for fecal coliforms was not achieved, presumably because the manure was treated for such a short time. Based on the oxygen demand measurements, it appears that longer treatment times would be desirable for individual manure feed cycles. This should also result in greater fecal coliform reductions.

\subsubsection{Methane Production}

Methane masses of $24 \mu \mathrm{mol}$ and $13 \mu \mathrm{mol}$ were measured in the MFC headspace at the end of manure feed cycles 1 and 2, respectively. Xiao et al. [185] studied the effects of methane production on MFC performance and found that their MFCs were producing 
over 13,000 $\mu \mathrm{mol}$ of $\mathrm{CH}_{4}$ in a laboratory-scale MFC. High levels of methane production in an MFC indicates that the bacteria are using another electron acceptor instead of the anode respiring bacteria [67], which lowers the CE. The small percentage of BOD converted to methane in the current study indicates that methane production was not a major factor affecting CE. 


\section{Chapter 5: Discussion}

\subsection{MFC Fabrication Feasibility in Tanzania}

Constructing the MFC took several iterations over several months. As previously discussed, the cathode was replaced due to excessive leaking, and several different brands of silicone were used before finding one that would hold a seal on the cathode. All of these iterations were made within the laboratory and with a variety of available materials. For this design of MFC to be fabricated in Tanzania, a more efficient and robust fabrication technique must be established. Logistically, it would not be possible to fabricate the tubular air cathode MFC design used in this study completely in Tanzania with only locally available materials. The carbon cloth cathode and graphite fiber brush anode specifically would have to be imported, and ideally pre-treated.

The cost of this MFC would also be prohibitive to widespread adoption in Tanzania. Previous research has shown that it is currently not feasible to achieve adequate performance with low-cost MFCs. Therefore, the scope of this study was limited to evaluating the feasibility of a MFC that could be used in the household, rather than developing a design that uses low-cost, locally available materials. Thus, for this study, it was assumed that the cost of MFCs would decrease over time, and that in the meantime, local NGOs could help offset the cost of MFCs, as has been the case with solar lights. A market study with MFCs in Tanzania would have to be conducted to evaluate the marketability of MFCs in Tanzania and the willingness of Tanzanians to pay for MFCs.

\subsection{Operation of MFCs in Tanzania}

This study showed that there are several advantages and disadvantages to the household MFC for potential use in Tanzania. Advantages include the following: (1) Minimal water/substrate loss occurred with the improved cathode, and therefore it was unnecessary to periodically add water or additional substrate, except at the end of a cycle. (2) The complex organic substrate in manure is converted gradually, meaning a single loading of diluted manure may be used to operate a MFC for an extended amount of time. (3) Treatment of manure in MFCs reduces the abundance of intestinal pathogens (as indicated by the reduction in fecal coliform indicator organisms), and it may be possible to optimize this pathogen reduction benefit in the future. Disadvantages include 
(1) the long startup time for MFCs, (2) voltage variations with changes in temperature, and (3) troubleshooting MFC issues in Tanzania.

The relatively long startup time for MFCs may be a hindrance for use in Tanzania. For this study, the startup time was reduced by using a large external resistance and acetate as the fuel source, although the electrochemically active bacteria needed time to reacclimate after the cathode replacement and the initial feeding of manure. If the MFC were to be operated in Tanzania, this startup time could be similar to that of this study if communities worked together to have a "mother" MFC that would produce effluent feed for the startup phase of new MFCs. Community organized MFC operation could allow for several MFCs to be in the startup phase at a time, which could decrease the waiting time for households to start using a fully operational MFC.

The temperature variations seen in manure feed cycles 1 and 2 (Figure 4.14 and Figure 4.18) were relatively small (only approximately $0.01 \mathrm{~V}$ ), yet the temperature within the laboratory varied within several degrees Centigrade. If the MFC prototype was to be used in the Hanan'g district, where temperature ranges from 10 to $25^{\circ} \mathrm{C}$, voltage variations would be expected to be much more pronounced $[168,186]$. During the cool season as well as during nighttime, the MFC performance would expect to drop and produce less electricity [186]. Using an energy harvesting system with a super capacitor in conjunction with an MFC would reduce issues in voltage fluctuations by storing the energy for later use. However, if voltage fluctuations were much more pronounced and MFC voltage dropped below the threshold for operating the energy harvesting system, there could be further concerns.

Troubleshooting MFC issues in Tanzania could also be a concern. Those using the MFCs in the household would need to be informed about how to handle various issues that can become a problem with MFC operation. For example, voltage drops during MFC operation can indicate a number of things, including increased methane production, oxygen permeation into the anode chamber, or depleted substrate. Without the ability to determine the reason for the voltage drop, it would be difficult to know what steps to take. The need for troubleshooting was greatly reduced in this study after replacing the original cathode with the improved cathode, however technical troubleshooting is expected to be needed when a new technology is introduced into the household. 


\subsection{Acceptance of MFCs in Tanzania}

The interviews conducted indicate that Tanzanians in the Hanan'g District would be open to using MFCs as an electricity source. Many Tanzanians interviewed were discontent with their lack of electricity or with the poor TANESCO service and were looking for alternative options for electricity in their homes. Many also were using solar lights at home, but were interested in an electricity source that was not dependent on the sun. In this set of circumstances, it could be possible to introduce a new electricity technology to the Tanzanians in the area.

In the interviews and in discussions outside of the interviews, the residents of the area clearly expressed interest in this new technology. From the interviews, it was also found that people in the area are very open to using manure for an electricity source and are very comfortable using manure. This openness to the use of manure for electricity indicates that MFCs could be accepted in households in the Hanan'g District. However, in the interviews, the informants expressed concerns about the MFC's cleanliness if they were to be used in the home, as well as concerns about safety of the wiring of MFCs, due to previous issues with unsafe electrical wiring. These concerns would need to be addressed in any further iterations of MFC design for use in the Hanan'g district.

The reduction of fecal coliforms in the manure slurry after MFC operation also shows that the manure slurry could more be used more safely as a fertilizer than before MFC operation. All Tanzanians interviewed for this study reported using manure for fertilizer, and many expressed concern about the use of MFCs because of their need for manure as a fertilizer. Fecal coliform reduction from MFC operation has an additional benefit to those unloading the diluted manure from the MFC. Fecal coliforms are present in the manure when it is loaded into the MFC, and is therefore unsafe to handle with bare hands. After MFC operation, however, the diluted manure in the MFC is much less of a safety hazard due to the reduced fecal coliforms. Therefore, there are minimal safety issues with manure use in the household MFCs. 


\section{Chapter 6: Recommendations for Future Work}

The scope of this study was limited to the relatively small Hanan'g District of Tanzania. The views and attitudes of local residents of the Hanan'g District may not be representative of Tanzania as a whole. In order to get a better view of the views of Tanzanians in general, a larger study would have to be conducted with a greater number of interview participants, in other parts of Tanzania and with other ethnic groups within Tanzania. In addition, it would be beneficial for another Peace Corps Master's International student at MTU to conduct a similar study outside of Tanzania to see how the household MFC design could be adapted for use in a different country and culture.

Additionally, to better understand if MFCs would be successful in the free market in Tanzania, and to determine a price that Tanzanians would be willing to pay for an MFC, a market study would have to be conducted. Materials availability and manufacturability would need to be explored as well. Any materials that are not available able to be manufactured in Tanzania would need to be imported and/or manufactured elsewhere, raising the cost of the MFC. Not all materials in the MFC prototype from this study would be able to be found or manufactured in Tanzania, therefore it would be beneficial to further examine the supply chain for the MFC materials. Improving the supply chain for MFCs could help to make them more cost-effective in the future.

The technical scope of the study was also very limited. To better understand the inputs needed to run the household MFC with manure for a long period of time, a much longer study would have to be conducted. This study did not operate the feed cycles for a long enough time to see the substrate be completely utilized. A longer study would be able to encompass several feed cycles from substrate loading to substrate depletion, and would be able to get more accurate results than this short-term study for the long-term working voltage measurements, $\mathrm{CE}$, and fecal coliform reduction.

It is also recommended that this study be continued by local development workers in the Hanan'g district. Local missionaries doing development work around Katesh town as well as development workers from the Hanan'g district office in Katesh could work alongside students at Michigan Technological University to allow for improvements in the MFC design in the laboratory that are motivated by responses from local Tanzanians in the district. It is important that the development workers who would be conducting 
further interviews in the Hanan'g district be very familiar with Tanzanian and American cultures and be able to commit to being in the Hanan'g district and interacting with local Tanzanians throughout the area for several years in order to fully establish trust with the locals. 


\section{Chapter 7: Conclusions}

The overall purpose of this study was to determine if MFCs could be culturally and technically feasible for use as an electricity source in the Hanan'g district of Tanzania. There are many viable technologies for electricity generation in rural areas in developing countries, and each household's needs and values are unique. Therefore, this feasibility assessment was meant primarily to determine if further studies should be conducted on MFCs for use in developing countries in general and in the Hanan'g district in particular, but not to prescribe MFCs as a solution to the electricity issues experienced in Tanzania.

Lack of reliable electricity and light sources in the household is an issue in the Hanan'g district of Tanzania, especially for families with children in school. Although many urban households have grid electricity, there are frequent and unexpected power cuts. For the many urban households and the majority of rural households without any grid electricity, small solar lights and expensive gas lamps provide inadequate light for the whole family. General discontent among residents in the Hanan'g district with the current electricity situation creates an opportunity for the introduction of new electricity generation technologies such as MFCs. Hanan'g district residents expressed interest in using MFCs and expressed openness in using cattle manure as a fuel source for MFCs. Similarly to rechargeable solar lights, which were subsidized by NGOs in the area and adopted by Tanzanians in Hanan'g, MFCs have the potential to be adopted in the area, provided they are made affordable. Additionally, before being accepted within Hanan'g residents' homes, the MFC design should be improved to eliminate any safety risks with electrical wiring and any uncleanliness associated with loading and unloading the MFC with cattle manure.

The household MFC built and operated for this study was able to produce electricity with manure as a fuel and minimal maintenance of the MFC was necessary after an improved cathode was used. The working voltage of the MFC through the manure feed cycles averaged to approximately $0.08 \mathrm{~V}$, which is lower than the necessary voltage to operate an energy harvesting system. However, subsequent manure feed cycles showed an increase in working voltage, therefore it can be assumed that the MFC prototype would have been able to reach the necessary minimum voltage after operating for several feed cycles. Useable power output would also increase with an increase in working voltage. Therefore, MFCs were found to be technically feasible to be used in conjunction with an 
energy harvesting system for small-scale electricity generation in the Hanan'g district, especially in the rural areas that are not yet connected to TANESCO's electric grid. MFCs connected with an energy harvesting system could most likely provide the necessary voltage and power to light a small light or charge a small mobile phone. However, before MFCs could be made for use in these rural areas of Tanzania, their fabrication and operation must become simpler, less time consuming, and more reliable.

Significant fecal coliform reduction in the cattle manure fuel source was also observed in the MFC prototype in this study. In the first 13 day feed cycle, $64 \%$ reduction was observed and in the second 19 day feed cycle, over a 93\% reduction was observed. It is expected that with a longer operating time, the fecal coliform reduction would further increase. The reduction in fecal coliforms in the cattle manure indicates that the manure would be much safer to handle after being used for fuel in the MFC than it is without any treatment. After treatment with the MFC, the cattle manure would also be a safer alternative for use as a fertilizer on crops, as the manure fertilizer characteristics stay intact through MFC operation. A safer fertilizer can lower the incidence of crop contamination with fecal coliforms, and therefore can lower risk of illness from contaminated crops.

All of the findings in this study indicate that further studies should be conducted on MFCs in the Hanan'g district of Tanzania in order to gain more information from the residents about how MFCs would be perceived and if they would be fully accepted in the household. The findings also indicate that further studies should be conducted in other districts of Tanzania and other developing countries to determine if the data from this study can be applied outside of the study area. 


\section{Chapter 8: References}

1. Barnes, D.F., The challenge of rural electrification : strategies for developing countries. 1st ed. 2007, Washington, DC: Resources for the Future : Energy Sector Management Assistance Program. xvii, 345 p.

2. Nielsen, L., Classifications of countries based on their level of development: How it is done and how it could be done. IMF Working Papers, 2011: p. 1-45.

3. Office, T.V.P.s., National Report for the United Nations Conference on Sustainable Development, Rio+20. 2012, United Republic of Tanzania, Vice President's Office, Division of Environment: Dar es Salaam, Tanzania.

4. Basic Demographic and Socio-Economic Profile Statistical Tables. 2014, National Bureau of Statistics, Tanzanian Ministry of Finance and: Dar es Salaam, Tanzania.

5. Bank, T.W. Access to Electricity (\% of Population). 2015; Available from: http://data.worldbank.org/indicator/EG.ELC.ACCS.ZS.

6. USAID, Tanzania: Country Development Cooperation Strategy - October 3, 2014 October 3, 2019. 2014, United States Agency for International Development.

7. Wedgewood, R. Education and Poverty Reduction in Tanzania. in UKFIET International Conference on Education and Development (8th). 2005. Oxford: HakiElimu.

8. Pre-Primary, Primary, and Secondary Education Statistics. 2014, United Repbulic of Tanzania Ministry of Education and Vocational Training: Dodoma, Tanzania.

9. TheWorldBank. GNI per capita, Atlas method (current US\$). Data: Economy \& Growth 2015; Available from:

http://data.worldbank.org/indicator/NY.GNP.PCAP.CD/countries/TZ-ZFXM?display=graph.

10. The World Factbook: Tanzania. U.S. Central Intelligence Agency Online Library, 2015.

11. Eggleston, C.M., et al., Binding and direct electrochemistry of OmcA, an outer-membrane cytochrome from an iron reducing bacterium, with oxide electrodes: A candidate biofuel cell system. Inorganica Chimica Acta, 2008. 361(3): p. 769-777.

12. Assembly, U.N.G., Open Working Group Proposal for Sustainable Development Goals. 2014, Open Working Group of the General Assembly on Sustainable Development Goals.

13. Ahlborg, H. and L. Hammar, Drivers and barriers to rural electrification in Tanzania and Mozambique-Grid-extension, off-grid, and renewable energy technologies. Renewable Energy, 2014. 61: p. 117-124.

14. Akella, A., R. Saini, and M.P. Sharma, Social, economical and environmental impacts of renewable energy systems. Renewable Energy, 2009. 34(2): p. 390-396.

15. Africa, L. Lighting Africa: Catalyzing markets for modern off-grid lighting. 2015; Available from: https://www.lightingafrica.org/.

16. SolarAid. Tanzania Country Report 2014: SolarAid Report of SunnyMoney activity in Tanzania. 2014; Available from: http://www.solar-

aid.org/assets/Uploads/Publications/Tanzania-report-2014-FINAL-web.pdf.

17. Bond, D.R. and D.R. Lovley, Electricity production by Geobacter sulfurreducens attached to electrodes. Applied and Environmental Microbiology, 2003. 69(3): p. 1548-1555.

18. Kim, H.J., et al., A mediator-less microbial fuel cell using a metal reducing bacterium, Shewanella putrefaciense. Enzyme and Microbial Technology, 2002. 30(2): p. 145-152.

19. Wingard, L.B., C.H. Shaw, and J.F. Castner, Bioelectrochemical fuel-cells. Enzyme and Microbial Technology, 1982. 4(3): p. 137-142. 
20. Logan, B.E., et al., Microbial Fuel Cells: Methodology and Technology. Environmental Science \& Technology, 2006. 40(17): p. 5181-5192.

21. Logan, B.E., et al., Electricity generation from cysteine in a microbial fuel cell. Water Research, 2005. 39(5): p. 942-952.

22. Cheng, S., H. Liu, and B.E. Logan, Increased power generation in a continuous flow MFC with advective flow through the porous anode and reduced electrode spacing. Environmental Science \& Technology, 2006. 40(7): p. 2426-2432.

23. Cheng, S., H. Liu, and B.E. Logan, Increased performance of single-chamber microbial fuel cells using an improved cathode structure. Electrochemistry Communications, 2006. 8: p. 489-494.

24. Liu, H., S.A. Cheng, and B.E. Logan, Production of electricity from acetate or butyrate using a single-chamber microbial fuel cell. Environmental Science \& Technology, 2005. 39(2): p. 658-662.

25. Bond, D.R., et al., Electrode-reducing microorganisms that harvest energy from marine sediments. Science, 2002. 295(5554): p. 483-485.

26. Liu, H., R. Ramnarayanan, and B.E. Logan, Production of electricity during wastewater treatment using a single chamber microbial fuel cell. Environmental Science \& Technology, 2004. 38(7): p. 2281-2285.

27. Kiely, P.D., et al., Anode microbial communities produced by changing from microbial fuel cell to microbial electrolysis cell operation using two different wastewaters. Bioresource Technology, 2011. 102: p. 388-394.

28. Feng, Y., et al., Brewery wastewater treatment using air-cathode microbial fuel cells. Applied Microbiology and Biotechnology, 2008. 78(5): p. 873-880.

29. leropoulos, I., J. Greenman, and C. Melhuish, Urine utilisation by microbial fuel cells; energy fuel for the future. Physical Chemistry Chemical Physics, 2012. 14(1): p. 94-98.

30. Lebone. Dirt Power. Available from: http://www.dirtpower.org/.

31. Aiden, A.P., Clean lighting leads to improved health in rural Africa: Field study and design of a dirt-powered generator. 2014, Harvard Medical School.

32. Stafford, W., et al., Technologies for recovery of energy from wastewaters: Applicability and potential in South Africa. Journal of Energy in Southern Africa, 2013. 24(1): p. 15-26.

33. Lawi, Y.Q., May the Spider Blind Witches and Wild Animals: Local Knowledge and the Political Ecology of Natural Resource Use in the Iraqwland, Tanzania, 1900-1985. 2000, Boston University.

34. Nyerere, J.K., Ujamaa: Essays on Socialism. 1968, Dar es Salaam: Oxford University Press.

35. United Nations, T., Development assistance plan: (UNDAP) 2011 - 2015. 2011, Office of the United Nations Resident Coordinator in Tanzania: Dar es Salaam, Tanzania.

36. Elevation of Katesh, Tanzania, in Elevationmap.net: Worldwide elevations. 2015.

37. Snyder, K.A., The Iraqw of Tanzania: Negotiating Rural Development. 2005: Westview Press.

38. Umbu, A., Demographics of Bassotughagn Village, E. Kunik, Editor. 2015.

39. Hando, W., Demographics and History of Endaiswold, E. Kunik, Editor. 2014.

40. Mandoo, P., Demographics and History of Katesh Town, E. Kunik, Editor. 2014.

41. Murphy, J.T., Making the energy transition in rural East Africa: Is leapfrogging an alternative? Technological Forcasting \& Social Change, 2001. 68: p. 173-193. 
42. D.light. d.light S2: The Learning Light. 2015; Available from:

http://www.dlight.com/solar-lighting-products/single-function/dlight-s2/.

43. Kossman, W., Biogas Digest Volume I.". Biogas Basics", Information and Advisory Service on Appropriate Technology, ISAT, GTZ.

44. Liu, W.K., Q.C. Yang, and L.F. Du, Soilless cultivation for high-quality vegetables with biogas manure in China: Feasibility and benefit analysis. Renewable Agriculture and Food Systems, 2009. 24(4): p. 300-307.

45. Sieling, K., et al., Biogas cropping systems: Short term response of yield performance and $N$ use efficiency to biogas residue application. European Journal of Agronomy, 2013. 47: p. 44-54.

46. Svoboda, N., et al., Nitrogen leaching losses after biogas residue application to maize. Soil \& Tillage Research, 2013. 130: p. 69-80.

47. Dimpl, E., Small-scale electricity generation from biomass. GTZ-HERA-Poverty-oriented Basic Energy Service, 2010.

48. Mwirigi, J.W., P.M. Makenzi, and W.O. Ochola, Socio-economic constraints to adoption and sustainability of biogas technology by farmers in Nakuru Districts, Kenya. Energy for Sustainable Development, 2009. 13(2): p. 106-115.

49. Mshandete, A.M. and W. Parawira, Biogas technology research in selected sub-Saharan African countries - A review. African Journal of Biotechnology, 2009. 8(2): p. 116-125.

50. Bond, T. and M.R. Templeton, History and future of domestic biogas plants in the developing world. Energy for Sustainable Development, 2011. 15(4): p. 347-354.

51. Hazeltine, B. and C. Bull, Appropriate Technology: Tools, Choices, and Implications. 1999, San Diego, CA: Academic Press.

52. Wicklein, R.C., Designing for appropriate technology in developing countries. Technology in Society, 1998. 20(3): p. 371-375.

53. Muhongo, S.M., Electricity Supply Industry Reform Strategy and Roadmap. 2014, The United Republic of Tanzania Ministry of Energy and Minerals: Tanzania.

54. Ngowi, D., Tanzania: Seven Killed Due to Illegal Electricity Connection in Kilimanjaro, in Tanzania Daily News. 2014: Dar es Salaam, Tanzania.

55. Malaya, A.N.M., Submission of the Signed Agreement between the Governments of Tanzania and Norway, T.U.R.o.T.M.o. Finance, Editor. 2012: Dar es Salaam.

56. Baera, S., Final agreement on the power project to support the conduct of additional studies on Masigira Hydro Power Project, N.M.o.F. Affaires and Economic, Editors. 2010: Dar es Salaam, Tanzania.

57. Symbion. Electrifying Southern Tanzania. Available from: http://symbionpower.com/marketing/Southern-Electrification-Project-Overview.pdf.

58. About Us: Generation, in Tanzania Electric Supply Company Web Site.

59. ElMekawy, A., et al., Food and agricultural wastes as substrates for bioelectrochemical system (BES): The synchronized recovery of sustainable energy and waste treatment. Food Research International, 2015. 73: p. 213-225.

60. Yokoyama, H., et al., Treatment of cow-waste slurry by a microbial fuel cell and the properties of the treated slurry as a liquid manure. Animal Science Journal, 2006. 77: p. 634-638.

61. Zhang, G., et al., Long-term operation of manure-microbial fuel cell. Biosource Technology, 2015: p. 365-369. 
62. Zhang, G., et al., Biocathode microbial fuel cell for efficient electricity recovery from dairy manure. Biosensors and Bioelectronics, 2012. 31: p. 537-543.

63. Zuo, Y., P.C. Maness, and B.E. Logan, Electricity production from steam-exploded corn stover biomass. Energy \& Fuels, 2006. 20(4): p. 1716-1721.

64. Gregoire, K.P. and J.G. Becker, Design and characterization of a microbial fuel cell for the conversion of a lignocellulosic crop residue to electricity. Bioresource Technology, 2012. 119: p. 208-215.

65. Buitrón, G. and C. Cervantes-Astorga, Performance Evaluation of a Low-Cost Microbial Fuel Cell. Water Air Soil Pollut, 2013.

66. Logan, B.E., Microbial Fuel Cells. 2008, Hoboken, New Jersey: John Wiley \& Sons, Inc.

67. Rabaey, K. and W. Verstraete, Microbial fuel cells: novel biotechnology for energy generation. TRENDS in Biotechnology, 2005. 23: p. 291-298.

68. Chaudhuri, S.K. and D.R. Lovley, Electricity generation by direct oxidation of glucose in mediatorless microbial fuel cells. Nature Biotechnology, 2003. 21(10): p. 1229-1232.

69. DiChristina, T.J. and E.F. Delong, Isolation of anaerobic respiratory mutants of Shewanella putrefaciens and genetic analysis of mutants deficient in anaerobic growth on Fe3+. Journal of Bacteriology, 1994. 176(5): p. 1468-1474.

70. Myers, C.R. and J.M. Myers, Localization of cytochromes to the outer-membrane of anaerobically grown Shewanella putrefaciens MR-1. Journal of Bacteriology, 1992. 174(11): p. 3429-3438.

71. Kim, B.H., et al., Electrochemical activity of an Fe(III)-reducing bacterium, Shewanella putrefaciens $I R-1$, in the presence of alternative electron acceptors. Biotechnology Techniques, 1999. 13(7): p. 475-478.

72. Rabaey, K., et al., Biofuel cells select for microbial consortia that self-mediate electron transfer. Applied Environmental Microbiology, 2004. 70: p. 5373-5382.

73. Logan, B.E. and J.M. Regan, Electricity-producing bacterial communities in microbial fuel cells. TRENDS in Microbiology, 2006. 14(12): p. 512-518.

74. Nealson, K.H. and D. Saffarini, Iron and manganese in anaerobic respiration Environmental significance, physiology, and regulation. Annual Review of Microbiology, 1994. 48: p. 311-343.

75. Oh, S.E., et al., Effects of applied voltages and dissolved oxygen on sustained power generation by microbial fuel cells. Water Science and Technology, 2009. 60(5): p. 13111317.

76. Liu, H. and B.E. Logan, Electricity generation using an air-cathode single chamber microbial fuel cell in the presence and absence of a proton exchange membrane. Environmental Science and Technology, 2004. 38: p. 4040-4046.

77. Emde, R., A. Swain, and B. Schink, Anaerobic Oxidation of Glycerol by Escherichia-Coli in an Amperometric Poised-Potential Culture System. Applied Microbiology and Biotechnology, 1989. 32(2): p. 170-175.

78. Park, D.H. and J.G. Zeikus, Electricity generation in microbial fuel cells using neutral red as an electronophore. Applied and Environmental Microbiology, 2000. 66(4): p. 12921297.

79. Delaney, G.M., et al., Electron-transfer coupling in microbial fuel-cells: 2. Performance of fuel-cells containing selected microorganism mediator substrate combinations. Journal of Chemical Technology and Biotechnology B-Biotechnology, 1984. 34(1): p. 13-27. 
80. Doong, R.A. and B. Schink, Cysteine-mediated reductive dissolution of poorly crystalline iron(III) oxides by Geobacter sulfurreducens. Environmental Science \& Technology, 2002. 36(13): p. 2939-2945.

81. Rabaey, K., et al., Microbial phenazine production enhances electron transfer in biofuel cells. Environmental Science \& Technology, 2005. 39(9): p. 3401-3408.

82. Gorby, Y.A., et al., Electrically conductive bacterial nanowires produced by Shewanella oneidensis strain MR-1 and other microorganisms. Proceedings of the National Academy of Sciences of the United States of America, 2006. 103(30): p. 11358-11363.

83. Turick, C.E., L.S. Tisa, and F. Caccavo, Melanin production and use as a soluble electron shuttle for Fe(III) oxide reduction and as a terminal electron acceptor by Shewanella algae BrY. Applied and Environmental Microbiology, 2002. 68(5): p. 2436-2444.

84. Madigan, M.T., J.M. Martinko, and J. Parker, Brock Biology of Microorganisms. 9th ed. 2000, Upper Saddle River, NJ: Prentice Hall. 991.

85. Pham, T.H., P. Aelterman, and W. Verstraete, Bioanode performance in bioelectrochemical systems: recent improvements and prospects. Trends in Biotechnology, 2009. 27(3): p. 168-178.

86. Holmes, D.E., et al., Microarray and genetic analysis of electron transfer to electrodes in Geobacter sulfurreducens. Environmental Microbiology, 2006. 8(10): p. 1805-1815.

87. Wang, H.M., J.D. Park, and Z.J. Ren, Practical Energy Harvesting for Microbial Fuel Cells: A Review. Environmental Science \& Technology, 2015. 49(6): p. 3267-3277.

88. Park, J.-D. and Z. Ren, Hysteresis-Controller-Based Energy Harvesting Scheme for Microbial Fuel Cells With Parallel Operation Capability. IEEE Transactions on Energy Conversion, 2012. 27(3): p. 715-724.

89. Degrenne, N., et al., Electrical energy generation from a large number of microbial fuel cells operating at maximum power point electrical load. Journal of Power Sources, 2012. 205: p. 188-193.

90. Woodward, L., et al., Comparison of Real-Time Methods for Maximizing Power Output in Microbial Fuel Cells. Aiche Journal, 2010. 56(10): p. 2742-2750.

91. Larminie, J. and A. Dicks, Fuel Cell Systems Explained. 2003: West Sussex, England: John Wiley \& Sons Ltd.

92. Cheng, S. and B.E. Logan, Increasing power generation for scaling up single-chamber air cathode microbial fuel cells. Bioresource Technology, 2011. 102: p. 4468-4473.

93. Scott, K., C. Murano, and G. Rimbi, A tubular microbial fuel cell. Journal of Applied Electrochemistry, 2007. 37: p. 1063-1068.

94. Logan, B., et al., Graphite fiber brush anodes for increased power production in aircathode microbial fuel cells. Environmental science \& technology, 2007. 41(9): p. 33413346.

95. Reimers, C.E., et al., Harvesting energy from the marine sediment-water interface. Environmental Scienc and Technology, 2001. 35\: p. 192-195.

96. Jang, J.K., et al., Construction and operation of a novel mediator-and membrane-less microbial fuel cell. Process Biochemistry, 2004. 39(8): p. 1007-1012.

97. Cheng, S., H. Liu, and B.E. Logan, Power densities using different cathode catalysts (Pt and COTMPP) and polymer binders (Nafion and PTFE) in single chamber microbial fuel cells. Environmental Science and Technology, 2006. 40: p. 364-369.

98. Oh, S., B. Min, and B.E. Logan, Cathode performance as a factor in electricity generation in microbial fuel cells. Environmental Science and Technology, 2004. 38: p. 4900-4904. 
99. Pham, T.H., et al., Improvement of cathode reaction of a mediatorless microbial fuel cell. Journal of Microbiology and Biotechnology, 2004. 14(2): p. 324-329.

100. Santoro, C., et al., Power generation of microbial fuel cells (MFCs) with low cathodic platinum loading. International Journal of Hydrogen Energy, 2013. 38: p. 692-700.

101. Membranes: Nafion, in Fuel Cell Store Web Site. 2015.

102. Min, B., S. Cheng, and B.E. Logan, Electricity generation using membrane and salt bridge microbial fuel cells. Water Research, 2005. 39: p. 1675-1686.

103. Ghadge, A.N. and M.M. Ghangrekar, Performance of low cost scalable air-cathode microbial fuel cell made from clayware separator using multiple electrodes. Biosource Technology, 2015. 182: p. 373-377.

104. Harnisch, F., U. Schroder, and F. Scholz, The suitability of monopolar and bipolar ion exchange membranes as separators for biological fuel cells. Environmental Science \& Technology, 2008. 42(5): p. 1740-1746.

105. Kim, J.R., et al., Power generation using different cation, anion, and ultrafiltration membranes in microbial fuel cells. Environmental Science \& Technology, 2007. 41(3): p. 1004-1009.

106. Mohan, S.V., S.V. Raghavulu, and P.N. Sarma, Biochemical evaluation of bioelectricity production process from anaerobic wastewater treatment in a single chambered microbial fuel cell (MFC) employing glass wool membrane. Biosensors \& Bioelectronics, 2008. 23(9): p. 1326-1332.

107. Dong, H., et al., A novel structure of scalable air-cathode without Nafion and Pt by rolling activated carbon and PTFE as catalyst layer in microbial fuel cells. Water Research, 2012. 46(17): p. 5777-5787.

108. Aldrovandi, A., et al., Sustainable power production in a membrane-less and mediatorless synthetic wastewater microbial fuel cell. Bioresource Technology, 2009. 100(13): p. 3252-3260.

109. Yang, S., B. Jia, and H. Liu, Effects of the Pt loading side and cathode-biofilm on the performance of a membrane-less and single-chamber microbial fuel cell. Bioresource Technology, 2009. 100(3): p. 1197-1202.

110. Li, W.W., et al., Recent advances in the separators for microbial fuel cells. Bioresource Technology, 2011. 102(1): p. 244-252.

111. You, S., et al., A graphite-granule membrane-less tubular air-cathode microbial fuel cell for power generation under continuously operational conditions. Journal of Power Sources, 2007. 173(1): p. 172-177.

112. Logan, B.E. and L.L.a.P. State Frequently asked questions about MFCs and our replies. Pennsylvania State University Web Site.

113. Zhang, F., et al., Mesh optimization for microbial fuel cell cathodes constructed around stainless steel mesh current collectors. Journal of Power Sources, 2011. 196(3): p. 10971102.

114. Zhang, F., et al., Microbial Fuel Cell Cathodes With Poly(dimethylsiloxane) Diffusion Layers Constructed around Stainless Steel Mesh Current Collectors. Environmental Science \& Technology, 2010. 44(4): p. 1490-1495.

115. Logan, B.E., Scaling up microbial fuel cells and other bioelectrochemical systems. Applied microbiology and biotechnology, 2010. 85(6): p. 1665-1671.

116. Evans, U.R., The Corrosion of Metals. 1926: E. Arnold \& Company. 
117. Toolbox, E. Resistivity, Conductivity, and Temperature Coefficients for some Common Materials. Available from: http://www.engineeringtoolbox.com/resistivity-conductivityd 418.html.

118. Choi, S., Microscale microbial fuel cells: Advances and challenges. Biosensors \& Bioelectronics, 2015. 69: p. 8-25.

119. Mink, J. and M. Hussain, Sustainable Design of High-Performance Microsized Microbial Fuel Cell with Carbon Nanotube Anode and Air Cathode. Acs Nano, 2013. 7(8): p. 69216927.

120. Mink, J., et al., Energy harvesting from organic liquids in micro-sized microbial fuel cells. Npg Asia Materials, 2014. 6.

121. Zhang, L., et al., Anodic current distribution in a liter-scale microbial fuel cell with electrode arrays. Chemical Engineering Journal, 2013. 223: p. 623-631.

122. Liu, H., et al., Scale-up of membrane-free single-chamber microbial fuel cells. Journal of Power Sources, 2008. 179: p. 274-279.

123. Liu, H., S.A. Cheng, and B.E. Logan, Power generation in fed-batch microbial fuel cells as a function of ionic strength, temperature, and reactor configuration. Environmental Science \& Technology, 2005. 39(14): p. 5488-5493.

124. Ghangrekar, M.M. and V.B. Shinde, Performance of membrane-less microbial fuel cell treating wastewater and effect of electrode distance and area on electricity production. Bioresource Technology, 2007. 98(15): p. 2879-2885.

125. Dekker, A., et al., Analysis and improvement of a scaled-up and stacked microbial fuel cell. Environ Sci Technol, 2009. 43(23): p. 9038-42.

126. Jiang, D., et al., Power recovery with multi-anode/cathode microbial fuel cells suitable for future large-scale applications. International Journal of Hydrogen Energy, 2010. 35(16): p. 8683-8689.

127. Ahn, Y. and B.E. Logan, A multi-electrode continuous flow microbial fuel cell with separator electrode assembly design. Applied microbiology and biotechnology, 2012. 93(5): p. 2241-2248.

128. Jiang, D., et al., A pilot-scale study on utilizing multi-anode/cathode microbial fuel cells (MAC MFCS) to enhance the power production in wastewater treatment. international journal of hydrogen energy, 2011. 36(1): p. 876-884.

129. Lanas, V., Y. Ahn, and B.E. Logan, Effects of carbon brush anode size and loading on microbial fuel cell performance in batch and continuous mode. Journal of Power Sources, 2014. 247: p. 228-234.

130. Oh, S.-E. and B.E. Logan, Voltage reversal during microbial fuel cell stack operation. Journal of Power Sources, 2007. 167(1): p. 11-17.

131. Aelterman, P., et al., Continuous electricity generation at high voltages and currents using stacked microbial fuel cells. Environmental science \& technology, 2006. 40(10): p. 3388-3394.

132. Choi, S. and J. Chae, Optimal biofilm formation and power generation in a micro-sized microbial fuel cell (MFC). Sensors and Actuators a-Physical, 2013. 195: p. 206-212.

133. leropoulos, I., et al., Waste to real energy: the first MFC powered mobile phone. Physical Chemistry Chemical Physics, 2013. 15(37): p. 15312-15316.

134. An, J. and H. Lee, Occurrence and Implications of Voltage Reversal in Stacked Microbial Fuel Cells. Chemsuschem, 2014. 7(6): p. 1689-1695. 
135. Shantaram, A., et al., Wireless sensors powered by microbial fuel cells. Environmental Science \& Technology, 2005. 39(13): p. 5037-5042.

136. Dewan, A., et al., Evaluating the performance of microbial fuel cells powering electronic devices. Journal of Power Sources, 2010. 195(1): p. 90-96.

137. Tyce, R., et al. Low Power Control Systems for Microbial Fuel Cell Batteries. in MTS/IEEE Oceans 2008 Conference and Exhibition. 2008. Quebec City, Canada: US Naval Research Laboratory.

138. Bandyopadhyay, P.R., et al., An Electronic Circuit for Trickle Charge Harvesting From Littoral Microbial Fuel Cells. IEEE Journal of Oceanic Engineering, 2013. 38(1): p. 32-42.

139. Ewing, T., et al., Scale-up of sediment microbial fuel cells. Journal of Power Sources, 2014. 272: p. 311-319.

140. Donovan, C., et al., Power management system for a $2.5 \mathrm{~W}$ remote sensor powered by a sediment microbial fuel cell. Journal of Power Sources, 2011. 196(3): p. 1171-1177.

141. Park, J.-D. and Z. Ren, High efficiency energy harvesting from microbial fuel cells using a synchronous boost converter. Journal of Power Sources, 2012. 208: p. 322-327.

142. Zhang, D., et al., Performance evaluation of power management systems in microbial fuel cell-based energy harvesting applications for driving small electronic devices. Journal of Power Sources, 2012. 217: p. 65-71.

143. Wang, X., et al., Synergy of electricity generation and wasted disposal in solid-state microbial fuel cell (MFC) of cow manure composting. International Journal of Electrochemical Science, 2014. 9: p. 3144-3157.

144. Scott, K. and C. Murano, A study of microbial fuel cell battery using manure sludge waste. Journal of Chemical Technology \& Biotechnology, 2007. 82: p. 809-817.

145. Lee, Y. and N. Nirmalakhandan, Electricity production in membrane-less microbial fuel cell fed with livestock organic solid waste. Bioresource Technology, 2011. 102: p. 58315835.

146. Diarrhoeal Disease Fact Sheet. 2013; Available from: http://www.who.int/mediacentre/factsheets/fs330/en/.

147. Weekly epidemiological record. 2008, World Health Organization. p. 421-428.

148. Grant, F. and F.J. Brommenschenkel, Liquid Aerobic Composting of Cattle Wastes and Evaluation of By-products. 1974, U.S. Environmental Protection Agency: Office of Research and Development: Washington D. C. p. 22-25.

149. Corbin, J. and A. Strauss, Basics of Qualitative Research: Techniques and Procedures for Developing Grounded Theory. 1998: Sage Publications.

150. Feng, Y., et al., Treatment of carbon fiber brush anodes for improving power generation in air-cathode microbial fuel cells. Journal of Power Sources, 2012. 195: p. 1841-1844.

151. Middaugh, J., et al. How to Make Cathodes with a Diffusion Layer for Single-Chamber Microbial Fuel Cells. Pennsylvania State University Web Site: Dr. Bruce Logan Research, Bioenergy, 2008.

152. MGChemicals, Silver Conductive Epoxy Adhesive Moderate Cure/High Conductivity 8331 Technical Data Sheet, M.G. Chemicals, Editor. 2015: Ontario, Canada.

153. Lanas, V. and B.E. Logan, Evaluation of multi-brush anode systems in microbial fuel cells. Bioresource Technology, 2013. 148: p. 379-385.

154. Hutchinson, A.J., J.C. Tokash, and B.E. Logan, Analysis of carbon fiber brush loading in anodes on startup and performance of microbial fuel cells. Journal of Power Sources, 2011. 196: p. 9213-9219. 
155. Liu, C., et al., Effects of brush lengths and fiber loadings on the performance of microbial fuel cells using graphite fiber brush anodes. International Journal of Hydrogen Energy, 2013. 38: p. 15646-15652.

156. Kim, J.R., B. Min, and B.E. Logan, Evaluation of procedures to acclimate a microbial fuel cell for electricity production. Applied Microbiology and Biotechnology, 2005. 68: p. 2330.

157. Hamilton, D. and H. Zhang, Solids Content of Wastewater and Manure, O.C.E. Service, Editor., Oklahoma State University.

158. Cogger, C., Manure on Your Farm: Asset or Liability?, L. Curriculum and S. Poultry Environmental, Editors., Washington State University.

159. Most Probable Number Procedure and Tables. 2014, United States Department of Agriculture: Food Safety and Inspection Service, Office of Public Health Science: Athens, GA.

160. Pathogen and Vector Attraction Reduction Requirements. 2002, Environmental Protection Agency: Washington, DC.

161. USDA, Electronic code of federal regulations: National organic program, in Title 7. Subtitle B. Chapter 1. Subchapter M. Part 205, U.S.D.o.A.-A.M. Services, Editor. 2000, Cornell University Law School.

162. Bard, A.J. and L.R. Faulkner, Electrochemical Methods: Fundamentals and Applications. 2nd ed. 2001, New York: Wiley. xxi, 833 p.

163. He, Z., et al., An upflow microbial fuel cell with an interior cathode: Assessment of the internal resistance by impedance Spectroscopy. Environmental Science \& Technology, 2006. 40(17): p. 5212-5217.

164. He, Z. and F. Mansfeld, Exploring the use of electrochemical impedance spectroscopy (EIS) in microbial fuel cell studies. Energy \& Environmental Science, 2009. 2(2): p. 215219.

165. Nam, J.Y., et al., Variation of power generation at different buffer types and conductivities in single chamber microbial fuel cells. Biosensors \& Bioelectronics, 2010. 25(5): p. 1155-1159.

166. 2012 Population and Housing Census: Population Distribution by Administrative Areas. 2013, National Bureau of Statistics, Tanzanian Ministry of Finance: Dar es Salaam, Tanzania.

167. OSAC, Tanzania 2014 Crime and Safety Report. 2014, U.S. Department of State: Bureau of Diplomatic Security: Washington, D.C.

168. Investment and Socio-Economic Profile: Manyara Region. 2013, United Republic of Tanzania, Regional Commisioner's Office: Manyara Region: Babati, Tanzania. p. 7.

169. New Tariff: Tanzania Electric Supply Company. Tanzania Electric Supply Company, 2014.

170. Administration, U.S.E.I. Electric Power Monthly: Table 5.6.A. Average Retail Price of Electricity to Ultimate Customers by End-use Sector. 2015; Available from: http://www.eia.gov/electricity/monthly/epm table grapher.cfm?t=epmt 56 a.

171. New Service Line Charges: Tanzania Electric Supply Company, in Tanzania Electric Supply Company Web Site.

172. Kim, J.R., et al., Removal of odors from swine wastewater by using microbial fuel cells. Applied and Environmental Microbiology, 2008. 74(8): p. 2540-2543. 
173. Hong, Y.Y., et al., Adaptation to high current using low external resistances eliminates power overshoot in microbial fuel cells. Biosensors \& Bioelectronics, 2011. 28(1): p. 7176.

174. leropoulos, I., J. Winfield, and J. Greenman, Effects of flow-rate, inoculum and time on the internal resistance of microbial fuel cells. Bioresource Technology, 2010. 101(10): p. 3520-3525.

175. Watson, V.J. and B.E. Logan, Analysis of polarization methods for elimination of power overshoot in microbial fuel cells. Electrochemistry Communications, 2011. 13(1): p. 5456 .

176. Jung, S. and J.M. Regan, Influence of External Resistance on Electrogenesis, Methanogenesis, and Anode Prokaryotic Communities in Microbial Fuel Cells. Applied and Environmental Microbiology, 2011. 77(2): p. 564-571.

177. Lyon, D.Y., et al., Is resistance futile? Changing external resistance does not improve microbial fuel cell performance. Bioelectrochemistry, 2010. 78(1): p. 2-7.

178. Rismani-Yazdi, H., et al., Effect of external resistance on bacterial diversity and metabolism in cellulose-fed microbial fuel cells. Bioresource Technology, 2011. 102(1): p. 278-283.

179. He, Z., et al., Effect of electrolyte $\mathrm{pH}$ on the rate of the anodic and cathodic reactions in an air-cathode microbial fuel cell. Bioelectrochemistry, 2008. 74(1): p. 78-82.

180. Marcus, A.K., C.I. Torres, and B.E. Rittmann, Analysis of a microbial electrochemical cell using the proton condition in biofilm (PCBIOFILM) model. Bioresource Technology, 2011. 102(1): p. 253-262.

181. Torres, C.I., A.K. Marcus, and B.E. Rittmann, Proton transport inside the biofilm limits electrical current generation by anode-respiring bacteria. Biotechnology and Bioengineering, 2008. 100(5): p. 872-881.

182. Ren, Z.Y., et al., Characterization of Microbial Fuel Cells at Microbially and Electrochemically Meaningful Time scales. Environmental Science \& Technology, 2011. 45(6): p. 2435-2441.

183. Sun, H.W., et al., Alcohol, volatile fatty acid, phenol, and methane emissions from dairy cows and fresh manure. Journal of Environmental Quality, 2008. 37(2): p. 615-622.

184. Miller, D.N. and V.H. Varel, In vitro study of the biochemical origin and production limits of odorous compounds in cattle feedlots. Journal of Animal Science, 2001. 79(12): p. 2949-2956.

185. Xiao, B.Y., et al., Relationship of methane and electricity production in two-chamber microbial fuel cell using sewage sludge as substrate. International Journal of Hydrogen Energy, 2014. 39(29): p. 16419-16425.

186. Larrosa-Guerrero, A., et al., Effect of temperature on the performance of microbial fuel cells. Fuel, 2010. 89(12): p. 3985-3994.

187. Liu, Y., et al., Improvement of the anodic bioelectrocatalytic activity of mixed culture biofilms by a simple consecutive electrochemical selection procedure. Biosensors and Bioelectronics, 2008. 24(4): p. 1006-1011.

188. Atlas, R.M., Handbook of Media for Environmental Microbiology. Second ed. 2005: CRC Press.

189. Zhang, X., et al., Separator characteristics for increasing performance of microbial fuel cells. Environmental science \& technology, 2009. 43(21): p. 8456-8461. 


\section{Chapter 9: Appendices \\ Appendix A: IRB Compliance Approval}

Office of Compliance,
Integrity, and Safety
302 Lakeshore Center
1400 Oownsend Drive
Houghton, MI 49931
906.487 .2902

\section{MEMO}

DATE:

May 14,2014

TO:

Kari Henquinet, PhD, Humanities

FROM:

Cheryl A Gherna, CIP, Coordinator Regulatory Review Boards

RE:

M1203, [555866-1]

TITLE:

Energy Use and Microbial Fuel Cell Feasibility Assessment

SUBMISSION TYPE:

New Project

STATUS:

New Project, APPROVED

The Institutional Review Board (IRB) has reviewed and approved your research application as compliant with all applicable sections of the federal regulations, Michigan law, and Michigan Tech IRB policies and procedures. All research must be conducted in accordance with this approved submission.

APPROVAL DATE: May 14, 2014

EXPIRATION DATE: May 13, 2015

A pdf of this signed memo and any stamped approved documents, if applicable, have been placed in the review details under "board documents" for this project.

This approval applies only for this project, and only under the conditions and procedures described in the application. If/when changes become necessary but are not limited to: changes in protocol, personnel, study location, participant recruitment, etc., as set forth in this approval, you must follow the INSTRUCTIONS and submit the FORM for Change Request during approval found in the IRBNet Library. You must receive notification of approval PRIOR to implementing the change(s).

Approvals are granted for up to a one year period. You are responsible for submitting requests for continuation in advance of the expiration date for each year of the project. You will need to request a continuation six weeks prior to the end date indicated above. It is very important that the expiration date is not missed. Failure to submit annual review materials on time will result in the termination of this protocol on the expiration date listed above.

Please note the following in order to comply with federal regulations and IRB policy:

1. Please remember that informed consent is a process beginning with a description of the study and assurance of participant understanding followed by a signed consent form. Informed consent must continue throughout the study via a dialogue between the researcher and research participant. Federal regulations require each participant receive a copy of the signed consent document. 
2. Individual identification of human subjects in any publication is an invasion of privacy. Before beginning a project involving human subjects, and only if required, the principal investigator must obtain a properly executed informed consent from each subject and/or the person legally responsible for the subject. If a consent form has been reviewed and approved it has been attached with an official date stamp on it. Only copies of the official date stamped informed consent are to be distributed to participants relating to this project. If any changes or modifications are needed regarding this form, you must first submit the revised document for review and approval prior to use. The PI must retain informed consent forms on file for at least three years after the end of the project.

3. The approved project will be subject to periodic review. This review will consist of consulting with the $\mathrm{PI}$ and examining the appropriate project records. All required research records must be securely retained in either paper or electronic format for a minimum of three years following the closure of the approved study. This includes signed consent documents from all participants.

4. All Unanticipated Problems / Serious Adverse Events to participants or other parties affected by the research must be reported to this office within two days of the event occurrence. All instances of non-compliance or complaints regarding this study must be reported to this office in a timely manner. Please use the INSTRUCTIONS and FORM: Unanticipated Problem / Serious Adverse Event Form found both on our web site and the IRBNet Library.

If you have any questions, please contact the Compliance, Integrity, and Safety Office at 906.487.2902 or send your message via email through IRBNet using the Send Project Mail feature. 


\section{Appendix B: Interview Oral Consent Form}

\section{Consent to Participate in Research (Oral)}

\section{Electricity use and microbial fuel cell feasibility oral interview consent form}

In addition to teaching at the secondary school for my Peace Corps duties, I am doing research on electricity use and the possibility of using manure for electricity for my university, Michigan Technological University, in the United States. I am conducting a study at my school to write a report for my Master's degree. If you agree to let me ask you questions, I will be reporting answers back to my professors at the university so they can get a better understanding of the electricity use situation in Hanang District in Tanzania. I would like to record our conversation, so that I can accurately record your response. You may ask me to turn off the device at any time if you become uncomfortable and no longer wish to be recorded. You may ask me questions at any time and talk about things you think I should know about, even if I don't ask. You should feel free to interrupt me if you want to ask questions, or if you want me to explain a question more. You are not required to talk to me or answer my questions. Even if you decide now to talk to me about your electricity use and your livestock manure use, you may later ask me to stop asking you about it. When you ask me to stop, I will stop asking you about your electricity and livestock manure use. Nothing bad will happen to you or me if you decide to not answer my questions about these issues.

I will not reveal anything that you say to me beyond anyone helping me whom I trust to maintain your confidentiality, such as my professor at the university. I will do everything I can to protect your privacy, but there is always a slight chance that someone could find out about our conversation.

I am asking if you would agree to participate in this study, and to talk to me about your electricity use and your livestock manure use. Do you agree to participate? Will you allow me to record our conversation? Do you give me permission to take and use photos of your household for my research report? 


\title{
Appendix C: Interview Written Consent Form
}

\section{CONSENT TO PARTICIPATE IN RESEARCH}

\author{
Electricity use and microbial fuel cell feasibility assessment
}

You are asked to participate in a research study conducted by Erinn Kunik, supervised by Dr. Jennifer Becker, from the Environmental Engineering Department at Michigan Technological University. This interview is part of the master's research project being conducted by Erinn Kunik. Your participation in this study is entirely voluntary. Please read the information below and ask questions about anything you do not understand, before deciding whether or not to participate.

\section{- PURPOSE OF THE STUDY}

This study is being conducted to determine if the microbial fuel cell technology being researched is feasible for various areas of rural Tanzania. Information about electricity use, sources, and costs will be used to help determine the feasibility of using the microbial fuel cell technology.

\section{- PROCEDURES}

If you volunteer to participate in this study, you will be asked to do the following things:

1. Allow the interviewer to make several observations around your home.

2. Answer several questions about your electricity use, while being digitally recorded.

3. See and use a microbial fuel cell (a device to get electricity from livestock manure).

4. Answer several questions about the microbial fuel cell and about livestock and its manure, also while being digitally recorded.

\section{- POTENTIAL RISKS AND DISCOMFORTS}

There are very few foreseeable risks involved with this study. Some small risks may include discomfort while talking about using manure in the home and discomfort while talking about not having electricity, if applicable, as this is a significant wealth indicator in the area.

In the event of physical and/or mental injury resulting from participation in this research project, Michigan Technological University does not provide any medical, hospitalization or other insurance for participants in this research study, nor will Michigan Technological University provide any medical treatment or compensation for any injury sustained as a result of participation in this research study, except as required by law.

\section{- POTENTIAL BENEFITS TO SUBJECTS AND/OR TO SOCIETY}

Although there are no direct benefits to participating in this study, there may be future benefits to the community with the introduction of the microbial fuel cell as a device to get electricity from manure in the future. 


\section{- CONFIDENTIALITY}

Any information that is obtained in connection with this study and that can be identified with you will remain confidential and will be disclosed only with your permission or as required by law. Confidentiality will be maintained by means of code names, using a village code and family number. The data will be stored in a password-protected file on the researcher's computer, allowing only the researcher and the professor to have access to it. The records will be destroyed 3 years after completion of the final report. Federal IRB regulations require the retention of records for three years after the completion of the final report. If you agree to allow the interview to be digitally recorded, only the researcher and professor will have access to the digital interviews. They will be used only for the use of the researcher's report, and will be erased after the completion of the researcher's report.

\section{- PARTICIPATION AND WITHDRAWAL}

You can choose whether or not to be in this study. If you volunteer to be in this study, you may withdraw at any time without consequences of any kind or loss of benefits to which you are otherwise entitled. You may also refuse to answer any questions you do not want to answer. There is no penalty if you withdraw from the study and you will not lose any benefits to which you are otherwise entitled.

\section{- IDENTIFICATION OF INVESTIGATORS}

If you have any questions or concerns about this research, please contact researcher Erinn Kunik or Dr. Jennifer Becker.

\author{
Erinn Kunik \\ Peace Corps Volunteer \\ Katesh Secondary School \\ +255786016911 (airtel) \\ +255758254679 (voda) \\ ekunik@mtu.edu
}

\author{
Dr. Jennifer Becker \\ Professor, Environmental Engineering \\ Michigan Technological University \\ jgbecker@mtu.edu
}

\section{- RIGHTS OF RESEARCH SUBJECTS}

The Michigan Tech Institutional Review Board has reviewed my request to conduct this project. If you have any concerns about your rights in this study, please contact the Institutional Review Board, Michigan Tech-IRB at 906-487-2902 or email IRB@mtu.edu. 
I understand the procedures described above. My questions have been answered to my satisfaction, and I agree to participate in this study. I have been given a copy of this form. I agree to participate in this study and be digitally recorded.

Printed Name of Subject

Signature of Subject

Date

I agree to participate in this study, but not be digitally recorded.

Initials of Subject

I agree to allow my photograph to be taken for use in this study.

Initials of Subject 


\section{Appendix D: Interview Outline}

Electricity Use and Microbial Fuel Cell Feasibility Assessment in Hanang District, Tanzania

Principal Investigator: Dr. Jennifer Becker

Co-Investigator: Erinn Kunik

A. Description of Project. This project is an assessment of electricity use of several households in rural Tanzania in the Hanang District, as well as an assessment of the feasibility of using a microbial fuel cell in the household for a light source and a lowlevel electricity source.

B. Procedures to be Followed. Three families will be chosen from each of the three communities (Bassotughagn, Endisiwold, and Katesh). These communities were chosen because of the strong relationship the interviewer has with the communities and many of the families within them. The communities were also chosen to represent a fairly wide range of wealth and living conditions within the area. The families will be interviewed voluntarily in their homes and given a microbial fuel cell to use and try out for the second part of the interview. Observations will be made around the houses if the families consent, and questions will be asked to both the male and female heads of the house (or to just the female head of household if the male is not present, due to the interviewer being a female). During the interview, the interviewees will be able to use the microbial fuel cell and then answer some questions about their perceptions of the fuel cell as well. Due to the conversational nature of Tanzanians, a digital recorder will be used to record the interview so as to not impede the flow of the interview. Before the interview, the interviewees will be told about the recorder and be able to voice any concerns. A translator with no ties to the interviewed families will also be used to fully explain the interview questions and to answer any questions for the interviewee in the local language of Kiswahili.

C. Potential Risks. People may become uncomfortable while talking about the use of manure inside their homes, but if they feel uncomfortable, they are able to stop the interview at any time. There is little risk with the families using the microbial fuel cells for a short time, as long as they follow instructions to keep them closed. There will be little risk of data from the interviews being seen by anyone other than the researcher, professor, and translator, who will be briefed on rules of confidentiality, as the data will be coded and stored in a confidential password-protected file on the researcher's computer.

D. Informed Consent. The interviewees will either read a consent form (translated into the common written language of the area, Kiswahili), or be read an oral consent form in Kiswahili, depending on their literacy level, which will be determined before conducting the interview. Both consent forms will explain the reasons behind the interview and research and explain that their participation is not mandatory, that they can stop the interview at any time, and that all of their responses and 
information will be confidential. After reading and being able to ask questions, they can decide whether or not to participate in the interview, be digitally recorded, and have their pictures taken for use in the research report. If they read the written consent form, they can sign the form to participate in the interview, be digitally recorded, and have pictures taken of them for use in the research report. If they were given the consent form orally, they can then orally consent to participating, being digitally recorded, and having their pictures taken for use in the research report. Oral consents will be recorded through the digital recorder for the record. 


\section{Appendix E: Interview Questions}

\section{Electricity use and microbial fuel cell feasibility interviews - Hanang \\ District, Tanzania}

\section{General}

Observations will be made within the home before conducting the interview.

-Are there livestock living near the home?

-What is the home made from?

-Is the cooking area inside? The toilet and bathing areas?

-Is the cooking area very dark? The toilet and bathing areas?

\section{Interview}

Village: Bassotughagn, Endisiwold, Katesh

1. How many people are currently living in your home?

2. Do you have any children in school?

a. If yes, how many?

\section{Electricity Use}

3. Do you have electricity in your home?

a. If yes:

i. What do you use your electricity for?

ii. How much do you pay per month (approximately) for electricity?

iii. How often does electricity go out? Does this cause problems or concerns? If so, what are they?

iv. What do you do for light when electricity is out at night?

v. Do you have lights in every room?

vi. If you have children in school, how often do they need electricity/lights in the evening to study? What other things do you need light for after sunset?

b. If no:

i. What would you want electricity for?

ii. What kind of light sources do you have for night time (i.e. solar light, cell phone light, torch, candles, fire)? Do you have other power sources? If so, what are they?

iii. What are the most difficult parts of not having electricity in your home?

iv. How much would you be able to pay to have electricity in your home (in general, not necessarily electricity from TANESCO)?

v. If you have children in school, how often do they need electricity/lights in the evening to study? Are they able to get access to it? What other things do you need light for after sunset? 
4. Do you have any other comments about electricity? About any problems you have with TANESCO electrical supply company?

Microbial Fuel Cell Feasibility (Show them a microbial fuel cell, give a very basic explanation of how it works, and let them use it for a short time before asking questions.)

5. How many cows do you have at home? Sheep? Goats? Donkeys? Whose are they?

6. If you have no livestock, are you able to get livestock manure easily?

7. Do you use the animals' manure for anything? If yes, what do you usually use it for?

8. Would you be willing to use some of the livestock manure for electricity generation instead of for other purposes?

9. If livestock manure could produce enough electricity for your family's needs, would you or someone in your home be willing to handle the manure in order to run the microbial fuel cell?

10. What problems might you have with using livestock manure for electricity production:

a. Inside the home?

b. Outside the home?

c. In the cooking area?

d. In the toilet or bathing areas?

11. Would you choose using a microbial fuel cell over other sources of electricity? Who would make this decision in your household?

12. How much would you be willing to pay for a microbial fuel cell, if there are no continuing costs for maintenance?

13. There are two basic kinds of microbial fuel cells:

a. Number 1: you make this one yourself. It may take a few tries and a month or two to make a working microbial fuel cell. To somewhat light one room in your home, it would cost around 30,000 Tsh (\$20) and you would have to maintain it every two weeks to a month, along with replacing the manure every time you maintain it.

b. Number 2: You buy this already-made. To light one room well, it would cost around 125,000 Tsh (\$75). You would not need to maintain the device, just replace the manure when your light goes dim. Which one of these technologies would you choose?

14. Do you have any other comments or thoughts on the microbial fuel cell or using livestock manure for electricity? 


\section{Appendix F: MFC Feed Solution Preparation}

\section{Materials and Equipment}

- Analytical balance

- Volumetric flasks/pipets

- Fisher Scientific XL50 pH/conductivity/temperature probe

- $10 \mathrm{~mL}$ luer lok® syringe

- DI water bottle

\section{Personal Protective Equipment}

- Safety glasses

- Purple nitrile gloves

- Lab Coat

\section{Chemicals and Reagents}

- Concentrated Trace mineral solution (see recipe)

- Stock Vitamin solution (see recipe)

- Sodium acetate

- $\mathrm{NH}_{4} \mathrm{Cl}$

- $\mathrm{KCl}$

- $\mathrm{NaH}_{2} \mathrm{PO}_{4} \cdot \mathrm{H}_{2} \mathrm{O}$

- $\mathrm{Na}_{2} \mathrm{HPO}_{4} \cdot 7 \mathrm{H}_{2} \mathrm{O}$

- $\mathrm{N}_{2}$ gas

- $\mathrm{CO}_{2}$ gas

Feed Solution Recipe [187]

\begin{tabular}{|c|c|c|c|c|c|c|}
\hline $\begin{array}{c}\text { Sodium } \\
\text { Acetate }\end{array}$ & $\mathrm{NH}_{4} \mathrm{Cl}$ & $\mathrm{KCl}$ & $\mathrm{NaH}_{2} \mathrm{PO}_{4} \cdot \mathrm{H}_{2} \mathrm{O}$ & $\mathrm{Na}_{2} \mathrm{HPO}_{4} \cdot 7 \mathrm{H}_{2} \mathrm{O}$ & $\begin{array}{c}\text { Mineral } \\
\text { Solution }\end{array}$ & $\begin{array}{c}\text { Vitamin } \\
\text { Solution }\end{array}$ \\
\hline $1 \mathrm{~g} / \mathrm{L}$ & $0.31 \mathrm{~g} / \mathrm{L}$ & $0.13 \mathrm{~g} / \mathrm{L}$ & $2.69 \mathrm{~g} / \mathrm{L}$ & $8.04 \mathrm{~g} / \mathrm{L}$ & $12.5 \mathrm{~mL}$ & $10 \mathrm{~mL}$ \\
\hline
\end{tabular}

Stock Feed Concentrated Solution Preparation (100 times feed solution)

\begin{tabular}{|c|c|c|c|c|c|}
\hline $\mathrm{NH}_{4} \mathrm{Cl}$ & $\mathrm{KCl}$ & $\mathrm{NaH}_{2} \mathrm{PO}_{4} \cdot \mathrm{H}_{2} \mathrm{O}$ & $\mathrm{Na}_{2} \mathrm{HPO}_{4} \cdot 7 \mathrm{H}_{2} \mathrm{O}$ & Sodium Acetate & Total volume \\
\hline $31 \mathrm{~g}$ & $13 \mathrm{~g}$ & $269 \mathrm{~g}$ & $804 \mathrm{~g}$ & $100 \mathrm{~g}$ & $1 \mathrm{~L}$ \\
\hline $3.1 \mathrm{~g}$ & $1.3 \mathrm{~g}$ & $26.9 \mathrm{~g}$ & $80.4 \mathrm{~g}$ & $10 \mathrm{~g}$ & $100 \mathrm{~mL}$ \\
\hline
\end{tabular}

Notes:

Solubility $20^{\circ} \mathrm{C}$

$\mathrm{Na}_{2} \mathrm{HPO}_{4} \cdot 7 \mathrm{H}_{2} \mathrm{O}: 1000 \mathrm{~g} / \mathrm{L} \quad \mathrm{MW}=268.07 \mathrm{~g} / \mathrm{mol}$ 
$\mathrm{NaH}_{2} \mathrm{PO}_{4}: 599 \mathrm{~g} / \mathrm{L} \quad \mathrm{MW}=119.98 \mathrm{~g} / \mathrm{mol}$

1) Weigh the above solid components and transfer them into $100 \mathrm{~mL}$ volumetric flask.

a. Add the $\mathrm{Na}_{2} \mathrm{HPO}_{4} \cdot 7 \mathrm{H}_{2} \mathrm{O}$ first to approximately $30 \mathrm{~mL}$ of water (or below half of the total volume of solution). It will be more difficult to dissolve, so it should be added slowly.

b. Add the rest of the solids to the volumetric flask.

2) Bring volume up to $100 \mathrm{~mL}$ in the volumetric flask by adding DI water.

3) Transfer the solution to $160 \mathrm{~mL}$ serum bottles for storage.

4) Autoclave the serum bottles using liquid slow exhaust cycle under $121^{\circ} \mathrm{C}$ for $20 \mathrm{~min}$.

When feed solution is needed, dilute the stock solution to the desired concentration by the following procedure.

1) The top of the serum bottle of stock feed solution should be sterilized by wiping with $70 \%$ ethanol, followed by flaming. Syringe $8 \mathrm{~mL}$ stock feed solution into a $2 \mathrm{~L}$ Erlenmeyer flask.

2) For a total of $800 \mathrm{~mL}$ feed solution, add $800 \mathrm{~mL}$ of DI water into the Erlenmeyer flask. Mix the solution with stir plates and a stir bar to mix in any solids that have settled during storage.

a. Note: $24 \mathrm{~mL}$ more DI water was added to balance the water loss during boiling later.

3) Add $8 \mathrm{~mL}$ trace mineral solution* into the Erlenmeyer flask.

4) Test the $\mathrm{pH}$ of the solution. Adjust $\mathrm{pH}$ to $7.0 \pm 0.2$ using $5 \mathrm{~N} \mathrm{NaOH}(5 \mathrm{M})$ and $5 \mathrm{~N}$ $\mathrm{HCl}(5 \mathrm{M})$ if necessary.

5) Boil the solution to get oxygen out and cool to room temperature using a water-filled ice bucket. Sparge the solution with $80 \% \mathrm{~N}_{2}+20 \% \mathrm{CO}_{2}$ gas using the porous stone.

6) Add $8 \mathrm{~mL}$ of the vitamin solution** into the Erlenmeyer flask. Sterilize the top of the vitamin solution storage vessel by wiping with $70 \%$ ethanol, followed by flaming.

7) Add $800 \mathrm{~mL}$ of MFC effluent to a $2 \mathrm{~L}$ sealable bottle. Add the acetate solution to the bottle. Stir the solution completely while sparging with $80 \% \mathrm{~N}_{2} / 20 \% \mathrm{CO}_{2}$ gas. Add carbon fibers from a working anode while mixing.

The feed solution is ready for feeding into the MFC. 


\section{* Mineral Solution Preparation}

The trace mineral medium is adapted from a recipe described by Logan, 2008 for enriching iron-reducing bacteria. (100mL)[66]

\begin{tabular}{|c|c|}
\hline Substance & Amount (g) \\
\hline $\mathrm{NaCl}$ & $0.88 \mathrm{~g}$ \\
\hline $\mathrm{MgCl}_{2} \cdot 7 \mathrm{H}_{2} \mathrm{O}$ & 0.033 \\
\hline $\mathrm{KH}_{2} \mathrm{PO}_{4}$ & 0.0014 \\
\hline $\mathrm{CaCl}_{2}$ & 0.0275 \\
\hline $\mathrm{K}_{2} \mathrm{HPO}_{4}$ & 0.0021 \\
\hline $\mathrm{Na}_{2} \mathrm{HPO}_{4} \cdot 7 \mathrm{H}_{2} \mathrm{O}$ & 0.0056 \\
\hline $\mathrm{FeSO}_{4} \cdot 7 \mathrm{H}_{2} \mathrm{O}$ & 0.001 \\
\hline $\mathrm{MnSO}_{4} \cdot \mathrm{H}_{2} \mathrm{O}$ & 0.0005 \\
\hline $\mathrm{NH}_{4} \mathrm{Cl}$ & 0.00031 \\
\hline $\mathrm{KCl}$ & 0.0002 \\
\hline $\mathrm{CoCl}_{2} \cdot 6 \mathrm{H}_{2} \mathrm{O}$ & 0.0001 \\
\hline $\mathrm{ZnCl}_{2}$ & 0.0001 \\
\hline $\mathrm{CuSO}_{4} \cdot 5 \mathrm{H}_{2} \mathrm{O}$ & 0.00001 \\
\hline $\mathrm{H}_{3} \mathrm{BO}_{3}$ & 0.00001 \\
\hline $\mathrm{Na}_{2} \mathrm{MoO}_{4}$ & 0.000025 \\
\hline $\mathrm{NiCl}_{2} \cdot 6 \mathrm{H}_{2} \mathrm{O}$ & 0.000024 \\
\hline EDTA & 0.0001 \\
\hline $\mathrm{NaHCO}_{3}$ & 0.01 \\
\hline
\end{tabular}

\section{**Vitamin Solution Preparation}

Recipe refers to Geobacter Medium [188, 189]

\begin{tabular}{|l|l|}
\hline Substance & Amount (g) \\
\hline Pyridoxine-HCl & 0.01 \\
\hline Thiamine-HCl-2 $\mathrm{H}_{2} \mathrm{O}$ & 0.005 \\
\hline Riboflavin (vitamin B2) & 0.005 \\
\hline Nicotinic acid & 0.005 \\
\hline D-Ca-pantothenate & 0.005 \\
\hline p-Aminobenzoic acid & 0.005 \\
\hline Lipoic acid & 0.005 \\
\hline Biotin & 0.002 \\
\hline Folic acid & 0.002 \\
\hline Vitamin $\mathrm{B}_{12}$ & 0.0001 \\
\hline
\end{tabular}

1) Add components to $1000 \mathrm{~mL}$ volumetric flask and bring volume $250 \mathrm{~mL}$ with DI water.

2) Seal an empty serum bottle with septum and aluminum seals, flush the bottle with $\mathrm{N}_{2}$ to get out of oxygen, then autoclave the bottle. 
3) Syringe 6omL Vitamin solution by sterilized syringe, put the syringe filter and $22 \mathrm{G}$ needle on.

4) Take the autoclaved serum bottle into fume hood, sterilize the top of the vessel by wiping with $70 \%$ ethanol, followed by flaming.

a. Note: Don't touch the needle and filter when connect with syringe.

5) Filter-sterilize the solution into the serum bottle, at the same time, put the other $22 \mathrm{G}$ needle in the septum for venting. Repeat until 10omL solution added.

6) Deoxygenate the solution through a combination of vacuum and flushing.

7) Sparge the solution with $\mathrm{N}_{2}$ and shake for 20 seconds (should see air bubbles get out from liquid). Turn the vacuum on for 20 seconds. Repeating until air bubbles cannot be seen while sparging the solution with $\mathrm{N}_{2}$. 


\section{Appendix G: Compiled Data from the 2012 Tanzanian Census [4]}

Table 9.1: Compiled data on roofing material used from 2012 Tanzanian census

\begin{tabular}{|c|c|c|c|c|c|c|c|c|}
\hline \multicolumn{9}{|c|}{ Manyara Information } \\
\hline \multicolumn{9}{|c|}{ Tanzania Rural Information } \\
\hline \multicolumn{9}{|c|}{ Tanzania Urban Information } \\
\hline \multicolumn{9}{|c|}{ Roofing Material used } \\
\hline $\begin{array}{l}\text { Total \# } \\
\text { Households } \\
\end{array}$ & Iron sheets & Tiles & Concrete & Asbestos & Grass/leaves & Mud and Leaves & Plastics/Box & Tent \\
\hline \multirow[t]{2}{*}{271,050} & 143,026 & 908 & 140 & 681 & 77105 & 47952 & 443 & 796 \\
\hline & $52.8 \%$ & $0.3 \%$ & $0.1 \%$ & $0.3 \%$ & $28.4 \%$ & $17.7 \%$ & $0.2 \%$ & $0.3 \%$ \\
\hline \multirow[t]{2}{*}{$6,192,303$} & $3,258,579$ & 13270 & 1819 & 15251 & 2177906 & 700710 & 17084 & 7683 \\
\hline & $52.6 \%$ & $0.2 \%$ & $0.0 \%$ & $0.2 \%$ & $35.2 \%$ & $11.3 \%$ & $0.3 \%$ & $0.1 \%$ \\
\hline \multirow[t]{2}{*}{3084694} & $\mathbf{2 8 1 0 9 4 6}$ & 24556 & 23226 & 8666 & 182000 & $\mathbf{2 8 6 2 7}$ & 3102 & 3571 \\
\hline & 91.1\% & $0.8 \%$ & $0.8 \%$ & $0.3 \%$ & $5.9 \%$ & $0.9 \%$ & o.1\% & o.1\% \\
\hline
\end{tabular}

Table 9.2: Compiled data on flooring material used from 2012 Tanzanian census

\begin{tabular}{|c|c|c|c|c|c|c|c|c|c|}
\hline \multicolumn{10}{|c|}{ Flooring Material Used } \\
\hline $\begin{array}{l}\text { Total \# } \\
\text { Households }\end{array}$ & Cement & $\begin{array}{l}\text { Ceramic } \\
\text { Tiles }\end{array}$ & $\begin{array}{l}\text { Parquet or } \\
\text { Polished } \\
\text { Wood }\end{array}$ & Terrazzo & $\begin{array}{l}\text { Vinyl or } \\
\text { Asphalt } \\
\text { Strips } \\
\end{array}$ & $\begin{array}{l}\text { Wood } \\
\text { Planks }\end{array}$ & Palm/Bamboo & Earth/Sand & $\begin{array}{l}\text { Animal } \\
\text { Dung }\end{array}$ \\
\hline \multirow[t]{2}{*}{271050} & 60200 & 837 & 156 & 353 & 191 & 1059 & 1626 & 198551 & 8077 \\
\hline & $22.2 \%$ & $0.3 \%$ & $0.1 \%$ & $0.1 \%$ & $0.1 \%$ & $0.4 \%$ & $0.6 \%$ & $73.3 \%$ & $3.0 \%$ \\
\hline \multirow[t]{2}{*}{6192303} & 1164244 & 13125 & 2728 & 4108 & 3274 & 19795 & 25914 & 4903719 & 55396 \\
\hline & $18.8 \%$ & $0.2 \%$ & $0.0 \%$ & $0.1 \%$ & $0.1 \%$ & $0.3 \%$ & $0.4 \%$ & $79.2 \%$ & $0.9 \%$ \\
\hline \multirow[t]{2}{*}{3084694} & 2288383 & 109901 & 1417 & 10624 & 966 & 2872 & 3122 & 665741 & 1668 \\
\hline & $74.2 \%$ & $3.6 \%$ & o.o\% & $0.3 \%$ & o.o\% & $0.1 \%$ & o.1\% & $21.6 \%$ & $0.1 \%$ \\
\hline
\end{tabular}


Table 9.3: Compiled data on house wall material used from 2012 Tanzanian census

\begin{tabular}{|c|c|c|c|c|c|c|c|c|c|}
\hline \multicolumn{10}{|c|}{ Wall Material Used } \\
\hline $\begin{array}{l}\text { Total \# } \\
\text { Households }\end{array}$ & Stones & $\begin{array}{l}\text { Cement } \\
\text { Bricks }\end{array}$ & $\begin{array}{l}\text { Sundried } \\
\text { Bricks }\end{array}$ & $\begin{array}{l}\text { Baked } \\
\text { Bricks }\end{array}$ & Timber & $\begin{array}{l}\text { Timber } \\
\text { and Iron } \\
\text { Sheets }\end{array}$ & $\begin{array}{l}\text { Poles and } \\
\text { Mud }\end{array}$ & Grass & Tent \\
\hline \multirow[t]{2}{*}{271050} & 1335 & 7511 & 37138 & 77232 & 685 & 1085 & 135775 & 9689 & 600 \\
\hline & $0.5 \%$ & $2.8 \%$ & $13.7 \%$ & $28.5 \%$ & $0.3 \%$ & $0.4 \%$ & $50.1 \%$ & $3.6 \%$ & $0.2 \%$ \\
\hline \multirow[t]{2}{*}{6192303} & 50314 & 278820 & 1999301 & 1699033 & 45986 & 17916 & 1956861 & 138949 & 5123 \\
\hline & $0.8 \%$ & $4.5 \%$ & $32.3 \%$ & $27.4 \%$ & $0.7 \%$ & $0.3 \%$ & $31.6 \%$ & $2.2 \%$ & $0.1 \%$ \\
\hline \multirow[t]{2}{*}{3084694} & 46616 & 1603174 & 440780 & 743783 & 8664 & 6241 & 222116 & 9961 & 3360 \\
\hline & $1.5 \%$ & $52.0 \%$ & $14.3 \%$ & $24.1 \%$ & $0.3 \%$ & $0.2 \%$ & $7.2 \%$ & $0.3 \%$ & $0.1 \%$ \\
\hline
\end{tabular}

范

Table 9.4: Compiled data on main energy source used for lighting from 2012 Tanzanian census

\begin{tabular}{|c|c|c|c|c|c|c|c|c|c|c|c|c|}
\hline \multicolumn{13}{|c|}{ Main Source of Energy for Lighting } \\
\hline 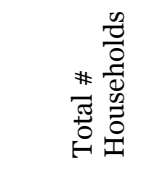 & 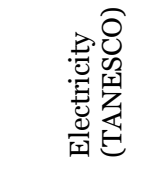 & 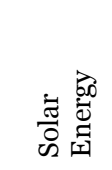 & 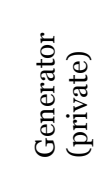 & 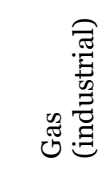 & 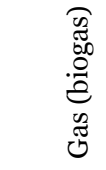 & 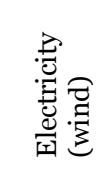 & 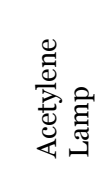 & 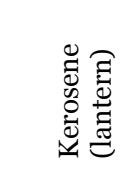 & 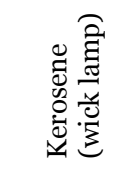 & $\frac{\mathscr{q}}{\overparen{\Xi}}$ & 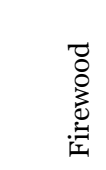 & 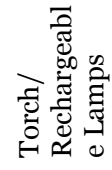 \\
\hline \multirow[t]{2}{*}{271050} & 28040 & 3912 & 547 & 101 & 93 & 262 & 10292 & 53139 & 106884 & 3392 & 14696 & 49693 \\
\hline & $10.34 \%$ & $1.44 \%$ & $0.20 \%$ & $0.04 \%$ & $0.03 \%$ & $0.10 \%$ & $3.80 \%$ & $19.60 \%$ & $39.43 \%$ & $1.25 \%$ & $5.42 \%$ & $18.33 \%$ \\
\hline \multirow[t]{2}{*}{6192303} & 350704 & 102467 & 18393 & 681 & 1599 & 2676 & 174742 & 941679 & 3161867 & 59646 & 171972 & 1205877 \\
\hline & $5.66 \%$ & $1.65 \%$ & $0.30 \%$ & $0.01 \%$ & $0.03 \%$ & $0.04 \%$ & $2.82 \%$ & $15.21 \%$ & $51.06 \%$ & $0.96 \%$ & $2.78 \%$ & $19.47 \%$ \\
\hline \multirow[t]{2}{*}{3084694} & 1458252 & $\mathbf{2 8 7 8 8}$ & $\mathbf{1 1 9 7 3}$ & 767 & 875 & 1168 & 71307 & 683338 & 613193 & 63353 & 9005 & 142675 \\
\hline & $47.27 \%$ & $0.93 \%$ & $0.39 \%$ & o.o2\% & $0.03 \%$ & $0.04 \%$ & $2.31 \%$ & $22.15 \%$ & $19.88 \%$ & $2.05 \%$ & $0.29 \%$ & $4.63 \%$ \\
\hline
\end{tabular}


Table 9.5: Compiled data on main source of energy for cooking from 2012 Tanzanian census

\begin{tabular}{|c|c|c|c|c|c|c|c|c|c|c|c|c|c|}
\hline \multicolumn{14}{|c|}{ Main Source of Energy for Cooking } \\
\hline 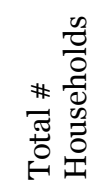 & 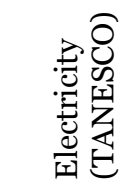 & 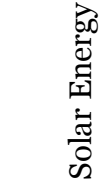 & 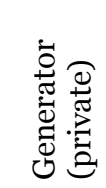 & 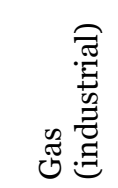 & $\begin{array}{l}0 \\
0 \\
0 \\
0 \\
0 \\
0 \\
0 \\
0 \\
0 \\
0\end{array}$ & 莺 & 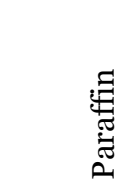 & లే & 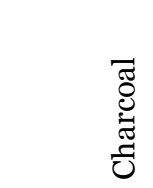 & 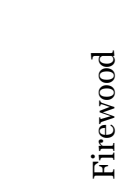 & 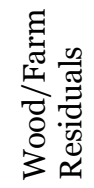 & 氶 & $\frac{\varangle}{\mathrm{z}}$ \\
\hline $\begin{array}{r}27105 \\
0 \\
\end{array}$ & 1022 & 179 & 171 & 799 & 147 & 141 & 4196 & 357 & 35944 & 225013 & 1471 & 557 & 1052 \\
\hline & $0.4 \%$ & $0.1 \%$ & $0.1 \%$ & $0.3 \%$ & $0.1 \%$ & $0.1 \%$ & $1.5 \%$ & $0.1 \%$ & $13.3 \%$ & $83.0 \%$ & $0.5 \%$ & $0.2 \%$ & $0.4 \%$ \\
\hline $\begin{array}{r}61923 \\
03 \\
\end{array}$ & 13506 & 3683 & 2757 & 8408 & 1400 & 1778 & 63382 & 4537 & 476314 & $\begin{array}{r}558576 \\
2 \\
\end{array}$ & 17479 & 5441 & 7856 \\
\hline & $0.22 \%$ & $0.06 \%$ & $0.04 \%$ & $0.14 \%$ & $0.02 \%$ & $0.03 \%$ & $1.02 \%$ & $0.07 \%$ & $7.69 \%$ & $90.20 \%$ & $\begin{array}{r}0.28 \\
\% \\
\end{array}$ & $0.09 \%$ & $0.13 \%$ \\
\hline $\begin{array}{r}3084 \\
694 \\
\end{array}$ & 131908 & 2166 & 2181 & 72014 & 2021 & 1008 & 161888 & 8004 & 1905523 & 767467 & 3065 & $\mathbf{3 8 5}$ & 27065 \\
\hline & $4.3 \%$ & $\mathbf{0 . 1 \%}$ & $\mathbf{0 . 1 \%}$ & $2.3 \%$ & $0.1 \%$ & 0.0\% & $5.2 \%$ & $0.3 \%$ & $61.8 \%$ & $24.9 \%$ & o.1\% & 0.0\% & $0.9 \%$ \\
\hline
\end{tabular}

Table 9.6: Compiled data on assets owned from 2012 Tanzanian census

\begin{tabular}{|r|r|r|r|r|}
\hline \multicolumn{5}{|c|}{ Assets Owned } \\
\hline $\begin{array}{r}\text { Total \# } \\
\text { Households }\end{array}$ & Oxen & Donkey/Camel & \multicolumn{1}{l|}{ House } & Land/Farm \\
\hline 271050 & 66271 & 55052 & 225736 & 212197 \\
\hline & $24.4 \%$ & $20.3 \%$ & $83.3 \%$ & $78.3 \%$ \\
\hline 6192303 & 809763 & 268616 & 5499359 & 5319863 \\
\hline & $13.1 \%$ & $4.3 \%$ & $88.8 \%$ & $85.9 \%$ \\
\hline $\mathbf{3 0 8 4 6 9 4}$ & $\mathbf{4 7 3 7 5}$ & $\mathbf{1 8 5 6 0}$ & $\mathbf{1 4 4 1 2 1 0}$ & $\mathbf{1 2 1 0 0 4 5}$ \\
\hline & $\mathbf{1 . 5} \%$ & $\mathbf{0 . 6 \%}$ & $\mathbf{4 6 . 7 \%}$ & $\mathbf{3 9 . 2 \%}$ \\
\hline
\end{tabular}


Table 9.7: Compiled data on livestock keeping from 2012 Tanzanian census

\begin{tabular}{|r|r|l|r|l|}
\hline \multicolumn{3}{|c|}{ Households Keeping Livestock (Cows, Goats, Sheep, and Poultry) } & \\
\hline & $\begin{array}{l}\text { Keeping } \\
\text { Total \# Households }\end{array}$ & $\begin{array}{l}\text { Rural with } \\
\text { Livestock }\end{array}$ & $\begin{array}{l}\text { Urban with } \\
\text { Livestock }\end{array}$ & \\
\hline 271050 & 152075 & 140068 & 12007 & \\
\hline & $56 \%$ & $52 \%$ & $4 \%$ & \\
\hline $\mathbf{9 2 7 6 9 9 7}$ & $\mathbf{3 8 9 5 6 6 5}$ & $\mathbf{3 3 8 2 7 8 3}$ & $\mathbf{5 1 2 8 8 2}$ & $\begin{array}{l}\text { Tanzania } \\
\text { Total }\end{array}$ \\
\hline & $42 \%$ & $36 \%$ & $6 \%$ & \\
\hline
\end{tabular}

Table 9.8: Compiled data on agricultural households from 2012 Tanzanian census

\begin{tabular}{|r|r|l|l|}
\hline \multicolumn{4}{|c|}{ Households Engaged in Agriculture } \\
\hline & $\begin{array}{l}\text { Engaged in } \\
\text { Agriculture }\end{array}$ & $\begin{array}{l}\text { Rural in } \\
\text { Agriculture }\end{array}$ & $\begin{array}{l}\text { Urban in } \\
\text { Agriculture }\end{array}$ \\
\hline Total \# Households & 201604 & 179661 & 21943 \\
\hline 271050 & $74 \%$ & $66 \%$ & $8 \%$ \\
\hline
\end{tabular}

Table 9.9: Compiled data on household livestock keeping from 2012 Tanzanian census

\begin{tabular}{|c|c|c|c|}
\hline \multicolumn{4}{|c|}{ Household Livestock Keeping } \\
\hline \multicolumn{4}{|c|}{ Total Livestock Keeping } \\
\hline Cattle & Goats & Sheep & Poultry \\
\hline 110234 & 105731 & 74650 & 124956 \\
\hline $72 \%$ & $70 \%$ & $49 \%$ & $82 \%$ \\
\hline 1492735 & 1689651 & 640293 & 3395410 \\
\hline $38 \%$ & $43 \%$ & $16 \%$ & $87 \%$ \\
\hline
\end{tabular}

Table 9.10: Compiled data on rural livestock keeping from 2012 Tanzanian census

\begin{tabular}{|r|r|r|r|}
\hline \multicolumn{5}{|c|}{ Rural Livestock Keeping } \\
\hline \multicolumn{1}{|r|}{ Cattle } & Goats & \multicolumn{1}{l|}{ Sheep } & Poultry \\
\hline 104408 & 100042 & 71955 & 115139 \\
\hline $75 \%$ & $71 \%$ & $51 \%$ & $82 \%$ \\
\hline $\mathbf{1 3 8 2 3 2 6}$ & $\mathbf{1 5 6 2 0 1 1}$ & $\mathbf{6 0 9 6 6 2}$ & $\mathbf{2 9 4 6 3 1 3}$ \\
\hline $\mathbf{4 1 \%}$ & $\mathbf{4 6 \%}$ & $\mathbf{1 8 \%}$ & $\mathbf{8 7 \%}$ \\
\hline
\end{tabular}


Table 9.11: Compiled data on urban livestock keeping from 2012 Tanzanian census Urban Livestock Keeping

\begin{tabular}{|c|c|c|c|}
\hline Cattle & Goats & Sheep & Poultry \\
\hline 5826 & 5689 & 2695 & 9817 \\
\hline $49 \%$ & $47 \%$ & $22 \%$ & $82 \%$ \\
\hline 110419 & 127640 & 30631 & 449097 \\
\hline $22 \%$ & $25 \%$ & $6 \%$ & $88 \%$ \\
\hline
\end{tabular}




\section{Appendix H: Fair Use Statement}

Figure 2.1, Figure 2.2, and Figure 2.3 are compliant with the Google Earth End-user License Agreement and fall under the category of fair use. 